Universidade de Brasília

Faculdade de Ciências da Saúde

Programa de Pós-Graduação em Nutrição Humana

Mestrado em Nutrição Humana

LARISSA MAZOCCO

\title{
AVALIAÇÃO DE ESTRATÉGIA DE EDUCAÇÃO NUTRICIONAL EM UNIDADE DE ALIMENTAÇÃO E NUTRIÇÃO
}

Brasília - DF

Agosto / 2015

LARISSA MAZOCCO 


\title{
AVALIAÇÃO DE ESTRATÉGIA DE EDUCAÇÃO NUTRICIONAL EM UNIDADE DE ALIMENTAÇÃO E NUTRIÇÃO
}

\author{
Dissertação apresentada ao Programa de \\ Pós-Graduação em Nutrição Humana como \\ requisito para obtenção do título de Mestre \\ em Nutrição Humana. \\ Orientadora: Prof ${ }^{a}$ Dr $^{a}$ Rita de Cássia C. A. \\ Akutsu \\ Co-orientadora: $\operatorname{Prof}^{\mathrm{a}} \operatorname{Dr}^{\mathrm{a}}$ Izabel Cristina \\ Rodrigues da Silva
}


MAZOCCO, Larissa

Avaliação de estratégia de educação nutricional em Unidade de Alimentação e Nutrição / Larissa Mazocco

Dissertação - Mestrado em Nutrição Humana

Brasília - DF, agosto de 2015.

Área de Concentração: Qualidade Nutricional e Alimentar

Orientador: Prof ${ }^{a} \operatorname{Dr}^{a}$ Rita de Cássia C. A. Akutsu

1. Educação Nutricional; 2. Densidade Energética; 3. Sódio; 4. Ficha Técnica de Preparação; 5. Cardápio; 6. Unidade de Alimentação e Nutrição; 7. Escolha alimentar; 8. Informação Nutricional. 


\section{AVALIAÇÃO DE ESTRATÉGIA DE EDUCAÇÃO NUTRICIONAL EM UNIDADE DE ALIMENTAÇÃO E NUTRIÇÃO}

Dissertação apresentada ao Programa de Pós-Graduação em Nutrição Humana como requisito para obtenção do título de Mestre em Nutrição Humana.

Orientadora: Rita de Cássia C. A. Akutsu

Co-orientadora: Raquel Bráz Assunção Botelho

Faculdade de Ciências da Saúde - Universidade de Brasília

\section{Prof $^{a}$ Dr $^{a}$ Izabel Cristina Rodrigues da Silva}

Co-Orientadora

Faculdade de Ceilândia - Universidade de Brasília

Prof $^{a}$ Dr $^{\mathrm{a}}$ Raquel Bráz Assunção Botelho

Faculdade de Ciências da Saúde - Universidade de Brasília

Prof $^{a} \operatorname{Dr}^{a}$ Karin Eleonora Sávio

Faculdade de Ciências da Saúde - Universidade de Brasília

Prof $^{a} \operatorname{Dr}^{\mathrm{a}}$ Renata Puppin Zandonadi

Suplente

Faculdade de Ciências da Saúde - Universidade de Brasília 


\section{DEDICO}

Aos meus pais, grandes incentivadores dos meus sonhos.

Aos meus professores da Graduação, por sempre acreditarem no meu potencial. 


\section{AGRADECIMENTOS}

À minha orientadora Prof ${ }^{a}$ Rita pelo inestimável apoio, orientação, conselhos, incentivos, conversas, explicações e por nunca ter desistido de mim. Todas as orientações e críticas foram de extrema importância para o meu desenvolvimento, muito obrigada, de todo coração!

À Prof ${ }^{a}$ Raquel Botelho por todo o apoio, pela passagem de experiência na área e pela grande ajuda na publicação do artigo que gerou o projeto de Mestrado.

À Prof ${ }^{a}$ Renata Zandonadi por tudo que me ensinou durante a graduação e na pósgraduação, compartilhando sua experiência e excelência comigo, além de ser um dos meus grandes exemplos de docente.

À amiga e Prof ${ }^{a}$ Raquel Adjafre, por ter acreditado no meu potencial desde o estágio há dois anos e por ser meu exemplo de profissional e Nutricionista.

Ao Prof ${ }^{0}$ Aldemir Mangabeira, chefe da Seção de Assistência Nutricional do Superior Tribunal de Justiça, por me receber de braços abertos e me auxiliar em todos os problemas e necessidades durante o desenvolvimento do meu projeto.

À Prof ${ }^{a}$ Izabel Cristina, minha co-orientadora, por todo o apoio e trabalho na análise estatística e na qualidade dos resultados apresentados do trabalho.

Às colegas de trabalho Fernanda Cavalcanti e Karina Leal por me ajudarem na coleta de dados das Fichas Técnicas, na qual se concentrou a parte mais difícil do meu projeto, e pelo auxílio na lida com os funcionários da UAN.

À estagiária e agora colega de profissão Myria Luanna Costa por ter sido meu braço direito na coleta das Fichas Técnicas, na aplicação do questionário e em todo o desenvolvimento do trabalho na UAN.

Às minhas colegas de profissão e amigas Thelma, Camila, Eid, Ruanda por me darem força e sempre acreditarem no meu trabalho e nos meus objetivos. Agradeço à Thelma e à Ruanda principalmente pela ajuda na aplicação dos questionários na UAN que foi crucial para a pesquisa.

Aos meus pais, base de todas as minhas conquistas e por serem meus principais exemplos e apoiadores/patrocinadores.

A todos os integrantes da Nutrir Consultoria - Empresa Junior de Nutrição da UnB - da gestão 2012/2013 e 2013/2014 pela compreensão, apoio, inquietações, conselhos, feedbacks e também por contribuírem no meu crescimento e aumentarem meu amor pela profissão.

À Sra. Jane, dona do restaurante Taioba Assados \& Grelhados, à Sra. Maria e à Jussara por cederem o espaço para que eu pudesse aplicar meu projeto de Mestrado.

E ao meu irmão Lucas, por ser meu melhor amigo, companheiro, parceiro e de grande ajuda nos momentos de dificuldade e também de comemorações. 


\section{RESUMO}

Uma alimentação equilibrada é um dos principais componentes do estilo de vida que pode ser modificado para se viver melhor e com qualidade. Para tal, as Unidades de Alimentação e Nutrição (UAN) precisam adotar estratégias para formular cardápios que atendam a coletividade favorecendo a adoção de práticas alimentares saudáveis. O objetivo deste trabalho é avaliar a estratégia educativa de classificação de cardápios em uma UAN com modalidade de atendimento do tipo cafeteria com auto-serviço. É um estudo de intervenção e randomizado com uma UAN selecionada por conveniência, com modalidade de atendimento do tipo cafeteria com auto-serviço por quilo (selfservice), do tipo institucional. O tamanho da amostra foi de 556 comensais. A metodologia foi dividida em cinco etapas, sendo elas a elaboração das Fichas Técnicas de Preparação do cardápio da UAN (i); determinação do prato médio servido na UAN e da porção de cada preparação (ii); classificação das preparações em três critérios Densidade Energética (DE) e Teor de Sódio (TS) (1º); Grupos de Alimentos e Recomendação de porções dos Grupos Alimentares $\left(2^{\circ}\right)$ e adição dos símbolos referentes ao glúten e à lactose $\left(3^{\circ}\right)$; definição de estratégias educacionais (iii); criação e aplicação de um instrumento de percepção (iv) e análise e tratamento de dados (v). Os participantes da pesquisa eram 52,5\% do sexo feminino, com média de idade de $37 \pm$ 15,2 anos e 52,1\% com pós-graduação. Foram elaboradas 144 FTPs e classificadas com as cores verde, amarelo e vermelho de acordo com a DE e TS. 88 FTPs $(61,1 \%)$ estavam inadequadas, sendo os molhos para salada, arroz, sobremesas, pratos principais e guarnições os que mais receberam as cores amarelas e vermelhas, com $40 \%$ devido ao moderado ou alto TS e 33\% pela moderada ou alta DE. Dos questionários, 86,3\% dos participantes observaram a metodologia na UAN e 54,5\% mudaram suas escolhas alimentares. Houve diferença significativa entre os que afirmaram que mudaram a escolha alimentar e os que não mudaram comparados ao número de itens que mais chamaram atenção na metodologia $(p=0,033)$, sendo que, quanto maior foi o número de itens fornecidos na metodologia, maior foi o favorecimento na mudança da escolha alimentar, sendo os principais: o uso das cores (verde, amarelo e vermelho) como indicadores de qualidade nutricional (DE e TS), a informação do tamanho da porção e os símbolos de contém ou não glúten e lactose. Por fim, a metodologia ativa de educação nutricional foi elaborada e validada, respondendo positivamente a questão de 
pesquisa deste trabalho de que a informação nutricional dada ao comensal intervém na sua escolha alimentar. Assim, os resultados deste estudo devem incentivar as UANs a preparações saudáveis aos clientes, utilizar as FTPs como itens permanentes e de suporte na produção de alimentos e fornecer informações nutricionais cuja abordagem deve adotar os pressupostos das metodologias ativas.

Palavras-chave: Educação nutricional, densidade energética, sódio, Ficha Técnica de Preparação, cardápio, Unidade de Alimentação e Nutrição, escolha alimentar, informação nutricional.

\section{ABSTRACT}

A balanced diet is a major component of lifestyle that can be modified to live better and with quality. To do this, the Food and Nutrition Units (FNU) need to adopt strategies to develop menus that meet the community promoting the adoption of healthy dietary practices. The objective of this study is to evaluate the educational strategy of menus classification in a FNU with mode-type cafeteria service with self-catering. It's a randomized intervention study with a FNU selected for convenience, with mode-type cafeteria service with self-catering with self-service per kilogram, the institutional type. The sample size was 556 consumers. The methodology was divided into five stages, these being the Preparation Technical Files (PTF's) of FNU menu preparation (i); determining the average dish served on FNU and the portion of each preparation (ii); Classification of preparations on three criteria - Energy Density (DE) and Sodium content (TS) $\left(1^{\circ}\right)$; Groups of Food and Recommendation of servings of Food Groups $\left(2^{\circ}\right)$ and adding the symbol relating to gluten and lactose $\left(3^{\circ}\right)$; definition of educational strategies (iii); creation and implementation of an instrument of perception and (iv) analysis and data processing (v). Survey participants were $52.5 \%$ female, with a mean age of $37 \pm 15.2$ years and $52.1 \%$ with graduate degrees. 144 PTFs were prepared and classified with the colors green, yellow and red according to the DE and TS. 88 PTFs $(61.1 \%)$ were inadequate, and the salad dressings, rice, desserts, main dishes and side dishes that have received the yellow and red colors, with $40 \%$ due to moderate or high TS and 33\% for moderate or DE high. The questionnaires, $86.3 \%$ of participants found the methodology in FNU and 54.5\% changed their food choices. There was a significant difference between those who said they changed the food choice and those who have 
not changed compared to the number of items that most drew attention in the methodology $(\mathrm{p}=0.033)$, and that the higher was the number of items provided in the methodology, the greater favoring the change in food choice, the main being the use of colors (green, yellow and red) as nutritional quality indicators (DE, TS), the portion size information and symbols contains no gluten or lactose and. Finally, the active methodology of nutrition education was developed and validated, positively answering the research question of this work that the nutritional information given to dinner intervenes in their food choice. Thus, the results of this study should encourage institutional foodservice healthy preparations to clients, use PTFs as permanent items and support for food production and provide nutrition information whose approach should adopt the assumptions of active methodologies.

Keywords: Nutrition education, energy density, sodium, Preparation of Technical Files, menu, Food and Nutrition Unit, food choice, nutritional information. 


\section{LISTA DE TABELAS, QUADROS E FIGURAS}

Tabela 1: Média da porção dos Tipos de Preparações e sua contribuição percentual no peso do prato médio consumido 46

Tabela 2: Determinação de sódio ideal na porção por Tipos de Preparações 49

Tabela 3: Classificação do Teor de sódio por Tipos de Preparações 50

Tabela 4: Classificação dos Grupos de Alimentos de acordo com o Guia Alimentar para a População Brasileira, de acordo com o My Plate e a classificação final ajustada para a pesquisa 54

Tabela 5: Recomendação das quantidades de porções dos grupos alimentares para homens e mulheres no almoço

Quadro 1: Legenda das cores das placas de identificação com classificação e recomendação de consumo 47

Figura 1 - Fluxograma das atividades realizadas na pesquisa 42

Figura 2 - Símbolos de contém glúten e lactose 56

Figura 3 - Símbolos de não-contém glúten e lactose 56

\section{ARTIGO 1}

Figura 1 - Pesquisa, seleção e exclusão de estudos sobre estratégias de educação nutricional que modificam a escolha alimentar de adultos 64

Tabela 1 - Características dos estudos sobre intervenção nutricional na mudança da escolha alimentar de adultos entre os anos de 2000 e 2013

\section{ARTIGO 2}

Tabela I. Determinação de sódio ideal na porção por Tipos de Preparações 90

Tabela II. Classificação do Teor de sódio por Tipos de Preparações 91

Tabela III. Classificação dos Grupos de Alimentos de acordo com o Guia Alimentar para a População Brasileira, de acordo com o My Plate e a classificação final ajustada para a pesquisa

Tabela IV. Recomendação das quantidades de porções dos grupos alimentares para homens e mulheres no almoço 
Tabela V. Medidas de tendência central e variância da Densidade Energética, Teor de Sódio e porção por Tipo de Preparação de um restaurante self-service no Brasil, 2015. ...

Quadro I. Legenda das cores das placas de identificação com classificação e recomendação de consumo 90

Figura I. Modelos de placas de identificação das preparações 95

\section{ARTIGO 3}

Tabela 1 - Variáveis sóciodemográficas e educacionais comparadas à mudança da escolha alimentar dos participantes através da Odds Ratio, Intervalo de Confiança e Coeficiente de Pearson de um restaurante self-service no Brasil, 2015

\section{APÊNDICES}

APÊNDICE 1 - Instrumento de Percepção 135

APÊNDICE 2 - Termo de Consentimento Livre e Esclarecido (TCLE)

APÊNDICE 3 - Modelos de placas de identificação das preparações

APÊNDICE 4 - Painel 1 140

APÊNDICE 5 - Pratos de almoço montados de acordo com a classificação (fotos) 141

APÊNDICE 6 - Painel 2 146

\section{ANEXOS}

ANEXO 1 - Termo de Aprovação do Projeto pelo CEP/FS - UnB 144

ANEXO 2 - Modelos de Fichas Técnicas de Preparação utilizados pelo software DietWin 


\section{LISTA DE SIGLAS E ABREVIATURAS}

\section{Abreviatura Significado}

ANVISA

AVC

AWASH

$\mathrm{CDC}$

CEP

CFN

DACNT

DE

DF

FCQ

FNU

FS

FTP

$\mathrm{g}$

IOM

IOTF

Kcal

$\mathrm{mg}$

OMS/WHO

OPAS

PAT

PMG

$\mathrm{POF}$

$\mathrm{RDC}$

$\mathrm{SC}$

SP

TCLE

PTF

TS
Agência Nacional de Vigilância Sanitária

Acidente Vascular Cerebral

Australian Division of the World Action on Salt Health

Centers Of Disease Control And Prevention

Comitê de Ética em Pesquisa

Conselho Federal de Nutrição

Doenças e Agravos Crônicos Não-transmissíveis

Densidade Energética

Distrito Federal

Food Choice Questionary

Food and Nutrition Unity (Unidade de Alimentação e Nutrição)

Faculdade de Ciências da Saúde

Ficha Técnica de Preparação

Grama (unidade de medida)

Institute of Medicine

International Obesity Task Force

Caloria

Miligrama

Organização Mundial da Saúde/World Health Organization

Organização Pan-Americana da Saúde

Programa de Alimentação do Trabalhador

Porção Pequena, Média e Grande

Pesquisa de Orçamento Familiar

Resolução da Diretoria Colegiada

Santa Catarina

São Paulo

Termo de Consentimento Livre e Esclarecido

Preparation of Technical File (Ficha Técnica de Preparação)

Teor de Sódio 
UAN

UnB

USDA

VET

VIGITEL

WCRF
Unidade de Alimentação e Nutrição

Universidade de Brasília

United States Department of Agriculture

Valor Energético Total

Vigilância de Doenças Crônicas por Inquérito Telefônico

World Cancer Research Fund 


\section{SUMÁRIO}

1 INTRODUÇÃ

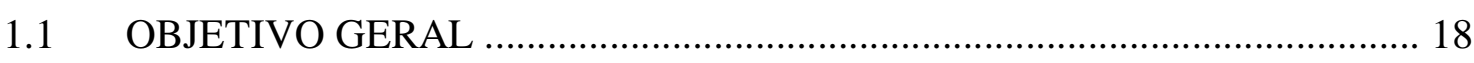

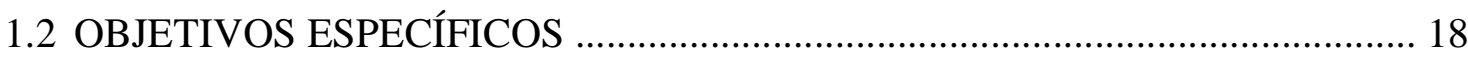

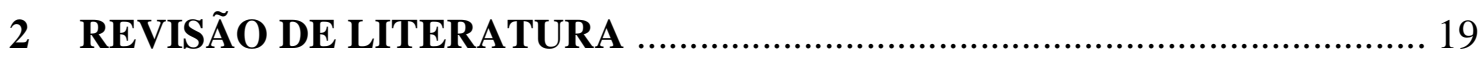

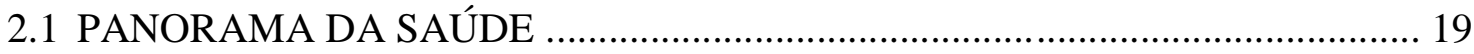

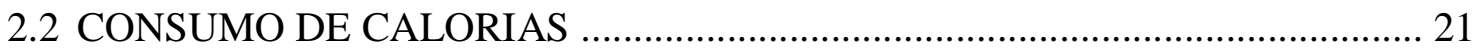

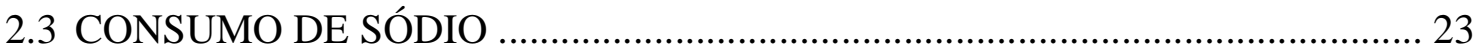

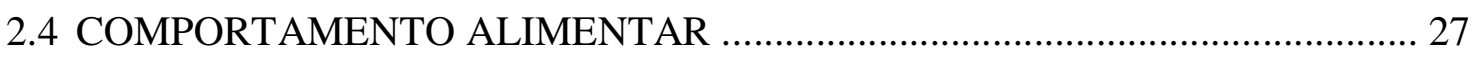

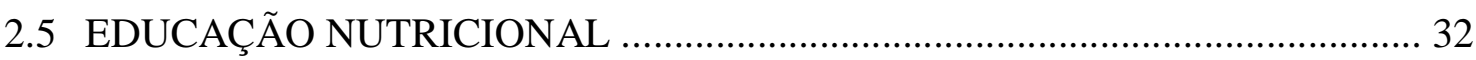

2.5.1 Estratégias de educação nutricional ................................................................. 34

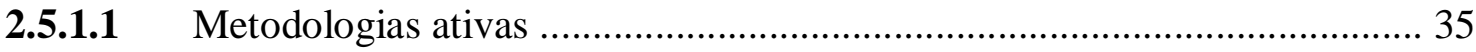

2.5.1.2 Influência da informação nutricional nos cardápios ..................................... 36

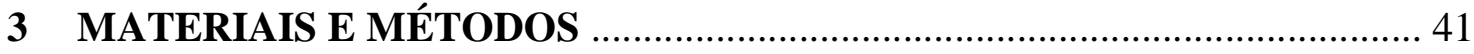

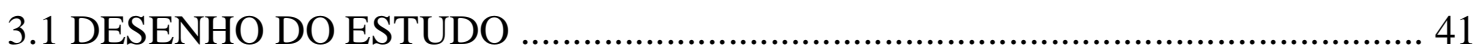

3.2 FLUXOGRAMA DE ATIVIDADES ............................................................. 41

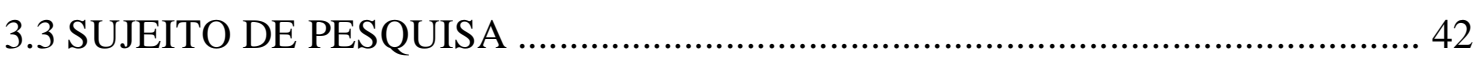

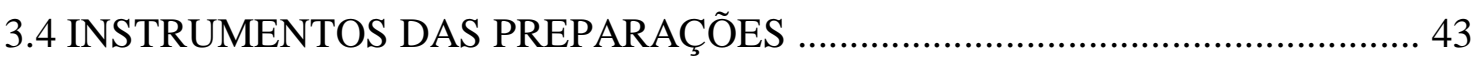

3.4.1 Fichas Técnicas de Preparação ........................................................................... 43

3.4.2 Determinação do prato médio e das porções ...................................................... 44

3.5 TÉCNICAS DE CLASSIFICAÇÃO DAS PREPARAÇÕES .................................. 46

3.5.1 Primeiro critério de classificação ………………................................................ 46

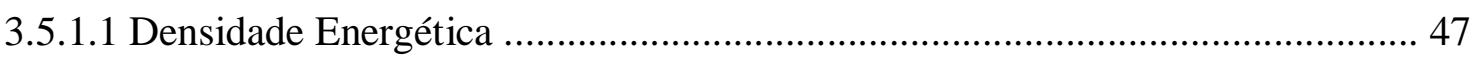

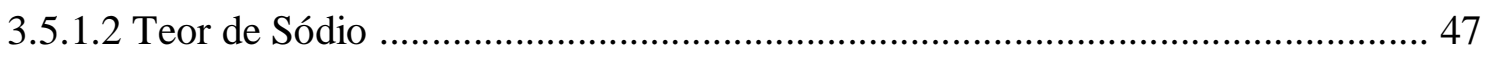

3.5.2 Segundo critério de classificação ......................................................................... 51

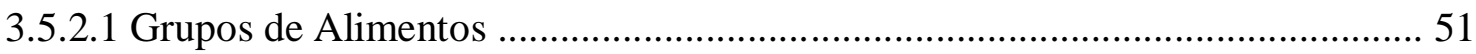

3.5.2.2 Recomendação de porções dos Grupos Alimentares .......................................... 55

3.5.3 Terceiro critério de classificação ................................................................... 55

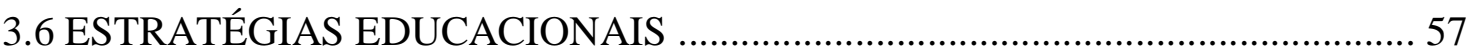

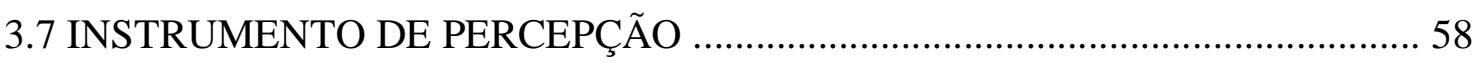

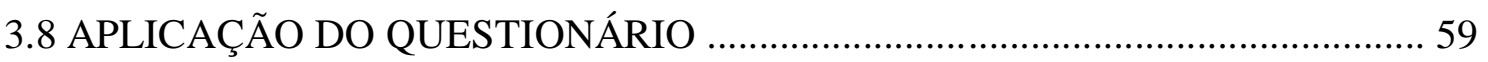

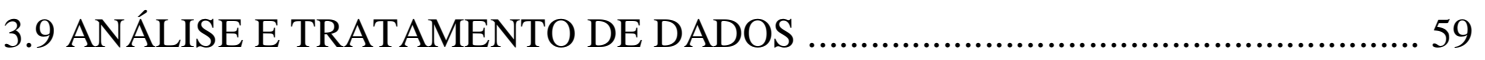


4 RESULTADOS E DISCUSSÕES 60

4.1 ARTIGO 1 - INTERVENÇÃO NUTRICIONAL NA MUDANÇA DO CONSUMO

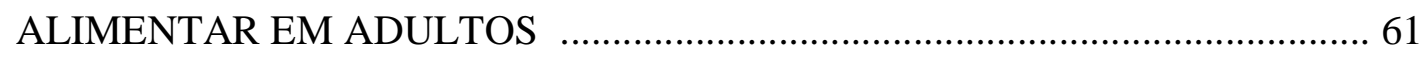

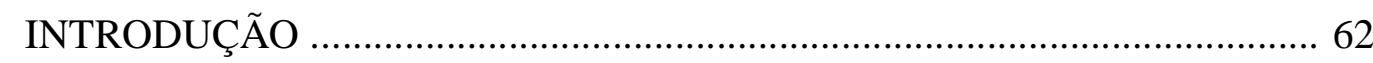

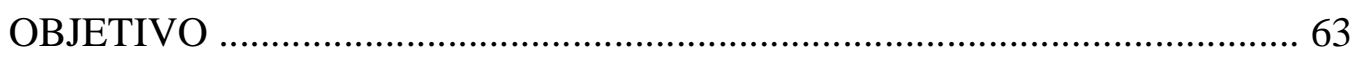

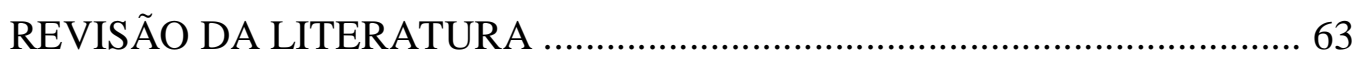

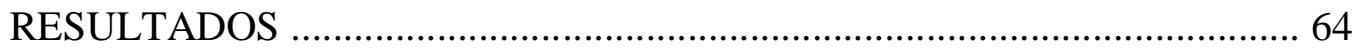

CONSIDERAÇÕES FINAIS .................................................................... 80

REFERÊNCIAS BIBLIOGRÁFICAS ……………………………………... 81

4.2 ARTIGO 2 - ESTRATÉGIA DE EDUCAÇÃO NUTRICIONAL EM

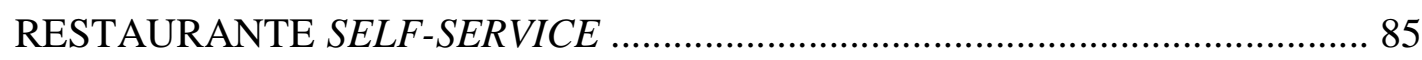

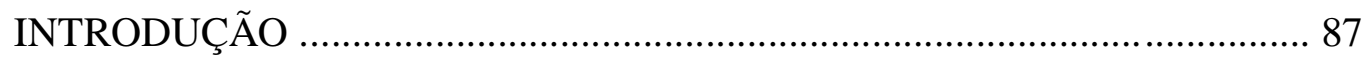

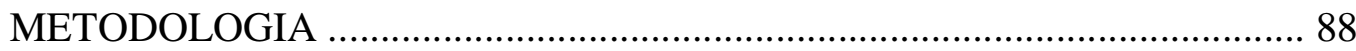

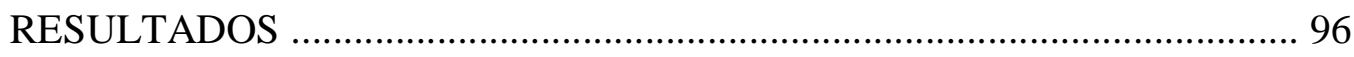

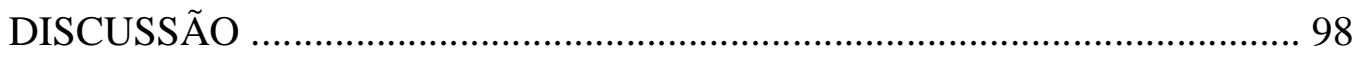

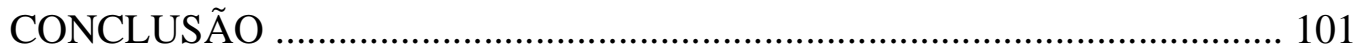

REFERÊNCIAS BIBLIOGRÁFICAS …………………………………....... 102

4.3 ARTIGO 3 - AVALIAÇÃO DE ESTRATÉGIA DE EDUCAÇÃO

NUTRICIONAL EM RESTAURANTE SELF-SERVICE …………………….... 106

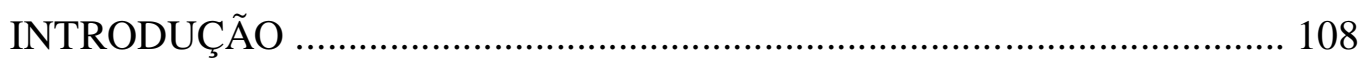

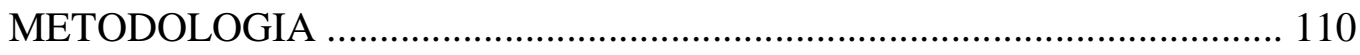

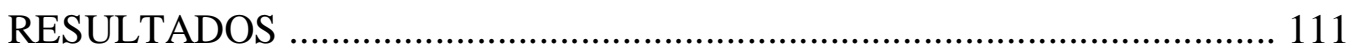

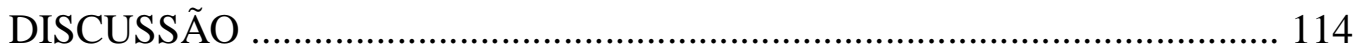

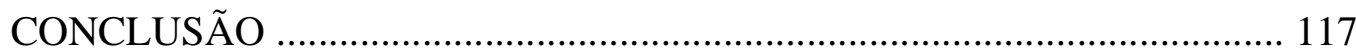

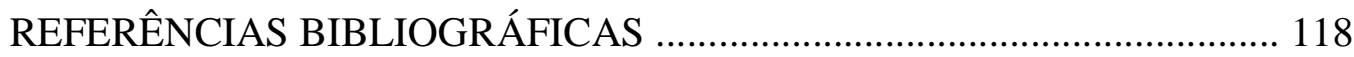

5 CONSIDERAÇÕES FINAIS .............................................................................. 122

REFERÊNCIAS BIBLIOGRÁFICAS ........................................................... 124

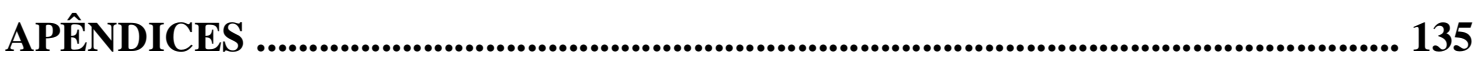

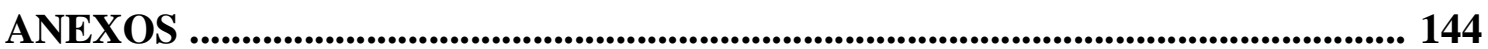




\section{INTRODUÇÃO}

Uma alimentação equilibrada é um dos principais componentes do estilo de vida que pode ser modificado para se viver melhor e com qualidade. Quando inadequada, a alimentação pode ser um importante fator de risco para doenças e agravos crônicos não transmissíveis (DACNT) (SOUSA, 2005).

Nesse sentido, o sobrepeso e a obesidade, segundo dados atuais da Vigilância de Fatores de Risco e Proteção para Doenças Crônicas por Inquérito Telefônico - VIGITEL (VIGITEL, 2014) têm sua porcentagem em ascendência no Brasil, sendo de 43\% na população em 2006 e de 49\% em 2011. É um dado alarmante, visto que essa comorbidade também pode levar ao aparecimento de outras doenças, como a hipertensão, diabetes mellitus, entre outras. A hipertensão arterial atinge adultos cada vez mais jovens, chegando a um quarto da população adulta mundial, podendo chegar a 1,56 bilhões de pessoas até 2025 (BRITO et al., 2011).

No Brasil estima-se que existem cerca de 17 milhões de portadores de hipertensão arterial, dos quais 35\% possuem idade igual ou superior a 40 anos. O sódio, quando consumido em excesso, é considerado um grande contribuinte dessa doença (BRITO et al., 2011).

Devido ao aumento da incidência das doenças oriundas da má alimentação e da falta de conhecimento de grande parte da população sobre formas de prevenção, eleva-se a demanda por estratégias de mudança de práticas e comportamentos individuais cujo objetivo seja a alimentação saudável (CERVATO et al., 2005). Assim, o papel da promoção da saúde, incluindo a educação nutricional, como estratégia no combate a esses problemas é essencial, sendo o nutricionista o responsável pela promoção da saúde por meio da realização de práticas educativas (CFN, 2006; SOUSA, 2005).

Atualmente, a sociedade moderna industrializada pouco facilita ao trabalhador o seu deslocamento até sua residência para a realização de suas refeições, por isto os trabalhadores buscam se alimentar ou no próprio local de trabalho ou em restaurantes próximos. Sendo assim, os restaurantes precisam ofertar uma alimentação equilibrada, de acordo com as recomendações nutricionais e adotar estratégias para que o cliente escolha uma alimentação saudável (CAMOSSA et al., 2005; CFN, 2006; SOUSA, 2005). 
Propostas educativas em nutrição para atendimentos em grupos têm por objetivo tornar o ambiente interativo e facilitador de aprendizagem. No trabalho em grupo é possível observar a reflexão dos membros do grupo sobre as suas práticas, com a possibilidade de intervenções lúdicas que facilitem e consolidem as mudanças de práticas, proporcionando assim melhor qualidade de vida (ALVAREZ; ZANELLA, 2009).

Os restaurantes necessitam adotar estratégias para formular cardápios que atendam a coletividade favorecendo a adoção de práticas alimentares saudáveis. Uma dessas estratégias é o Guia Alimentar para a População Brasileira (BRASIL, 2014) e por se tratar de um documento gerado pelo Ministério da Saúde e indicado para esse fim. Esse instrumento também permite que sejam realizadas boas escolhas alimentares, com base em princípios comprovados pela ciência da nutrição e de fácil entendimento por parte de profissionais e leigos (BRASIL, 2014).

Nos Estados Unidos, o guia alimentar para americanos do norte foi revisado em 2010, tendo a pirâmide alimentar sido substituída pelo My Plate, figura que apresenta as recomendações de porções alimentares em função da idade e das necessidades energéticas da população. O My Plate também é usado como apoio para estratégias de educação nutricional desta mesma a população (USDA, 2011).

Na prática, o porcionamento apresentado pelo Guia Alimentar brasileiro e pelo My Plate se refere à equivalência entre alimentos, determinando uma quantidade necessária de certo gênero alimentício ou preparação a fim de que seja possível sua substituição, mantendo o mesmo fornecimento qualitativo e quantitativo de nutriente. Entretanto, a quantificação das porções é dependente da necessidade energética do indivíduo. Em Unidades de Alimentação e Nutrição (UAN) esta quantificação é definida por meio das necessidades energéticas advindas da média obtida a partir da avaliação nutricional da clientela.

No Brasil, além do Guia Alimentar, também são usadas as normas do Programa de Alimentação do Trabalhador (BRASIL, 2006) para referenciar a porcentagem de energia necessária nas refeições de trabalhadores em Unidades de Alimentação. Além disso, são necessários outros aliados para que o trabalho do Nutricionista ganhe maior qualidade, como a utilização das Fichas Técnicas de Preparação - FTPs, baseada sempre nos quatro princípios de Pedro Escudero qualidade, quantidade, harmonia e adequação dos nutrientes dos alimentos 
(LANDABURE, 1968; AKUTSU et al., 2005; BRASIL, 2008; CAMARGO; BOTELHO, 2012).

Nesse sentido, se coloca a questão de pesquisa do presente trabalho: as estratégias de educação nutricional são eficientes para modificar a escolha alimentar dos comensais em uma Unidade de Alimentação e Nutrição (UAN)? Para investigar as estratégias de educação nutricional em UAN foram elaborados os objetivos de pesquisa descritos a seguir.

\subsection{OBJETIVO GERAL}

Avaliar a estratégia educativa de classificação de cardápios em Unidade de Alimentação e Nutrição com modalidade de atendimento do tipo cafeteria com autosserviço.

\subsection{OBJETIVOS ESPECÍFICOS}

Elaborar as Fichas Técnicas de Preparação do cardápio da UAN;

Classificar nutricionalmente as preparações servidas pela UAN;

Oferecer a informação nutricional das preparações ao comensal;

Aplicar método de educação nutricional;

Avaliar as estratégias educativas adotadas.

Para facilitar o entendimento e detalhar a pesquisa, esta dissertação está dividida em cinco capítulos. Este primeiro, introdutório, onde se apresenta o cenário da pesquisa e seus objetivos; o segundo, a revisão bibliográfica onde foi realizada uma busca na literatura sobre os temas que envolvem a pesquisa; no capítulo três constam o método e os materiais para desenvolvimento da pesquisa; o capítulo quatro apresenta os resultados do estudo, dividido em três artigos de títulos "1 - Intervenção Nutricional na Mudança do Consumo Alimentar em Adultos", "2 - Estratégia de educação nutricional em restaurante self-service" e "3 - Avaliação de estratégia de educação nutricional em restaurante self-service". O capítulo cinco traz os limites do estudo e as considerações finais da pesquisa. 


\section{REVISÃO DE LITERATURA}

\subsection{PANORAMA DA SAÚDE}

As doenças e agravos crônicos não-transmissíveis (DACNT) são consideradas um problema de saúde global, encontrado em diversos países, prejudicando o desenvolvimento humano. Em 2007, cerca de $72 \%$ das mortes no Brasil foram atribuídas às DACNT (doenças cardiovasculares, respiratórias crônicas, renais, diabetes, câncer e outras), responsáveis por 58,5\% de todas as mortes mundiais e por 45,9\% da carga global da morbidade adulta (ANDRADE et al., 2013).

Esse cenário, no Brasil, ocorreu em um contexto de desenvolvimento econômico e social marcado por avanços sociais importantes e pela resolução dos principais problemas de saúde pública vigentes naquela época. Crescimento da renda, industrialização e mecanização da produção, urbanização, maior acesso a alimentos em geral, incluindo os processados, e globalização de hábitos não saudáveis produziram rápida transição nutricional, expondo a população cada vez mais aos riscos dessas doenças (ANDRADE et al., 2013).

A mortalidade atribuível às DACNT diminuiu 20\% entre 1996 e 2007, sobretudo devido a reduções de doenças cardiovasculares $(31 \%)$ e respiratórias crônicas (38\%); para o diabetes e outras doenças crônicas, a mortalidade permaneceu estável (aumento de $2 \%$ e diminuição de $2 \%$, respectivamente). A mortalidade por DACNT padronizada por idade em 2004 no Brasil (625 por 100.000 pessoas), conforme relatado pela OMS, foi maior que a do Reino Unido e do Canadá (OMS, 2005), e no Brasil, foi maior no Nordeste e menor no Sul e Sudeste, deixando o Norte e o Nordeste (as regiões mais pobres do Brasil) com a mortalidade mais alta por DACNT em 2007. As duas últimas regiões também tiveram os maiores aumentos de mortalidade por diabetes nesse período (SCHMIDT et al., 2011).

Em 2007, no Brasil, as doenças do aparelho circulatório levaram 308.466 pessoas ao óbito, contribuindo com $31,89 \%$ de todas as mortes. Em conjunto, elas representaram uma taxa de 162,9 óbitos por cem mil habitantes. As neoplasias, no ano referido, dentro dos grandes grupos de causas de morte, resultaram numa carga de 159.092 óbitos, contribuíram com $16,7 \%$ de todas as mortes e uma taxa de mortalidade específica de 84,0 óbitos por cem mil habitantes (VERDE; OLINDA, 2010). 
Sobre a hipertensão, dados nacionais representativos obtidos em 2008 a partir de quase 400.000 entrevistas estimam que $24 \%$ das mulheres e $17,3 \%$ dos homens com idade $\geq 20$ anos e cerca de metade dos homens e mais da metade das mulheres com idade $\geq 60$ anos relataram diagnóstico prévio de hipertensão. As doenças cardiovasculares foram e continuam a ser, apesar de sua diminuição, a principal causa de morte no Brasil (SCHMIDT et al., 2011).

O diabetes como causa básica de morte aumentou $11 \%$ de 1996 a 2000, e aumentou $8 \%$ de 2000 a 2007, sendo que 9,3\% de todos os custos hospitalares no período 1999-2001 puderam ser atribuídos ao diabetes (SCHMIDT et al., 2011).

Estima-se também que no Brasil já haja cerca de três milhões de crianças com idade inferior a dez anos apresentando excesso de peso. Destes casos, $95 \%$ estariam relacionados à má alimentação, enquanto, apenas, 5\% seriam decorrentes de fatores endógenos (PELLANDA et al., 2002; MOREIRA et al., 2012). De acordo com a Organização Mundial da Saúde (OMS), é previsto que 2,3 bilhões de adultos terão excesso de peso e mais de 700 milhões serão obesos em 2015 (WHO, 2005).

No Brasil, as prevalências do excesso de peso e obesidade em adultos aumentaram desde os estudos conduzidos na década de 1970. A International Obesity Task Force (IOTF) estimou, em 2007, que houvesse mais de 1,1 bilhão de adultos em todo o mundo com sobrepeso (PELLANDA et al., 2002.

Estima-se que existam mais de um bilhão de adultos com excesso de peso na população mundial, sendo pelo menos 30 milhões estão clinicamente obesos. Dados publicados pelas National Health and Nutrition Examination Surveys estimam que, se as atuais tendências continuarem, até 2030 , mais da metade $(51,1 \%)$ dos adultos norteamericanos será suscetível à obesidade e outros 86,3\% ao sobrepeso. Projeções para o Brasil preveem que mais de $25 \%$ das pessoas terão excesso de peso no ano de 2025 (VELLOSO, 2006; SILVA, 2010).

Resultados divulgados pela Vigilância de Fatores de Risco e Proteção para Doenças Crônicas por Inquérito Telefônico (VIGITEL), de 2013 (BRASIL, 2014), confirmam o crescimento de excesso de peso na população adulta das 26 capitais brasileira, além do Distrito Federal, com 43,3\% e 13\% para a frequência de sobrepeso e de obesidade, respectivamente (SILVA, 2010).

Em relação aos aspectos históricos das DACNT, no Brasil tem sido detectada a progressão da transição nutricional, caracterizada pela redução na prevalência dos déficits nutricionais, ocorrência mais expressiva de sobrepeso e 
obesidade na população adulta. Essas doenças têm importantes fatores de risco, claramente descritos na literatura. Entre eles, encontramos os fatores ambientais como tabagismo, alcoolismo, prática de atividade física e alimentação (TRICHES; GIUGLIANI, 2005).

A epidemia de obesidade e de outras DACNT se dá por fatores nutricionais inadequados consequência do aumento descontrolado no consumo de alimentos ricos em gordura e com alto valor calórico, associados ao sedentarismo condicionado por redução na prática de atividade física e incremento de hábitos que não geram gasto calórico como assistir televisão, uso de vídeo games e computadores. O consumo alimentar tem sido relacionado à obesidade não somente quanto ao volume da ingestão como também à composição e qualidade da dieta (SONDA, 2011).

Dados obtidos em quatro grandes pesquisas representativas sobre compras de alimentos pelas famílias, realizadas no Brasil entre 1970 e 2004 sugerem uma redução na compra de alimentos tradicionais básicos, como arroz, feijão e hortaliças, e aumentos notáveis (de até $400 \%$ ) na compra de alimentos processados, como bolachas e biscoitos, refrigerantes, carnes processadas e pratos prontos. No mesmo período, a proporção de energia proveniente de gorduras no total dos alimentos adquiridos aumentou de $25,8 \%$ para $30,5 \%$, e a energia proveniente de gorduras saturadas aumentou de 7,5\% para 9,6\% (LEVY et al., 2009).

Outros indicadores que interferem no aparecimento dessas DACNT são o consumo excessivo de açúcar simples que se expressa na quantidade de calorias totais consumidas e sódio. Estimativas nacionais sobre ingestão de sódio mostram um consumo diário de cerca duas vezes a ingestão máxima recomendada (SARNO et al., 2009). Já o açúcar adicionado corresponde a 18\%, segundo dados de folhas de balanço de alimentos em 2003, excedendo a ingestão máxima recomendada em 60-80\% (FAO, 2004). Dentro desses fatores, o que tem aparecido com mais frequência são o sódio, alto consumo de calorias e inatividade física nos estudos como fatores precursores de DACNT.

\subsection{CONSUMO DE CALORIAS}

A alimentação fora do domicílio tem importante participação na dieta do brasileiro, representando $21 \%$ do total de gastos com alimentação. Habitualmente, a refeição realizada fora do domicílio fornece maior quantidade de energia, com maior 
participação de gorduras total e saturada em relação à preparada no lar. Além disso, um maior consumo de refeições fora do domicílio está positivamente associado com excesso de peso e obesidade entre adultos no Brasil (CANELLA et al., 2011).

O sobrepeso e a obesidade são DACNT cada vez mais frequentes no Brasil, têm sido relacionados ao aumento da oferta alimentar e ao consumo crescente de alimentos com alta Densidade Energética (DE) (MARCHIONI et al., 2012).

A DE é definida como a quantidade de energia fornecida por grama de peso do alimento $(\mathrm{kcal} / \mathrm{g})$. Assim, dietas com baixa DE fornecem menos energia por grama que as dietas com alta DE (ELLO-MARTIN et al., 2005). A classificação da DE em baixa, média e alta quantidade foi proposta pelo Centers of Disease Control and Prevention (CDC, 2005). Cabe destacar que a DE também é considerada um importante indicador para se medir a qualidade da dieta da população (PREVIDELLI et al., 2011; CANELLA et al., 2013). Os alimentos com elevada quantidade de água em sua composição, como frutas e hortaliças apresentam baixa $\mathrm{DE}$, enquanto os com baixa quantidade de água, tais como farinhas, grãos, açúcar, óleos e manteiga, têm alta DE (MARCHIONI et al., 2012).

Dietas com alta DE tendem a ser mais palatáveis o que favorece o aumento da ingestão de alimentos e energia, consequentemente, o aumento excessivo do peso corporal e desenvolvimento de doenças associadas, como as DACNT (RICARDO; CLARO, 2012). Quando a DE das preparações diminui, junto com ela reduz-se a ingestão de energia. Assim, para um mesmo valor calórico, indivíduos seguindo uma dieta de baixa DE podem consumir maior quantidade de alimentos de baixa DE e, portanto, podem ter menor sensação de fome que indivíduos seguindo uma dieta que restringe as porções de alimentos (ELLO-MARTIN et al., 2007).

O estudo de Marchioni et al. (2012) com os recordatórios alimentares de 24 horas de 710 adultos em São Paulo mostrou que a DE média consumida diariamente foi de $1,98 \mathrm{kcal} / \mathrm{g}$ e correlacionou-se positivamente com a ingestão de energia, gordura, carboidrato, colesterol, gordura saturada, sacarose, gordura trans e açúcar adicionado, e também com outros fatores como idade e hábito de fumar; e negativamente com o consumo de fibras. No entanto, os autores não encontraram correlação da DE com a maioria dos fatores sociais, demográficos e de estilo de vida investigados, o que confirma a generalização desse fenômeno em todo o estado de São Paulo.

Um estudo anterior de Canella et al. (2011) que avaliou a densidade energética do almoço de funcionários de 21 UANs de São Paulo, obteve resultados 
semelhantes, mostrando que houve relação positiva entre DE e a oferta de proteína, gordura total e gordura saturada. Além disso, os autores verificaram diferença significativa na DE quando os cardápios eram planejados por Nutricionistas. Ou seja, os cardápios elaborados por profissionais habilitados apresentavam menores DE. A correlação com a idade também foi encontrada por esses autores.

No estudo de Ricardo e Claro (2012) realizado com os dados da POF 2008/2009 (BRASIL, 2011) com o objetivo de avaliar a relação entre DE e custo da alimentação do brasileiro, observou-se que há uma correlação significativa inversa entre DE e o custo desses alimentos, mostrando que a população de baixa renda tende a consumir maior número de alimentos com alta $\mathrm{DE}$, pois são mais baratos $\mathrm{e}$ industrializados.

Diante do avanço da alimentação fora do domicílio - tendo o ambiente de trabalho como importante cenário - e do reconhecimento da DE como fator de risco relevante para a epidemia de obesidade, é necessária maior atenção tanto na oferta quanto no consumo de alimentos com alta e média DE, alertando os comensais para optarem por alimentos com baixa DE (CANELLA et al., 2011).

Cabe destaque que o consumo elevado de DE está associado ao elevado consumo de sódio. Em linha geral, quanto maior a ingestão de alimentos, maior a de energia, maior a de nutrientes, e entre eles está o sódio, nutriente presente em praticamente todos os alimentos industrializados (CANELLA et al., 2013).

Essa presença de sódio nos alimentos industrializados se deve principalmente ao seu papel como conservante dos alimentos, atributo este que se por um lado revolucionou a capacidade da armazenar alimentos, por outro elevou a oferta desse nutriente que tem se mostrado danoso a saúde quando consumido em excesso (ARAÚJO et al., 2011).

\subsection{CONSUMO DE SÓDIO}

O consumo de sal na maioria dos países tem sido excessivo nos últimos anos, variando de 9 a $12 \mathrm{~g}$ por pessoa por dia. No Brasil, de acordo com a última Pesquisa de Orçamento Familiar (POF) realizada em 2008/2009 pelo Instituto Brasileiro de Geografia e Estatística (IBGE), o brasileiro consome atualmente o dobro da quantidade de sal recomendada diariamente pela Organização Mundial da Saúde (OMS) 
de uma ingestão diária, para adultos, de no máximo $5 \mathrm{~g}$ de sal (2 g de sódio) (OMS, 2005; BRASIL, 2011).

Também existem evidências, em modelos animais, de que o consumo de sódio na gravidez pode determinar um aumento da preferência por sódio na fase adulta nos descendentes (NILSON et al., 2012), indicando a necessidade de maior atenção também às gestantes. Além disso, a literatura aponta uma associação entre o consumo excessivo de sódio e o desenvolvimento de doenças crônicas, desde a hipertensão arterial e doenças cardiovasculares até o câncer de estômago, doenças renais e osteoporose, entre outros (HE; MACGREGOR, 2005; DICKINSON, 2007).

A Hipertensão Arterial Sistêmica é a mais frequente das doenças cardiovasculares citadas, causadas também pelo alto consumo de sódio. É também o principal fator de risco para as complicações mais comuns, como acidente vascular cerebral (AVC) e infarto agudo do miocárdio, além da doença renal crônica terminal (BRASIL, 2010b).

Atualmente, a transição nutricional do Brasil é composta também pelo aumento do consumo de alimentos de uma maneira geral e consequente ingestão de calorias (BRASIL, 2011), em especial os itens que contém maior quantidade sódio, seja ele presente em produtos industrializados quanto em produtos consumidos em casa ou na rua, com grande adição de sal. Entre outros fatores, essa mudança parece estar associada à mudança de local para fazer a principal refeição do brasileiro (o almoço), que deixou o ambiente doméstico para consumir em restaurantes (KUNERT et al., 2013).

Sabe-se, então, que o hábito de fazer refeições fora de casa pode contribuir para o aumento da ingestão energética, pois essas refeições, geralmente, são maiores, com maior densidade calórica e maior conteúdo de gordura total, gordura saturada, colesterol e sódio. A repetição desse padrão alimentar ao longo da vida de um indivíduo pode contribuir muito para o aumento da prevalência de DACNT (KUNERT et al., 2013).

No caso do brasileiro, essa mudança de local de consumo do almoço esteve desde os primórdios associada ao Programa de Alimentação do Trabalhador (PAT), em virtude da alimentação está diretamente relacionada ao rendimento do trabalhador, aumentando a produtividade e diminuindo os riscos de acidentes de trabalho (VANIN et al., 2007; SOUSA et al., 2009). 
O Programa de Alimentação do Trabalhador (PAT) foi instituído pela Lei 6.321, de 14/4/1976 (BRASIL, 2006), com o objetivo de melhorar as condições nutricionais dos trabalhadores que tem a maior parte da sua alimentação fora de casa e prioritariamente em seu local de trabalho, através de Unidades de Alimentação e Nutrição (UAN) (SAVIO et al., 2005; SOUSA et al., 2009; ZANDONADI et al., 2014). De acordo com as orientações do Programa, nas refeições como, almoço, jantar e ceia, devem oferecer de 720 a 960 mg de sódio (CAPALONGA et al., 2010).

A agenda mundial pela redução do sódio é reforçada pelo envolvimento das principais agências internacionais, com destaque para a força-tarefa para a Redução do Consumo de Sódio nas Américas, coordenada pela Organização Pan-Americana da Saúde (OPAS), da qual participa o Brasil. Um dos principais produtos da força-tarefa é uma declaração política que estabelece o compromisso dos países da região com a redução do consumo de sal para menos de 5 g ao dia até 2020 (NILSON et al., 2012).

No Brasil, o Ministério da Saúde tem coordenado estratégias nacionais com vistas à redução do consumo de sódio, com ações articuladas a planos setoriais como o Plano Nacional de Saúde 2012-2015 e o Plano de Ações Estratégicas para o Enfrentamento das DACNT no Brasil 2011-2022. As estratégias de redução do consumo de sódio no Brasil têm como principais eixos a promoção da alimentação saudável (particularmente no que tange ao uso racional do sal) e a realização de ações educativas e informativas para profissionais de saúde, manipuladores e fabricantes de alimentos e população. Outras iniciativas voltadas à redução do consumo de sódio se destacam, e entre as principais estratégias encontram-se a redução de sódio de alimentos produzidos que são ofertados aos comensais que se alimentam fora de casa com frequência (NILSON et al., 2012; BRASIL, 2014).

A participação da alimentação fora do domicílio nas despesas familiares aumentou para um terço do total dos gastos alimentares, e a participação dos alimentos processados cresceu em todos os estratos de renda, reforçando o papel dessas categorias na ingestão de sódio pela população brasileira (BRASIL, 2010a). Com isso, o estímulo ao consumo de alimentos básicos é o centro das ações de promoção da alimentação saudável no país, estando presente em todas as ações e programas de alimentação e nutrição, por meio da alimentação saudável que contemple o uso racional do sal, tanto em casa quanto em estabelecimentos que servem refeições como de UANs.

Pesquisas revelam que as refeições produzidas em restaurantes e UANs têm alto teor de sódio, devido à propriedade de sódio de melhorar o sabor e a aceitação dos 
alimentos, expondo os consumidores ao risco de ingestão elevada (KUNERT et al., 2013; ZANDONADI et al., 2014).

Kunert et al. (2013) na sua pesquisa sobre o teor de sódio e gordura em preparações semelhantes ofertadas em três restaurantes self-service em Goiás, observou que as quantidades de sódio e gordura encontradas estavam acima da recomendação, variando entre $140,1 \%$ e $214,2 \%$ da recomendação diária de óleo e atingiu entre $54,4 \%$ e $82,6 \%$ da recomendação diária de sódio.

Na pesquisa realizada por Zandonadi et al. (2014) com 37 UANs localizadas nas cinco regiões do Brasil, foi encontrado que, para quem se alimenta fora de casa, o arroz, o feijão e o prato principal ocupam $74,02 \%$ do peso do prato médio do almoço e consequentemente, onde há também maior oferta de sódio. Esses três componentes oferecem juntos $82,19 \%$ do sódio da refeição. A maioria das saladas e vegetais de folhas verdes $(86,16 \%)$ não contém adição de sal. A quantidade de sódio oferecido nesses estabelecimentos pesquisados foi $257,4 \%$ maior do que o limite máximo de ingestão para esta refeição, de acordo com a recomendação da OMS e do PAT (OMS, 2005; BRASIL, 2006). Ainda nesse estudo, as autoras propõem uma redução do sódio ofertado com base na distribuição da quantidade máxima de sódio recomendada para o almoço, que é de 920 mg (OMS, 2005; BRASIL, 2006).

Além dessa necessidade de adequação dos alimentos oferecidos por UAN, a população necessita de orientações e educação nutricional que promovam reflexões em relação aos hábitos, com o objetivo de reduzir a ingestão de sódio também fora das UANs (ZANDONADI et al., 2014).

O estudo australiano de Cobcroft et al. (2008) demonstrou que reduções de até $30 \%$ de sódio nas preparações não diminuem sua aceitabilidade. Com isso, as metas de consumo de sódio devem partir da redução gradual do sódio até a oferta ideal de 920 mg no almoço para o somatório das porções das preparações servidas (BRASIL, 2014).

Em 2011, a Australian Division of the World Action on Salt Health (AWASH, 2011) criou a campanha Drop the salt!, traduzida como "largue o sal" que teve por objetivo principal aproximar o consumo de sódio da população ao recomendado pela OMS (OMS, 2005), de $2000 \mathrm{mg} / \mathrm{dia}$ a partir do ano de 2012. A meta é que o valor se aproxime do adequado em até cinco anos. Uma das estratégias apresentadas à população é de reduzir imediatamente $25 \%$ de sal adicionado nos alimentos preparados em casa (COBCROFT et al., 2008; WEBSTER et al., 2009; AWASH, 2011). 
Outra estratégia que vem sendo fortemente recomendada é a implantação da rotulagem de todos os alimentos disponíveis para venda, desde industrializados até os preparados em restaurantes/lanchonetes, deixando evidente a quantidade de sódio que contém, alertando o consumidor para essas quantidades (AWASH, 2011).

Portanto, em um primeiro momento, a UAN pode utilizar como estratégia inicial de redução de sódio, a retirada imediata de $30 \%$ do sal das preparações em virtude dessas reduções não serem percebidas. Maiores reduções serão viáveis se forem executadas gradativamente para não diminuir bruscamente a aceitabilidade pelos comensais (BRASIL, 2014). Num segundo momento, após a adaptação e reeducação alimentar dos comensais, a redução pode ser incrementada para aproximar o valor consumido do valor ideal orientado pela OMS e pelo PAT (OMS, 2005; BRASIL, 2006).

Segundo Sarno (2010), várias razões indicam o ambiente de trabalho como um dos locais adequados para intervenções promotoras de saúde, principalmente quanto à redução no consumo de alimentos ricos em sódio. Em primeiro lugar, proporcionam acesso a um importante segmento da população (adultos) cuja abordagem seria dificultada de outra forma.

No Brasil existem cerca de 50 milhões de trabalhadores empregados e um indivíduo adulto chega a passar um terço do seu dia no local de trabalho, fazendo ao menos uma grande refeição durante essa jornada laboral. Em segundo lugar, o ambiente de trabalho permite o acesso contínuo aos funcionários e programas de intervenção podem ser oferecidos em longo prazo. Esse contato intenso pode facilitar mudanças nos hábitos e comportamentos dessa população (SARNO, 2010).

\subsection{COMPORTAMENTO ALIMENTAR}

O interesse na investigação sobre o comportamento alimentar baseia-se na possibilidade de aumentar a efetividade de intervenções nutricionais. $\mathrm{O}$ aspecto mais importante na promoção da saúde é tornar o indivíduo capaz de traduzir as inúmeras informações sobre nutrição ao qual ele está exposto, para informações práticas sobre quais alimentos deve escolher para garantir uma alimentação saudável. Contudo, é importante destacar que o fornecimento de informações sobre qualquer comportamento de saúde é fundamental nas atividades educativas. O conhecimento contribui para 
sustentar ou desenvolver novas atitudes; é o componente racional necessário para motivar uma ação desejada (TORAL; SLATER, 2007).

O estudo de Stables et al. (2002) afirma que a consciência e o conhecimento sobre as recomendações dietéticas são precursores significativos da mudança de comportamento alimentar. Por outro lado, ressalta-se que o objetivo de uma intervenção nutricional não é apenas o fornecimento de informações, mas o alcance de uma modificação no comportamento alimentar (VAN-WEEL, 1999). Há evidências de que intervenções nutricionais apresentam maior efetividade quando são pautadas no comportamento, nas necessidades e crenças da população-alvo. Observa-se que há relatos mais frequentes de fatores intrínsecos do que extrínsecos como motivação para modificações dietéticas. As dificuldades que motivam os indivíduos a alterar o seu consumo alimentar têm sido muito estudadas, devendo-se considerar a gama de fatores envolvidos nesse comportamento (BRUG et al., 1996; TORAL, 2010).

Um estudo realizado com 1.700 consumidores do Reino Unido constatou que as principais razões que estimulavam a adoção de práticas alimentares saudáveis eram o desejo de melhorar o estado geral de saúde (60\%), motivos pessoais de saúde (20\%), perda de peso (34\%), matérias veiculadas em revistas (11\%), na televisão ou no rádio (10\%) e a pressão exercida pelo cônjuge ou parente (9\%) (BUTTRISS, 1997).

Para que a modificação no padrão alimentar aconteça, é preciso iniciar processos de intervenção para que se modifique o comportamento alimentar em longo prazo. Um dos modelos mais indicados são as intervenções no local de trabalho. Ações como oferecer maior disponibilidade de alimentos saudáveis nos pontos de venda dos locais de trabalho (LASSEN et al., 2007), ter simultaneamente em vista vários fatores dietéticos, tais como a redução das gorduras na dieta e aumento do consumo de fruta e hortaliças, provou-se eficaz no cenário dos cuidados de saúde primários (STEVENS et al., 2002). O aconselhamento comportamental, em conjunto com o nutricional, parece muito eficaz nesses cenários.

Sobre o local de trabalho dos consumidores, o setor de alimentação fora de casa engloba tanto estabelecimentos coletivos quanto comerciais (PROENÇA, 2000). Um tipo de restaurante que tem sido muito frequentado pelos brasileiros nos últimos anos, inicialmente no setor comercial e atualmente também no coletivo, é o restaurante por peso. Esse é um modelo self-service, onde o comensal escolhe o que deseja consumir pagando pelo peso do que foi colocado em seu prato (MAGNEÉ, 1996). 
Nesse sistema, há uma oferta ampla de opções de preparações alimentares, delegando certa autonomia ao comensal para escolher. Esta característica ressalta a importância do restaurante por peso como um ambiente propício para se avaliar a escolha alimentar dos indivíduos (MAGNEÉ, 1996).

A escolha alimentar humana está baseada, por um lado, na condição onívora do homem, isto é, sua a capacidade de comer de tudo e, por outro lado, na autonomia do indivíduo em realizar essas escolhas (determinado por diversas condições que irão influenciar essa decisão) (JOMORI, 2006). As condições que influenciam essas escolhas são a apresentação visual, o sabor, o valor nutricional, os tipos de preparações e a variedade oferecida.

Essas escolhas são influenciadas por fatores individuais, como os biológicos, os econômicos, os socioculturais e os antropológicos. Destaca-se, contudo, que as diferenças na escolha alimentar entre homens e mulheres são determinadas por motivos que vão além das questões biológicas evidentes, já que o contexto históricocultural, expresso no gênero, pode exercer influência na escolha dos indivíduos (JOMORI et al., 2008).

Em relação aos alimentos, alguns determinantes de sua escolha podem ser citados em diversos estudos como a aparência, sabor, variedade, valor nutricional e qualidade (NIELD et al., 2000; MILLS; CLAY, 2001; SCHOLDERER et al., 2004).

Nield et al. (2000) objetivou verificar o papel e a importância da alimentação em restaurantes na satisfação de 341 turistas na Romênia através de um questionário. Os resultados indicaram que a qualidade da comida, o valor em dinheiro, a variedade de pratos e a apresentação da comida foram os atributos de maior impacto nas experiências satisfatórias.

Mills e Clay (2001) desenvolveram e validaram um questionário para identificar quais fatores são mais importantes para os comensais quando esses escolhem os alimentos disponíveis no cardápio de um restaurante. Foram 330 questionários respondidos por frequentadores de restaurantes dos Estados Unidos. O questionário levava em consideração alguns fatores para se pesquisar sobre o que eles denominaram de 'verdade no cardápio' no momento da escolha dos itens, com informações nutricionais, de saúde, de tamanho e número da porção, da origem dos alimentos, da quantidade, qualidade, do método de preparo, entre outras questões de seguridade de produtos alimentícios. 
Algumas questões falavam sobre informações nutricionais dos cardápios, informações da descrição dos itens do cardápio (conhecimento do tamanho ideal da porção, apresentação visual, quantidade e qualidade dos alimentos, meios de conservação, técnicas de preparo) e informações sobre os ingredientes presentes nos itens do cardápio. Esses fatores foram pontuados pelos sujeitos pesquisados dentro de uma escala de quatro pontos pelos graus de importância de 'não importante' a 'extremamente importante'. O tamanho da porção foi considerado o mais importante fator pelos respondentes. Os resultados gerais mostraram que conhecer mais a fundo os alimentos ofertados no cardápio é o fator mais importante da escolha alimentar, seguido da apresentação visual do prato (MILLS; CLAY, 2001).

Scholderer et al. (2004) desenvolveram e validaram um instrumento chamado Food-related lifestyle instrument (FRL) nas diferentes culturas da Europa ocidental, traduzido como instrumento de estilo de vida alimentar relatado. Este foi utilizado para avaliar as dimensões que estão associadas ao estilo de vida de um consumidor em três fatores: atitudes, interesses e opiniões. O questionário consistiu em 69 itens medindo 23 dimensões dentro dos cinco países. Cada dimensão mediu três itens em uma escala de sete pontos, que compreendiam valores desde "discordo completamente" até "concordo completamente".

Após a análise do FRL, concluiu-se que as medidas do instrumento têm as mesmas construções, inter-relações e, variabilidade entre os países. As propriedades de medida dos domínios - técnicas de preparo do alimento, aspectos qualitativos, situações de consumo e motivos de compra (considerado importante para medir diferenças individuais específicas em relação aos valores pessoais sobre o alimento) - foram invariáveis durante as aplicações do instrumento. Esses resultados demonstram que o FRL fornece medidas consistentes das culturas ocidentais europeias, cujos itens relatados podem ser citados como variáveis relacionadas aos alimentos (SCHOLDERER et al., 2004).

Esses estudos possuem em comum os motivos da procura do homem por determinando alimento. Além desses fatores de influência descritos, também está a classe social na qual o consumidor está inserido (BOURDIEU, 2011).

Nesse contexto, Stepoe et al. (1995) desenvolveu um instrumento de medida dos motivos relatados para a escolha alimentar, denominado Questionário de Escolha Alimentar (FCQ - Food Choice Questionary) com 358 adultos em Londres. Esse questionário baseou-se numa extensa literatura, sugerindo a avaliação da percepção 
individual desses fatores, num contexto multidimensional da escolha alimentar. O FCQ oferece a oportunidade de avaliar os fatores relevantes da escolha alimentar percebidos individualmente pela população urbana ocidental. Esses fatores, entretanto, não se referiram necessariamente ao comportamento real de escolha alimentar, ou seja, às práticas alimentares realizadas por esses indivíduos, mas sim às representações dos motivos que levam a essas escolhas.

Outro autor que vem se debruçando fortemente sobre esse tema e Jean Pierre Poulain. Uma abordagem importante é a linha metodológica utilizada nas pesquisas de Poulain entre os anos de 1996 e 2004. Esses estudos são baseados na aplicação de três técnicas de coletas de dados: a observação direta, a aplicação de questionário sobre alimentação e, por último, a aplicação de um questionário acerca da satisfação do cliente com o atendimento. Poulain enfatiza as práticas alimentares observadas, comparadas com práticas declaradas pelos indivíduos (POULAIN, 1999; 2002; 2004).

Outras abordagens relacionadas à avaliação dos fatores que levam à escolha alimentar estão associadas à equipe da Divisão de Ciências Nutricionais (Division of Nutritional Sciences) da Universidade de Cornell de Nova Iorque, nos EUA composta pelos pesquisadores Falket al. (1996; 2001), Devine et al. (1999) e Connors et al. (2001). Esses pesquisadores empregaram um método qualitativo e construtivista para coleta e análise dos dados para explicar o processo de escolha alimentar dos diferentes grupos estudados através de entrevistas e questionários.

Assim, os principais achados demonstram que os indivíduos levam em consideração vários itens antes de realizar a escolha alimentar - seus ideais, identidade, cultura e mudança de contextos e situações (DEVINE et al., 1999); saúde, sabor, custo, relação tempo/conveniência e organização de relacionamentos (CONNORS et al., 2001); e experiências prévias de escolha alimentar relacionadas à saúde (FALK, 2001) como determinantes da escolha alimentar.

Outros estudos verificaram a associação entre alguns fatores de escolha alimentar. Os participantes dos estudos realizados por Poulain (1999; 2002; 2004), Mills e Clay (2001), Nieldet al. (2000) e Scholderer et al. (2004) afirmam que a informação do valor nutricional do alimento influencia a escolha alimentar do indivíduo, e é denominada uma variável relacionada aos alimentos. Cabe destacar que o valor nutricional dos alimentos foi relacionado como importante fator de escolha alimentar pelos autores. 


\subsection{EDUCAÇÃO NUTRICIONAL}

A educação nutricional é conceituada como um processo educativo que tem como objetivo principal tornar os sujeitos autônomos e seguros para realizarem suas escolhas alimentares de forma que garantam uma alimentação saudável e prazerosa, propiciando, então, o atendimento de suas necessidades fisiológicas, psicológicas e sociais (CAMOSSA, 2005).

Do ponto de vista de sua importância, a educação nutricional é apontada como estratégia de ação, no campo da educação em saúde, a ser adotada prioritariamente em saúde pública para conter o avanço da ocorrência de doenças crônico-degenerativas uma vez que a alimentação de má qualidade é considerada um fator de risco para inúmeras doenças (RAMOS, 2013).

Além disso, a educação nutricional é um conjunto de estratégias sistematizadas para impulsionar a cultura e a valorização da alimentação, concebidas no reconhecimento da necessidade de respeitar, mas também de modificar, crenças, valores, atitudes, representações, práticas e relações sociais que se estabelecem em torno da alimentação, visando o acesso econômico e social de todo cidadão a uma alimentação quantitativa e qualitativamente adequada (BOOG, 2004).

Entre os diversos conceitos de educação nutricional, Rodrigues e Boog (2006) afirmam que a educação nutricional pode promover o desenvolvimento da capacidade de compreender práticas e comportamentos, e os conhecimentos ou as aptidões resultantes desse processo. Gaglianone (2006) mostra que a educação nutricional é um processo multidisciplinar que envolve transferência de informações, desenvolvimento da motivação e a mudança de hábitos, podendo reduzir os gastos públicos com o tratamento de doenças associadas aos maus hábitos alimentares.

O profissional Nutricionista é o importante difusor dessa prática educativa, com fundamentação teórica no campo da nutrição, capaz de traduzir esta ciência para a linguagem de seu público, orientando o comportamento alimentar dos indivíduos (CFN, 2006). Sua presença em ambientes que promovam atividades voltadas para aquisição e construção de conhecimento sistematizado, como as UANs, é muito importante e capaz de contribuir na formação de hábitos alimentares duradouros.

Nessas UANs, é importante que o nutricionista desempenhe o papel de educador tanto para os seus funcionários quanto para seus clientes, além de oferecer 
uma refeição que atenda às exigências sanitárias e nutricionais estabelecidas e promover a realização de atividades educacionais através da transmissão de mensagens claras, coerentes, de fácil interpretação e de forma convincente que desperte o interesse do comensal em adquirir novos conhecimentos a respeito de alimentação e nutrição, uma vez que mudanças no hábito alimentar é uma questão de decisão e escolha individual (PASCHOA, 2005; OLIVEIRA; ALVES, 2008).

Onde quer que o Nutricionista atue, deverá ser sempre um educador, suas ações deverão ser como agente de mudança num processo que ocorre, no mínimo entre duas pessoas: educando e educador. Aquino e Campos (2007) ressaltam que a educação nutricional deve ser pensada como um encontro, instaurado através do diálogo. Ela não deve ser uma ferramenta para se "obedecer à dieta", ao contrário, deve ser um processo de trabalho com as pessoas visando à conscientização da importância da alimentação, realizado de forma libertadora.

O contexto da educação nutricional no Brasil tem sido abordado através da difusão da noção de promoção das práticas alimentares saudáveis, observada nas mais diversas ações políticas e estratégias relacionadas com alimentação e nutrição. O papel da promoção da saúde cresce em sua importância como uma estratégia fundamental para o enfrentamento dos problemas do processo saúde-doença-cuidado e da sua determinação. A direção, nesse caso, é o fortalecimento do caráter promocional e preventivo, contemplando o diagnóstico e a detecção precoce das DACNT (SANTOS, 2011).

Segundo Buss (2000), a definição de promoção de saúde são as “atividades dirigidas centralmente à transformação dos comportamentos dos indivíduos, focando os seus estilos de vida e localizando-os no seio das famílias e, no máximo, no ambiente das culturas da comunidade em que se encontram”. Essa concepção, segundo o autor, tende a se centrar nos componentes educativos, o que se adequa à alimentação saudável e suas práticas.

Entre os fatores importantes para a promoção da saúde está à promoção de hábitos alimentares saudáveis, e a consequente diminuição dos índices de obesidade, que têm sido associadas aos conhecimentos sobre alimentação e nutrição (TRICHES; GIUGLIANI, 2005). Estas ações devem favorecer a formação de hábitos alimentares adequados e prevenir o surgimento e o aumento de patologias relacionadas a uma alimentação inadequada, assim como garantir qualidade de vida (CARVALHO et al., 2010a). 
Conforme Triches e Giugliani (2005) a educação nutricional apresenta-se como instrumento eficaz para a adoção de práticas alimentares saudáveis que irão determinar o peso saudável. Carvalho et al. (2010a) também afirmam que a utilização da educação nutricional como estratégia para auxiliar a mudança dos hábitos alimentares e a promoção de estilos de vida saudáveis, tem sido apontada em diversos estudos como uma ferramenta eficaz para a aquisição de conhecimentos sobre nutrição, a adoção ou mudanças de atitude em relação à alimentação.

Com isso, a implantação de programas de educação nutricional em UANs e a consequente criação de um ambiente favorável à saúde e à promoção de práticas alimentares e estilo de vida saudáveis constituem-se em importantes estratégias para enfrentar problemas alimentares e nutricionais já citados anteriormente (CARVALHO, 2010b).

\subsubsection{Estratégias de educação nutricional}

Diversos instrumentos e metodologias têm sido utilizados para as práticas de educação nutricional: resgate da culinária na prática, materiais impressos educativos (LOCARNO; NAVARRO; 2011); entrevistas semi-estruturadas, ações de instrução e ensino planejadas (REZENDE, 2011); encontros em grupo (CRISCUOLO et al., 2012); questionário aberto de múltipla escolha (GOMES, 2013), uso da mídia para promoção da alimentação saudável pela metodologia ativa (RODRIGUES; RONCADA, 2008; BOOG, 2010); cursos práticos de capacitação em alimentação e nutrição (BERNARDON et al., 2009); ações educativas utilizando Guias Alimentares (YOKOTA et al., 2010).

Tais estratégias, apesar da avaliação positiva de seus autores, não ofereceram um modelo completo e consistente a serem adotados em intervenções permanentes ou de longo prazo, principalmente em Unidades de Alimentação cuja comensalidade contemporânea é caracterizada pela escassez de tempo para o preparo e consumo de alimentos, pela presença de produtos gerados com novas técnicas de conservação e preparo, pelo vasto leque de itens alimentares, pelos deslocamentos das refeições de casa para estabelecimentos que comercializam alimentos, pelo arsenal publicitário, pela flexibilização de horários para comer agregada à diversidade de alimentos e pela crescente individualização dos rituais alimentares (OLIVEIRA; ALVES, 2008). 
Nesse sentido, o uso de uma metodologia ativa para aplicar as estratégias de educação nutricional em um grupo de pessoas foi relatada como a melhor forma de se intervir no comportamento e nas escolhas alimentares dos participantes (RODRIGUES; RONCADA, 2008).

\subsubsection{Metodologias ativas}

As práticas de educação nutricional têm sido consideradas estratégicas em relação aos problemas alimentares e nutricionais contemporâneos, auxiliando no controle e redução da prevalência de DACNT, redução de danos, promoção de uma cultura de consumo sustentável, hábitos alimentares saudáveis e valorização da cultura alimentar tradicional (BRASIL, 2012).

A Educação Nutricional é um campo de conhecimento e prática contínua e permanente que precisa utilizar diferentes abordagens educacionais, principalmente de forma ativa que vise o diálogo e a reflexão junto a indivíduos ao longo de todo o curso da vida, através de diversas populações, assim como a coletividade. Considerando os determinantes, as interações e significados que compõem o comportamento alimentar, essas metodologias ativas de ensina precisam levar em consideração a valorização da cultura alimentar, a sustentabilidade e a geração de autonomia para que as pessoas estejam empoderadas para a adoção de hábitos alimentares saudáveis e a melhoria da qualidade de vida (BOOG, 2010).

Uma estratégia ativa e participativa de todos os sujeitos envolvidos é a integração dos saberes científicos e populares, sendo um desafio na área da educação nutricional. Essas ponderações remetem a perspectivas concretas de desenvolver ações menos normativas e mais formativas junto a diferentes grupos de comensais. A opção preferencial para que esse empoderamento ocorra, então, deve ser por processos e metodologias ativas e participativa, em virtude de ampliar a sustentabilidade das ações e mudanças pretendidas (RODRIGUES; RONCADA, 2008).

O fortalecimento e ampliação dos graus de autonomia para as escolhas e práticas alimentares implicam, por um lado, o aumento da capacidade de interpretação e análise do sujeito sobre os alimentos e, por outro, a capacidade de fazer suas escolhas. Para tanto, é importante que o indivíduo desenvolva a capacidade de lidar com diferentes situações, a partir do conhecimento dos determinantes dos problemas que o afetam, encarando-os com reflexão crítica. 
Diante dos interesses e pressões do mercado comercial de alimentos, bem como das regras de disciplinamento e prescrição de condutas dietéticas no campo da saúde, ter mais autonomia significa conhecer as várias perspectivas, poder experimentar, decidir, reorientar, ampliar os graus de liberdade em relação a todos os aspectos do comportamento alimentar (BRASIL, 2012). Assim como relata Paulo Freire (2002, p. 14), "educar não é transferir conhecimento, mas criar as possibilidades para a sua própria produção ou a sua construção".

Porém, os instrumentos e metodologias de educação nutricional não se limitam a processos de comunicação e informação, mas a forma de comunicação é fundamental e influencia de maneira decisiva os resultados. A comunicação compreende o conjunto de processos mediadores de educação nutricional e, para ser efetiva, deve ser pautada na escuta ativa, reconhecimento das diferentes formas de saberes e práticas, valorização do conhecimento, cultura e patrimônio alimentar; comunicação realizada para atender as necessidades reais dos indivíduos e grupos e também a busca de soluções contextualizadas (BRASIL, 2012).

Nesse sentido, a estratégia que no seu conjunto demonstraram melhores resultados foi a exposição das informações nutricionais aos indivíduos, tanto de rotulagem de preparações quanto de informações acerca do efeito dos nutrientes sobre a saúde da população, cuja estratégia foi abordagem por metodologias ativas.

\subsubsection{Influência da informação nutricional nos cardápios}

Ainda no Brasil, a alimentação fora do domicílio mostrou-se positivamente associada ao excesso de peso e obesidade entre homens adultos (BEZERRA; SICHIERI, 2010). Dessa forma, o hábito de se alimentar fora do domicílio e a falta de informações nutricionais referentes aos alimentos disponíveis em restaurantes podem comprometer as escolhas saudáveis dos indivíduos, pois no momento da compra, essas escolhas poderiam se basear no rótulo e em suas informações. Além disso, os indivíduos tendem a subestimar o número de calorias presentes nas refeições realizadas fora de casa. Sendo assim, a disponibilização de informação nutricional em cardápios e painéis pode afetar potencialmente as escolhas alimentares e a quantidade de calorias ingeridas, em virtude do maior acesso do consumidor à informação (SANCHEZ, 2013).

A educação alimentar e nutricional está vinculada à produção de informações que possam subsidiar a tomada de decisões por parte dos indivíduos, dando 
a eles o direito de optar por alimentos mais saudáveis. Mudanças nos hábitos alimentares têm sido observadas em recentes décadas. $\mathrm{O}$ consumo de alimentos está relacionado com informações que os consumidores têm sobre o produto, e eles compram e consumir certos alimentos, devido à sua qualidade ou porque eles parecem ser seguros ou confiáveis (BRASIL, 2008).

No estudo de Souza et al. (2011) realizado em Natal com 368 participantes de 23 supermercados, a declaração nutricional dos alimentos serviu para subsidiar o controle dietoterápico para determinados tipos de doenças crônicas não transmissíveis, e auxiliar no momento da escolha alimentar.

O mesmo foi relatado no estudo nacional de Lewis et al. (2009) com 5603 participantes dos Estados Unidos, no qual pessoas com histórias de doenças crônicas referiram que verificavam e utilizavam a rotulagem nutricional.

Observa-se que a cultura, educação e outros hábitos são fatores que podem interferir no conceito de qualidade. Atualmente, os atributos relacionados com a saúde podem ser importantes para a escolha de alimentos pelos consumidores (SANCHES, 2013). Os rótulos dos alimentos são uma fonte importante deste tipo de informação, pois fornecem informação nutricional sobre os teores de nutrientes e benefícios de saúde (COUTINHO; RECINE, 2007).

No Brasil, apesar de importante, o processo de informação sobre segurança alimentar fornecida aos consumidores em restaurantes é infrequente, principalmente para as pessoas que sofrem de alergias alimentares e requerem informações precisas. Estes dados podem servir como uma ajuda preciosa para o desenvolvimento de programas que envolvem a informação nutricional. A disponibilidade de informações é de grande valor como uma ajuda para o desenvolvimento de programas para obter informações e regulamentos nutricionais em restaurantes (MAESTRO; SALAY, 2008).

O uso de informação nutricional é justificado como uma forma de ajudar as pessoas a melhorar suas dietas, fornecendo aos consumidores com informações úteis e confiáveis, estimulando a comercialização de produtos de saudáveis. Na literatura, encontram-se resultados positivos em que a maioria do público está se tornando ainda mais conscientes da importância do uso de informação nutricional em restaurantes em suas escolhas em relação a alimentos, incentivando, assim, um crescente número de restaurantes a aderir a esta política (MAESTRO; SALAY, 2008). No entanto, de acordo com a RDC $n^{\circ} 360$, essa informação é uma obrigação apenas para bens industrializados 
e, no Brasil, pouco se sabe sobre o uso de informação nutricional para alimentos servidos em restaurantes (BRASIL, 2003).

Iniciativas sobre fornecimento de informações sobre os alimentos preparados ainda são escassas e o governo certamente terá de conceber formas inovadoras de regulação de serviços de alimentação para que os consumidores tenham informações disponíveis para escolher um estabelecimento de acordo com a qualidade desejada.

No estudo de Barbieri et al. (2012) que buscou avaliar a atitude dos consumidores em relação às informações alimentares para preparações prontas em um restaurante comercial, foram desenvolvidas informações de alimentos com o nome da preparação, ingredientes, benefícios para a saúde e alertas e valor calórico. Depois de fornecer essas informações nutricionais, um questionário foi aplicado a 300 consumidores em um restaurante de Santa Maria (RS) para que os consumidores declarassem suas práticas quanto à presença da informação nutricional nos alimentos.

Barbieri et al. (2012) verificaram que 10,98\% dos participantes possuíam doença, sendo necessária a restrição de moderação e/ou total desses alimentos e 58,54\% dos participantes consumiram algum alimento porque observaram benefícios potenciais para a sua saúde baseado nas informações nutricionais. Ao avaliar o nível de satisfação dos participantes sobre as informações de alimentos, $72,76 \%$ consideraram as informações muito boas. Os participantes tenderam a mudar seu consumo depois de ter acesso a informações alimentares dos alimentos preparados (BARBIERI et al., 2012).

Lando e Labine-Wolfe (2007) estudaram sobre o interesse do consumidor por informações nutricionais de rótulos e de preparações, além de entender quais as reações do consumidor após modificarem essas informações para ajudar a focar nas calorias contidas nesses alimentos e proporcionar escolhas mais saudáveis. Esse estudo foi realizado em quatro cidades dos Estados Unidos com 68 consumidores, e constataram que os entrevistados estavam interessados em conhecer a informação nutricional dos alimentos, e sugeriram que a melhor forma desses alimentos serem rotulados seria através de utilização de ícones, etiquetas, e sinais no menu que indicassem as opções mais saudáveis.

Em estudo recente no município de Campinas (SP) com amostra de 114 restaurantes comerciais, encontrou-se informação nutricional e de saúde em $16 \%$ dos restaurantes de serviço completo (fullservice - que servem todas as refeições do dia). Nestes estabelecimentos, o tipo de informação mais disponível foi a "declaração de 
nutrientes", com destaque para a informação do valor energético, de macronutrientes e fibras, e estas informações eram encontradas dispostas no cardápio (VADIVELLO et al., 2011).

Na pesquisa conduzida por Sanches (2007) com 250 consumidores adultos de Campinas (SP), a autora desenvolveu e validou um instrumento composto por 56 questões referentes ao conhecimento dos alimentos fontes de alguns nutrientes e da relação entre dieta e doença. Cerca de $78 \%$ dos consumidores entrevistados concordaram muito que as informações nutricionais dos alimentos oferecidos nos restaurantes são fundamentais para consumidores que necessitam ter uma dieta específica. Encontrou-se que 54,8\% revelaram uma atitude extremamente positiva em relação às informações nutricionais disponibilizadas nos restaurantes. Com relação ao conhecimento nutricional, verificou-se que 50\% dos participantes obtiveram notas superiores a 6,3 para o conhecimento dos nutrientes e, acima de 7,5 para a relação dietadoença. Os testes estatísticos detectaram associações significativas entre a frequência de consumo das refeições fora de casa, o nível de conhecimento nutricional e a atitude com as variáveis socioeconômicas e demográficas. Identificou-se uma associação positiva entre a atitude referente às informações nutricionais e o conhecimento nutricional dos indivíduos.

Numa pesquisa mais recente realizada por Sanches (2013) sobre a disponibilidade de informação nutricional em restaurantes de São Paulo, foram avaliados 472 estabelecimentos de alimentação comercial., sendo que cerca de um quarto dos estabelecimentos pertencia à categoria dos restaurantes que comercializavam refeições completas (almoço, jantar). Em relação à informação nutricional, esta estava disponível ao consumidor em apenas cinco estabelecimentos $(1,1 \%)$ e todos estes pertenciam à categoria de lanchonetes de comida rápida. O autor afirma que, a disponibilização de informações nutricionais das preparações oferecidas é um dos quesitos necessários para que esses restaurantes, de fato, representem opções saudáveis. Dentre esses restaurantes, os do tipo self-service merecem destaque, pois apresentam características como maior variedade de escolhas, possibilidade de preços acessíveis, rapidez e conveniência, podendo representar uma alternativa de alimentação saudável fora de casa.

Todos esses trabalhos mostram a força das metodologias ativas como instrumento de educação nutricional. Entretanto, esses estudos não trazem, em sua 
maioria, as avaliações dos processos educacionais o que prejudica sobremaneira sua adoção em estudos mais amplos. 


\section{MATERIAIS E MÉTODOS}

\subsection{DESENHO DO ESTUDO}

O desenho de estudo é de intervenção e randomizado, por se tratar de um estudo de campo que os participantes foram selecionados aleatoriamente para serem expostos a determinado fator considerado protetor. Assim, o pesquisador controlou as condições do experimento, para realizar o estudo de intervenção que é prospectivo e tem por objetivo avaliar a eficácia do instrumento de intervenção (PEREIRA, 2008).

\subsection{FLUXOGRAMA DE ATIVIDADES}

Para explicar o cronograma de atividades deste trabalho, foi elaborado um fluxograma (Figura 1) que apresenta todos os passos da metodologia descrita a seguir. 
Escolha e autorização da Unidade de Alimentação e Nutrição

Apresentação dos documentos junto ao Comitê de Ética em Pesquisa CEP/FS - UnB

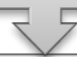

Revisão da literatura

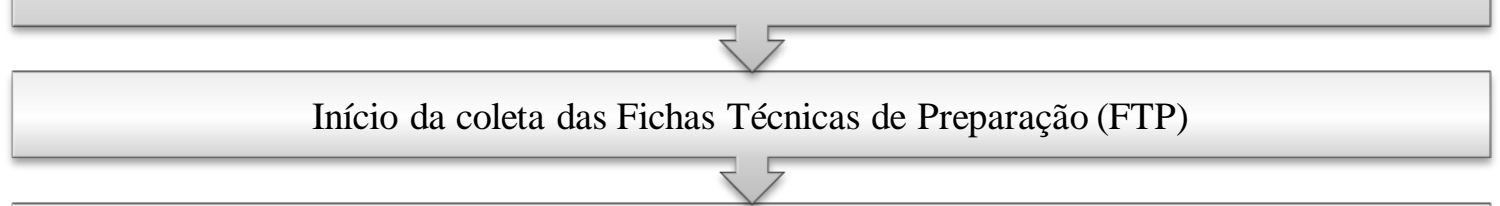

Determinação da porção de cada preparação e prato médio por observação direta

Classificação das FTPs com os critérios (Densidade energética, teor de sódio, cor, grupo alimentar e porção)

Elaboração das placas de identificação de cada preparação do buffet de acordo com as fichas técnicas e os critérios

\begin{tabular}{|c|}
\hline Elaboração do instrumento de percepção - questionário impresso \\
\hline Recrutamento dos comensais para participar da pesquisa e assinatura do Termo de \\
Consentimento Livre e Esclarecido
\end{tabular}

Figura 1 - Fluxograma das atividades realizadas na pesquisa

\subsection{SUJEITO DE PESQUISA}

Para aplicação da metodologia foi selecionada uma UAN por conveniência, com modalidade de atendimento do tipo cafeteria com auto-serviço por quilo. A UAN escolhida está localizada no centro de Brasília - DF e atende em torno de 1000 comensais no almoço de segunda a sexta-feira, sendo a grande maioria de trabalhadores do local - a UAN é do tipo institucional.

Para determinação da amostra da população da UAN, foi utilizado o cálculo de tamanho da amostra para populações finitas, utilizando um nível de confiança de 95\% e um erro amostral de 5\%. De acordo com a população de 1000 comensais, o 
tamanho médio da amostra é de 550 comensais (LEVIN, 1987; TRIOLA, 1999; PEREIRA, 2008).

Os critérios de inclusão dos comensais para participarem da pesquisa foram almoçar na UAN pelo menos uma vez na semana ou mais e ter idade maior ou igual a 18 anos; foram excluídos da pesquisa os comensais que trazem seu próprio almoço para o trabalho e aqueles que optam pela marmita vendida pela UAN.

Para avaliar a intervenção foi aplicado um instrumento de percepção aos comensais (Apêndice 1) que foram abordados aleatoriamente no horário de almoço na entrada da UAN e apresentados ao projeto de pesquisa com seus objetivos, e com o pedido de assinatura do Termo de Consentimento Livre e Esclarecido (TCLE) (Apêndice 2).

O projeto foi aprovado pelo Comitê de Ética em Pesquisa da Faculdade de Ciências da Saúde da Universidade de Brasília - CEP/FS - UnB, conforme Termo de Aprovação do Projeto no Anexo 1.

\subsection{INSTRUMENTOS DAS PREPARAÇÕES}

\subsubsection{Fichas Técnicas de Preparação}

Para realização do presente trabalho, foram elaboradas as Fichas Técnicas de Preparação (FTP) (AKUTSU et al., 2005; CAMARGO; BOTELHO, 2012) da UAN para todas as preparações servidas no cardápio semanal. Para o desenvolvimento destas, realizou-se o acompanhamento da produção dos alimentos de todos os dias de cardápio de uma semana completa de segunda a sexta-feira.

O restaurante servia 16 pratos quentes por dia, sendo seis pratos principais, três tipos de arroz, dois tipos de feijão, uma farofa, um prato vegano, um prato vegetariano, uma opção de guarnição com ovos e uma massa; e servia 12 saladas por dia, sendo seis do tipo elaboradas e as outras seis simples (sem adição de outros ingredientes), com acompanhamentos a parte (temperos e sementes), quatro opções de frutas e oito opções de sobremesas. O cardápio era mensal (quatro semanas), ou seja, se repetia a cada quatro semanas. Foi realizada a coleta de uma semana completa de cardápio por conta da grande quantidade de FTPs e da maioria das preparações serem diferentes todos os dias de todas as semanas. 
Os dados coletados para elaboração das FTPs foram os ingredientes, modo de preparo, peso bruto e líquido de todos os ingredientes, fatores de correção e cocção, índice de absorção de água e/ou gordura (quando aplicáveis), porção média do alimento de acordo com o método descrito por Sávio et al. (2005) -observação direta dos pesos das porções teóricas de tamanho pequeno, médio e grande ("P MG") de acordo com os utensílios utilizados no buffet; cálculo do rendimento total, macronutrientes (carboidrato, proteína e lipídio) do rendimento total e da porção real, valor energético total (VET) da preparação e da porção real, quantidade de sal adicionado e quantidade de sódio por porção real e também no rendimento total.

Todos os dados foram computados no software dietWin Rótulos de Alimentos ${ }^{\circledR}$ versão 1 de 2003 - que utiliza uma compilação de dados das principais tabelas de composição de alimentos: TACO, IBGE, USDA, CENEXA, Alemã e Repertório Geral dos Alimento - para análise da informação nutricional das preparações, com modelo de FTP adaptada de Camargo e Botelho (2012) (Anexo 2). Foram elaboradas 144 FTPs.

Foram elaboradas 122 FTPs de pratos elaborados (22 pratos principais, acompanhamentos - divididos em seis de feijão e sete de arroz, 31 guarnições, 26 saladas elaboradas, dez molhos para salada e 20 sobremesas), além de 22 FTPs individuais para frutas, folhagens e saladas cruas, itens adicionais/prontos como azeite de oliva, sementes e grãos (granola, aveia em flocos), doces e complementos de saladas e sobremesas servidos separados como creme de leite, leite condensado, mel, entre outros.

\subsubsection{Determinação do prato médio e da porção}

Para determinação da porção média de todas as preparações, foi utilizado o método descrito por Sávio et al. (2005). Para determinação do prato médio real e da porção média real, foi realizada uma observação direta de 50 comensais e assim determinada a frequência que cada comensal colocava em seu prato cada preparação, segundo fórmula abaixo. 
( $\mathrm{N}^{\circ}$ de comensais que se serviram da preparação $\mathbf{x} \mathrm{n}^{\circ}$ de porções servidas) $\mathbf{x}$ peso da porção em gramas/50 (número de comensais observados) = valor médio da porção em gramas.

Ou $(\mathrm{A} \times \mathrm{B}) \times \mathrm{C} / \mathrm{D}=\mathrm{E}$

Sendo, A: $N^{o}$ de comensais que se serviram da preparação

B: $n^{\circ}$ de porções servidas

C: peso da porção em gramas

D: número de comensais observados

E: valor médio da porção em gramas

Essa observação foi realizada para todos os Tipos de Preparações - pratos principais, acompanhamentos (feijão e arroz), guarnições, saladas, molhos para saladas e sementes. Foi realizada uma observação direta dos Tipos de Preparações e porções que os comensais se serviam (em média os comensais se serviram de uma opção de cada Tipo de Preparação), e o resultado mostrou que a maioria dos comensais acompanhados se serviu de uma opção de cada Tipo de Preparação (um prato principal, um arroz, um feijão, uma guarnição, saladas, molhos e sementes).

O peso do prato médio (média do somatório dos Tipos de Preparações) pode ser observado na Tabela 1. As sobremesas e as frutas também tiveram suas porções médias observadas, sendo de $71 \mathrm{~g}$ de frutas sem casca e sem caroço (com exceção da melancia que era servida sem casca, mas com caroço) e 104 g para sobremesas elaboradas. Esses valores não entram no cálculo do peso do prato médio em virtude de serem consumidos separados após a refeição. 
Tabela 1: Média da porção dos Tipos de Preparações e sua contribuição percentual no peso do prato médio consumido em Unidade de Alimentação e Nutrição de Brasília-DF, 2015.

\begin{tabular}{ccc}
\hline Tipos de preparações & Média da porção & $\begin{array}{c}\text { Contribuição \% da } \\
\text { preparação no peso do } \\
\text { prato médio }\end{array}$ \\
\hline Prato principal & $69,0 \mathrm{~g}$ & $16 \%$ \\
Guarnição & $63,0 \mathrm{~g}$ & $15 \%$ \\
Arroz & $103,0 \mathrm{~g}$ & $24 \%$ \\
Feijão & $69,0 \mathrm{~g}$ & $16 \%$ \\
Saladas & $102,0 \mathrm{~g}$ & $24 \%$ \\
Molhos para salada & $22,0 \mathrm{~g}$ & $5 \%$ \\
Sementes & $4,5 \mathrm{~g}$ & $1 \%$ \\
\hline Total & $432 \mathrm{~g}$ & $100 \%$ \\
\hline
\end{tabular}

\subsection{TÉCNICAS DE CLASSIFICAÇÃO DAS PREPARAÇÕES}

Em relação à metodologia de classificação e avaliação das preparações culinárias produzidas na UAN, foram escolhidos três critérios de acordo com a revisão de literatura (BRASIL, 2014; ZANDONADI et al., 2014).

\subsubsection{Primeiro critério de classificação}

Foi atribuído às preparações através das cores verde, amarela e vermelha, de forma lúdica, associada à sinalização de trânsito - cores do semáforo. Essa classificação contempla a Densidade Energética (DE) e o Teor de Sódio (TS) da preparação.

As preparações classificadas com a cor verde são as constituídas de alimentos com Baixo Teor de Sódio e Baixa Densidade Energética. A cor amarela é destinada aos valores Médios de DE e TS. Por fim, as preparações que recebem a cor vermelha são as que possuem Alta DE e Alto TS. Se houver uma mesma preparação com diferentes faixas atribuídas para sódio e DE, prevalece sempre o pior critério atribuído a preparação. Exemplificando, se uma preparação for classificada como Baixo TS, porém Médio DE, prevalecerá a cor do valor Médio - a cor amarela. 
O uso das três cores refere-se à recomendação de consumo, sendo diário da cor verde, consumo moderado da cor amarela e consumo menor da cor vermelha, assim como apresenta as legendas do Quadro 1.

Quadro 1: Legenda das cores das placas de identificação com classificação e recomendação de consumo

\begin{tabular}{|c|c|c|}
\hline Cor & Classificação & Recomendação de consumo \\
\hline Verde & $\begin{array}{c}\text { Baixa quantidade de sódio e } \\
\text { de gordura }\end{array}$ & Consumo diário \\
\hline Amarela & $\begin{array}{c}\text { Quantidade moderada de } \\
\text { sódio e de gordura }\end{array}$ & $\begin{array}{c}\text { Consumo de 2 a 3 vezes na } \\
\text { semana }\end{array}$ \\
\hline Vermelha & $\begin{array}{c}\text { Alta quantidade de sódio e } \\
\text { gordura }\end{array}$ & Consumo de 1 vez na semana \\
\hline
\end{tabular}

\subsubsection{Densidade Energética}

A Densidade Energética (DE) é um indicador de qualidade da alimentação e é definida como a quantidade de energia disponível por unidade de peso ( $\mathrm{kcal} / \mathrm{g}) \mathrm{de}$ alimentos, refeições e dietas; fortemente influenciada pelo conteúdo de água e de gordura (CROWE et al., 2004). Exerce importante papel na saciedade, no consumo energético e, em longo prazo, no peso corporal dos indivíduos (COX; MELA, 2000; DREWNOWSKI, 2003).

A densidade energética (DE) expressa em kcal/g é classificada de acordo com o Centers of Disease Control and Prevention (CDC, 2005) em baixa ( $<1,5 \mathrm{kcal} / \mathrm{g}$ ), média $(1,5-4 \mathrm{kcal} / \mathrm{g})$ e alta $(>4 \mathrm{kcal} / \mathrm{g})$. A DE foi calculada dividindo o VET da preparação em kcal pelo rendimento total da preparação em gramas.

\subsubsection{Teor de sódio}

O PAT (BRASIL, 2006) recomenda que seja ofertado em torno de $920 \mathrm{mg}$ de sódio (cerca de $40 \%$ da quantidade diária, a semelhança do VET do almoço), lembrando que esse valor é ofertado de acordo com uma dieta de $2000 \mathrm{kcal} / \mathrm{dia}$ e dividida em cinco refeições ao dia, sendo os $40 \%$ o correspondente do almoço, nesses critérios. Essa quantidade de sódio ideal $(920 \mathrm{mg})$ foi distribuída pelas porções dos Tipos de Preparações de acordo com o percentual proposto por Zandonadi et al. 
(2014) utilizando a porcentagem de sódio que o tipo de preparação requer de acordo com o prato médio encontrado no estudo (Tabela 2). Essa estratégia se deve a adoção dos pressupostos apontados por Zandonadi et al. (2014) que analisam a afinidade dos Tipos de Preparações pelo sal. A distribuição do sódio na preparação representa a porcentagem de sódio ideal na porção do total de sódio indicado para o almoço (920 $\mathrm{mg})$. 
Tabela 2: Determinação de sódio ideal na porção por Tipos de Preparações

\begin{tabular}{cccc}
\hline $\begin{array}{c}\text { Tipos de } \\
\text { Preparações }\end{array}$ & $\begin{array}{c}\text { Média } \\
\text { porção }(\mathbf{g})\end{array}$ & $\begin{array}{c}\text { Distribuição \% sódio } \\
\text { preparação* }\end{array}$ & $\begin{array}{c}\text { Sódio ideal } \\
\text { porção mg }\end{array}$ \\
\hline Prato principal & $69 \mathrm{~g}$ & $32,5 \%$ & $299 \mathrm{mg}$ \\
Guarnição & $63 \mathrm{~g}$ & $13,5 \%$ & $124,2 \mathrm{mg}$ \\
Arroz & $103 \mathrm{~g}$ & $33 \%$ & $303,6 \mathrm{mg}$ \\
Feijão & $69 \mathrm{~g}$ & $18,5 \%$ & $170,2 \mathrm{mg}$ \\
$\begin{array}{c}\text { Saladas e molhos } \\
\text { para salada }\end{array}$ & $102+22 \mathrm{~g}$ & $18,5 \%$ & $23 \mathrm{mg}$ \\
Sementes & $4,5 \mathrm{~g}$ & - & - \\
\hline Total & $432 \mathrm{~g}$ & $100 \%$ & $920 \mathrm{mg} * *$ \\
\hline \multicolumn{4}{c}{ Fonte: $*$ ZANDONADI et al., 2014***BRASIL, 2006. }
\end{tabular}

Portanto, os pratos principais foram elaborados com maior porcentagem de sódio no prato médio - 32,5\% do sódio total do almoço, ou seja, 299 mg de sódio - em virtude de não apresentarem grande concentração de substâncias extrativas de sabor e necessitarem de maior adição de temperos, para melhorar o sabor e a aceitação (ARAÚJO et al., 2011).

O arroz, por sua vez, não é acrescido de outro tempero por apresentar coloração branca e a adição de ervas ou outros ingredientes, para redução do acréscimo de sódio, poderia modificar a cor e diminuir a aceitabilidade desta preparação. Já o feijão e as preparações das guarnições possibilitam maior facilidade de mudança do percentual de sódio, pois permitem o acréscimo de outros temperos (BRASIL, 2014). Essas razões explicam o arroz ter a proporção de sódio semelhante à dos pratos principais $(33 \%)$ e a proporção de sódio do feijão e das guarnições serem menores (18,5\% e 13,5\%, respectivamente) (ZANDONADI et al., 2014).

Para classificar o teor de sódio (miligramas de sódio em 100 g de alimento) das preparações em Baixo (adequado), Médio e Alto, foram utilizados parâmetros encontrados na revisão de literatura (COBCROFT et al., 2008; AWASH, 2011; BRASIL, 2014; ZANDONADI et al., 2014). De início, o teor de sódio ideal (Baixo) das preparações que compõem o prato médio do almoço, corresponde até 920 mg de sódio, e porcentagens distribuídas nos Tipos de Preparações conforme o apresentado na Tabela 2. 
O teor de sódio Médio foi baseado no consumo atual de sódio (4600 mg de sódio/dia - que de acordo com a POF 2008/2009 do IBGE é em média o dobro de sal recomendado, aproximadamente $12 \mathrm{~g}$ sal/dia) (BRASIL, 2011) e permaneceu atribuindo-se os $40 \%$ do almoço conforme PAT (BRASIL, 2006), ou seja, o consumo atual de sódio é em torno de $1840 \mathrm{mg}$ para o almoço.

Desse valor foi debitado $30 \%$ da quantidade de sódio por porção, em virtude dos estudos apontarem que não há percepção na aceitabilidade neste percentual de distribuição, quantidade essa que já pode ser retirada de imediato dos pratos, como mostra a revisão de literatura (COBCROFT et al., 2008; AWASH, 2011; BRASIL, 2014). O número final para teor de sódio Médio do almoço nessa classificação foi em torno de $1288 \mathrm{mg}$. Este valor foi distribuído nas porções do prato médio considerandose as recomendações de Zandonadi et al. (2014).

O teor de sódio Alto, por fim, assume valores maiores de $1288 \mathrm{mg}$, ou seja, valores maiores que o teor de sódio Médio. A classificação do teor de sódio em Baixo, Médio e Alto está apresentada na Tabela 3.

Tabela 3: Classificação do Teor de sódio por Tipos de Preparações

\begin{tabular}{cccc}
\hline Tipos de & \multicolumn{3}{c}{ Teor de sódio (por 100 g) } \\
preparações & Baixo & Moderado & Alto \\
\cline { 2 - 4 } Prato principal & $<433 \mathrm{mg}$ & $433-607 \mathrm{mg}$ & $>607 \mathrm{mg}$ \\
Guarnição & $<197 \mathrm{mg}$ & $197-276 \mathrm{mg}$ & $>276 \mathrm{mg}$ \\
Arroz & $<295 \mathrm{mg}$ & $295-413 \mathrm{mg}$ & $>413 \mathrm{mg}$ \\
Feijão & $<247 \mathrm{mg}$ & $247-345 \mathrm{mg}$ & $>345 \mathrm{mg}$ \\
Saladas e molhos & $<19 \mathrm{mg}$ & $19-26 \mathrm{mg}$ & $>26 \mathrm{mg}$ \\
para salada & & & \\
\hline Total & $<920 \mathrm{mg}$ & $920 \mathrm{mg}-1288 \mathrm{mg}$ & \\
correspondente ao & & & \\
consumo total de & & & \\
sódio no almoço & & & \\
\hline
\end{tabular}

Cabe destacar que o World Cancer Research Fund (WCRF, 2012) classifica o "teor de sódio moderado" em uma escala muito ampla de valores (100 mg-600 mg/100 g), o que, no caso do Brasil, considerando-se o somatório de todas as 
preparações que contivessem o valor máximo da faixa do "teor de sódio moderado" (600 mg/100 g), implicaria em uma oferta de $2400 \mathrm{mg}$ de sódio para o almoço, na medida em que o consumo médio em gramas das preparações que compõem o prato do almoço, verificado em vários estudos, foi de aproximadamente 400 g (ABREU; TORRES, 2003; CONCEIÇÃO; AMORIM, 2014; ZANDONADI et al., 2014).

\subsubsection{Segundo critério de classificação}

O segundo critério classificatório está associado aos quatro princípios da alimentação saudável descritos por Pedro Escudero, sendo eles: quantidade, qualidade, harmonia e adequação de alimentos e nutrientes (LANDABURE, 1968). Para que os quatro princípios sejam seguidos na composição do prato do almoço, além de classificálos em cores como o primeiro critério trabalhando com os nutrientes que influenciam na Densidade Energética e no Teor de Sódio, é preciso dividir os Tipos de Preparações em grupos alimentares para obter o consumo de diferentes tipos de nutrientes e compor adequadamente o prato associando o tamanho e a quantidade da porção de cada Grupo Alimentar.

\subsubsection{Grupos de Alimentos}

Usados como referência, o Guia Alimentar categoriza todos os alimentos que devem ser consumidos durante o dia em grupos de I a VIII (I - Cereais, tubérculos, raízes e derivados; II - Feijões; III - Frutas e sucos de frutas naturais; IV - Hortaliças; V - Leite e derivados; VI - Carnes e ovos; VI - Óleos, gorduras e sementes oleaginosas e VIII - Açúcares e doces) (BRASIL, 2008), e o My Plate categoriza os alimentos em grupos que devem ser consumidos no almoço (Frutas, Vegetais, Proteínas, Grãos e Laticínios) (USDA, 2011). Para facilitar o entendimento dos comensais quanto ao agrupamento de alimentos indicados para o prato de almoço, a classificação foi ajustada em grupos menores que tenham relação com a refeição do almoço.

Cada grupo desta reclassificação ganhou um código - uma letra - para facilitar o cálculo das porções. O grupo dos Cereais, raízes, tubérculos e seus derivados (Grupo I) ou dos Grãos (My Plate) foi renomeado para "Grupo dos Carboidratos" e foi nomeado "C". O grupo dos Feijões (Grupo II) levou o mesmo nome e é representado pela letra "F". O grupo das Hortaliças (Grupo IV - Hortaliças - ou Vegetais (My Plate) 
foi reduzido para os vegetais do tipo B e C, e alguns do tipo A que tradicionalmente são cozidos, e ganhou o nome "Grupo dos Vegetais" e recebeu a letra "V".

O grupo do Leite e Derivados (Grupo V) ou Laticínios (My Plate) e o das Carnes e Ovos (Grupo VI) ou Proteínas (My Plate) tornaram-se um só, e atribuiu-se o nome de "Grupo das Proteínas", representado pela letra "P”. O Grupo dos Açúcares e Doces (Grupo VIII) não entrou no cálculo do almoço para não incentivar o consumo desse grupo, mas as sobremesas disponíveis no almoço foram classificadas com as respectivas cores de acordo com sua $\mathrm{DE}$, porém não receberam um código (Grupo Alimentar) ou uma porção ideal descrita, em virtude dessa proposta educacional estar baseada nos indicadores de sobrepeso e obesidade da população brasileira (BRASIL, 2011).

O grupo dos óleos, gorduras e sementes oleaginosas (Grupo VII) não foi classificado, pois a principal fonte de gordura a parte no prato de almoço é o azeite de oliva extra-virgem. Com isso, teve seu consumo incentivado à parte, ganhando a cor verde na sua placa de identificação e com a porção ideal para o dia de uma colher de sobremesa (ou um fio de azeite pequeno) assim como apresenta o Guia (BRASIL, 2008), pois é um ingrediente primordial no prato de almoço saudável por conter ácidos graxos insaturados e estar associado à melhora no perfil das gorduras no sangue e proteção cardiovascular (ESTRUCH et al., 2013; SANTOS et al., 2013).

As sementes (gergelim preto, gergelim branco e linhaça marrom também tiveram seu consumo incentivado à parte, pelas suas propriedades nutricionais benéficas e por fazerem diferença na dieta balanceada quando consumidos regularmente. Ambos receberam a cor verde na placa de identificação e as porções ideais recomendadas foram uma colher de chá de um dos tipos de semente (ANILAKUMAR et al., 2010; SANTOS et al., 2013).

Para o grupo dos Cereais, tubérculos, raízes e derivados é incentivado o consumo de seis porções de $150 \mathrm{kcal}$ diárias, sendo o VET diário de 2000 kcal. Logo, para o novo "Grupo dos Carboidratos" do almoço determinou-se 2,5 porções (40\% desse valor). Para o Grupo dos Feijões, o indicado é uma porção de 55 kcal e, considerando que o consumo de leguminosas é praticamente todo no almoço, o "grupo dos feijões" permaneceu com uma porção.

No Grupo dos Vegetais, o indicado são três porções de 15 kcal diárias, e como já citado, foi incentivado o consumo de hortaliças e não reduzido o cálculo para $40 \%$, permanecendo as três porções para o almoço. Para o "Grupo das Proteínas", o 
indicado é o consumo de três porções de leite de $120 \mathrm{kcal}$ e uma porção de carnes e ovos de 190 kcal diárias. Após ajuste, o consumo para o "Grupo das Proteínas” para o almoço foi de 1,5 porções de $140 \mathrm{kcal}$ cada.

As frutas (Frutas ou grupo III - Frutas ou sucos naturais), por sua vez, também receberam a cor verde na placa de identificação e a porção equivalente contendo em média $70 \mathrm{kcal}$, para que sejam consumidas como sobremesas saudáveis à parte caso seja da opção do comensal (BRASIL, 2008). O Grupo dos Óleos, gorduras e sementes oleaginosas indica uma porção ao dia, valor este que foi utilizado para determinar a quantidade de $8 \mathrm{~g}-72 \mathrm{kcal}$ de azeite de oliva extra-virgem para o tempero da salada. A divisão dos grupos está disposta na Tabela 4. 
Tabela 4. Classificação dos Grupos de Alimentos de acordo com o Guia Alimentar para a População Brasileira, de acordo com o My Plate e a classificação final ajustada para a pesquisa.

\begin{tabular}{|c|c|c|c|c|c|c|c|c|}
\hline \multicolumn{4}{|c|}{ Classificação de acordo com o Guia (BRASIL, 2008) } & \multicolumn{2}{|c|}{$\begin{array}{c}\text { Classificação de acordo com o } M y \\
\text { Plate (USDA, 2011) }\end{array}$} & \multicolumn{3}{|c|}{ Classifcação ajustada } \\
\hline $\begin{array}{c}\text { Grupos de } \\
\text { Alimentos do } \\
\text { Guia }\end{array}$ & $\begin{array}{l}\text { Recomendação } \\
\text { calórica média } \\
\text { do grupo para o } \\
\text { almoço (kcal)* }\end{array}$ & $\begin{array}{l}\text { Número de } \\
\text { porções do } \\
\text { grupo para o } \\
\text { almoço }\end{array}$ & $\begin{array}{c}\text { Valor } \\
\text { energético } \\
\text { médio por } \\
\text { porção (kcal) }\end{array}$ & $\begin{array}{c}\text { Grupos de } \\
\text { Alimentos do } \\
\text { My Plate }\end{array}$ & $\begin{array}{l}\text { Recomendação } \\
\text { média em \% do } \\
\text { grupo para o } \\
\text { almoço }\end{array}$ & $\begin{array}{c}\text { Reclassificação } \\
\text { dos grupos } \\
\text { (novos grupos) }\end{array}$ & $\begin{array}{l}\text { Recomendação } \\
\text { calórica média } \\
\text { dos novos grupos } \\
\text { para o almoço } \\
\text { (kcal)** }\end{array}$ & $\begin{array}{c}\text { Número de } \\
\text { porções dos } \\
\text { novos grupos } \\
\text { para o almoço }\end{array}$ \\
\hline $\begin{array}{l}\text { Cereais, } \\
\text { tubérculos, } \\
\text { raízes e } \\
\text { derivados }\end{array}$ & 375 & 2,5 & 150 & Grãos & $30 \%$ & $\begin{array}{c}\text { Grupo dos } \\
\text { Carboidratos }(\mathrm{C})\end{array}$ & 180 & 2 \\
\hline Feijões & 55 & 1 & 55 & & & $\begin{array}{l}\text { Grupo dos Feijões } \\
\text { (F) }\end{array}$ & 55 & 1 \\
\hline $\begin{array}{c}\text { Frutas e sucos } \\
\text { de frutas } \\
\text { naturais }\end{array}$ & 70 & 1 & 70 & Frutas & $10 \%$ & 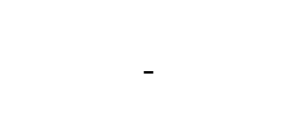 & 70 & 1 \\
\hline Hortaliças & 45 & 3 & 15 & Vegetais & $40 \%$ & $\begin{array}{c}\text { Grupo dos } \\
\text { Vegetais (V) }\end{array}$ & 15 & 3 \\
\hline $\begin{array}{c}\text { Leite e } \\
\text { derivados } \\
\text { Carnes e Ovos }\end{array}$ & 144 & $\begin{array}{l}3 \\
1\end{array}$ & $\begin{array}{l}48 \\
76\end{array}$ & $\begin{array}{l}\text { Laticínios } \\
\text { Proteínas }\end{array}$ & $\begin{array}{c}1 \text { copo } \\
10 \%\end{array}$ & $\begin{array}{l}\text { Grupo das } \\
\text { Proteínas }(\mathrm{P})\end{array}$ & 140 & 1,5 \\
\hline $\begin{array}{c}\text { Óleos, gorduras } \\
\text { e castanhas } \\
\text { Sementes } \\
\text { (linhaça e } \\
\text { gergelim) }\end{array}$ & 73 & 1 & 73 & - & - & - & 72 & 1 \\
\hline
\end{tabular}

*Esta distribuição atingiu 838 kcal e **Esta distribuição atingiu $842 \mathrm{kcal}$ 
A recomendação do VET do almoço é diferente para homens e mulheres. De acordo com Cervatoet al. (1997) e Bonomo et al. (2003), as mulheres consomem em média um VET 29\% menor que os homens, pois necessitam de menos energia para manter o corpo em equilíbrio. Com isso, a recomendação de porções do almoço foi reduzida em 29\% para mulheres comparada à classificação apontada no tópico 3.7 deste trabalho que aborda o terceiro critério de classificação para as preparações servidas na UAN.

Os Grupos Alimentares foram convertidos de acordo com o tamanho e VET da porção média real das preparações, cuja recomendação está disposta na Tabela 5.

Tabela 5: Recomendação das quantidades de porções dos grupos alimentares para homens e mulheres no almoço

\begin{tabular}{cccc}
\hline \multicolumn{2}{c}{ Grupo alimentar } & Quantidades de porções recomendadas \\
\hline $\begin{array}{c}\text { Nome do } \\
\text { grupo }\end{array}$ & $\begin{array}{c}\text { Símbolo na placa de } \\
\text { identificação }\end{array}$ & Homem & Mulher \\
\hline Carboidratos & $\mathrm{C}$ & 2 porções & 1 porção \\
Proteínas & $\mathrm{P}$ & 1 porção & 1 porção \\
Feijão & $\mathrm{F}$ & 1 porção & 1 porção \\
Vegetais & $\mathrm{V}$ & $\begin{array}{c}3 \text { porções } \\
1 \text { fio pequeno } \\
1 \text { colher de chá }\end{array}$ & $\begin{array}{c}1 \text { porções } \\
1 \text { colher de chá }\end{array}$ \\
Itens extras & $\begin{array}{c}\text { Azeite de oliva } \\
\text { Sementes }\end{array}$ & &
\end{tabular}

\subsubsection{Terceiro critério de classificação}

O terceiro e último critério de classificação das preparações contempla a adição dos símbolos referentes ao glúten e à lactose, em virtude do crescimento da população com doença celíaca e intolerância à lactose. O glúten, causador da doença celíaca, é uma proteína encontrada no trigo e seus derivados, na cevada e no centeio, e pode desencadear a doença celíaca à pessoas que são alérgicas à essa proteína. Já a lactose é um açúcar presente no leite e seus derivados, e pessoas que não produzem a enzima para digeri-la são intolerantes (ZANDONADI, 2012; ALMADA, 2013). 
Algumas pessoas também são alérgicas às proteínas presente no leite. Ambos ingredientes são considerados os mais alergênicos, por isso a importância de informar se contém ou não glúten e lactose em cada preparação servida pela UAN, além do número de pessoas alérgicas/intolerantes estar crescendo a cada ano (ZANDONADI, 2012; ALMADA, 2013). Além disso, foram listados todos os itens inclusos na preparação como forma de esclarecer ao comensal a presença de possíveis ingredientes alergênicos como castanhas, crustáceos e corantes (PEYERLS; DE MATOS, 2012).

Para classificar as preparações, cada placa recebeu dois símbolos. Um deles a letra "L" de lactose envolta em um círculo. Se o círculo estiver cortado com um traço na transversal, significa que não contém lactose. Caso não esteja com esse traço, contém lactose. O mesmo para o glúten, representado pela letra "G". As Figuras 2 e 3 apresentam os símbolos de contém ou não glúten e lactose. Ambos os símbolos estavam explicados e detalhados em painéis expostos à frente do balcão de distribuição- buffet, e as placas de identificação contendo essas informações estão dispostas no Apêndice 3.
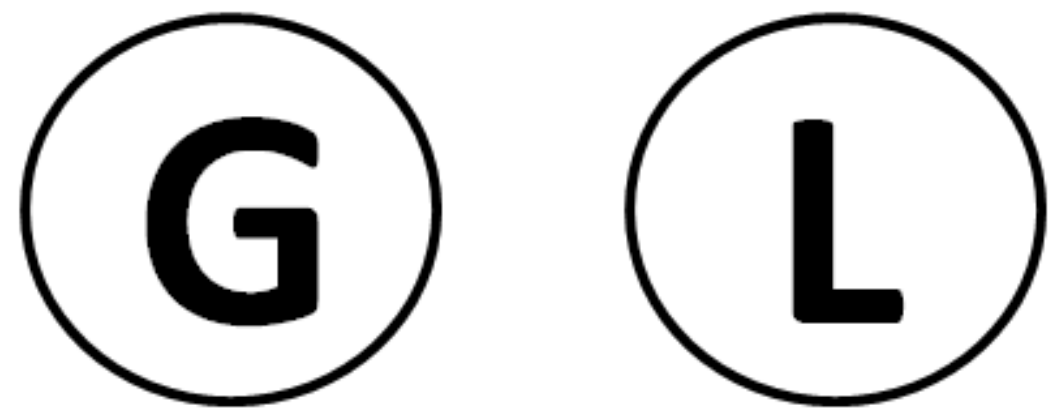

Figura 2: Símbolos de contém glúten e lactose
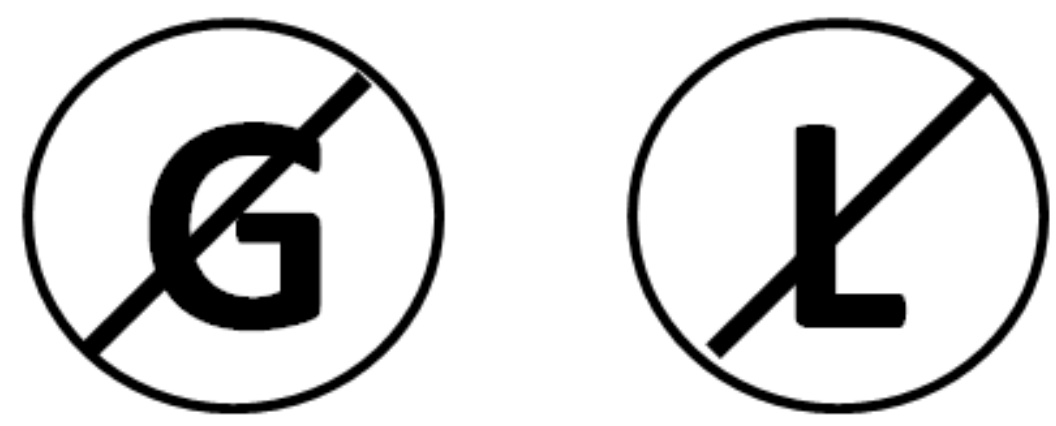

Figura 3: Símbolos de não contém glúten e lactose 
Assim, foram determinados os três critérios de classificação da preparação para exposição aos comensais, sendo eles densidade energética e teor de sódio das preparações através das cores do semáforo (primeiro critério), a divisão das preparações em grupos de alimentos e porções equivalentes concretizando os quatro princípios de Pedro Escudero (segundo critério) e a presença ou não de ingredientes alergênicos (terceiro critério).

\subsection{ESTRATÉGIAS EDUCACIONAIS}

Para divulgar a classificação das preparações, foram confeccionadas placas de identificação para cada alimento servido, impressas e plastificadas, medindo aproximadamente $7 \mathrm{~cm} \times 11 \mathrm{~cm}$ e posicionadas no buffet em local de fácil visibilidade, à frente de sua respectiva preparação, com modelo mostrado no Apêndice3. Essas placas levam uma das três cores - verde, amarelo ou vermelho, um código em letra caracterizando o grupo dos alimentos que se encontra, o nome da preparação, os ingredientes, o tamanho da porção que equivale a um código previamente adequado aos utensílios da UAN e os símbolos "G" e "L".

Com o objetivo de explicar ao comensal essa medida de educação nutricional, dois painéis explicativos foram elaborados e posicionados próximo ao buffet da UAN para orientar e explicar ao comensal como interpretar as informações dadas.

O primeiro painel (Apêndice 4) continha: a imagem de uma placa de identificação modelo e a legenda de todos os itens que compõem essa placa, sendo eles o grupo alimentar, o nome da preparação, os ingredientes, a porção ideal, a cor da placa e se contém ou não glúten e lactose. Além disso, contém a explicação do conceito associado a cada cor; as legendas sobre o que cada símbolo do grupo alimentar e de glúten e lactose representam, a quantidade de "C, F, V e P" que podem ser consumidos para se obter um prato nutricionalmente equilibrado, de acordo com as necessidades energéticas da clientela em questão dividida por gênero.

A informação incentivando o consumo livre de folhosos também foi adicionada ao primeiro painel. Além disso, o primeiro painel foi impresso colorido em folha de tamanho A4 e colocada uma cópia em todas as mesas do refeitório da UAN durante todos os dias da semana em tempo integral (do momento da abertura até o fechamento da UAN). 
O segundo painel foi formulado para incentivar a participação da pesquisa. Uma frase de efeito foi destacada no início referente ao tema abordado: "Você sabia que diminuir o consumo de sódio e gordura reduz o risco de infartos e de obesidade?". Além disso, direciona os comensais para observarem o buffet e perceberem as mudanças feitas. Além disso, de acordo com a recomendação de porções apresentada na Tabela 5, foram elaborados quatro pratos de almoço, registrados em fotografia e dispostos no segundo painel, servindo de exemplo e modelo aos comensais, imagens que estão no Apêndice 5.

No final do painel, foi informado aos leitores que no final da semana em questão seria realizada a aplicação dos questionários e que a adesão à participação era de grande importância. O segundo painel está no Apêndice 6. Além disso, dois Nutricionistas que trabalhavam no local e dois estagiários de Nutrição abordavam ativamente os comensais durante os dias da semana para fazê-los observarem a metodologia proposta, incentivando a percepção de que todas as preparações ganharam placas de identificação contendo informações nutricionais importantes e sobre as questões de saúde associadas à oferta de alimentação saudável.

\subsection{INSTRUMENTO DE PERCEPÇÃO}

Foi desenvolvido um instrumento de acordo com a necessidade da pesquisa, para que seja possível analisar os resultados, que visou observar quantitativamente o impacto causado na escolha alimentar dos comensais, quando foram disponibilizadas as informações nutricionais das preparações.

O questionário contempla os dados demográficos, a frequência que o comensal almoça na UAN, a percepção acerca da intervenção, da clareza dos instrumentos de educação, da intensidade de mudança na escolha alimentar e dos itens observados pelo comensal durante a pesquisa.

Nesse contexto, o presente estudo se propôs responder às seguintes perguntas de investigação: “A informação nutricional interfere na escolha alimentar?”, “O comensal está capacitado para fazer escolhas alimentares melhores e saudáveis?", "Houve mudança no padrão de escolha alimentar do comensal após a aplicação da metodologia em questão?”. 


\subsection{APLICAÇÃO DO QUESTIONÁRIO}

Durante uma semana de segunda a sexta-feira, todas as preparações e itens do buffet foram identificados com suas respectivas placas de identificação. No último dia da semana, foi aplicado o questionário impresso junto com o TCLE no horário do almoço, pois a grande maioria dos comensais $(75 \%)$ almoçavam no local todos os dias. Os comensais foram abordados aleatoriamente no horário de almoço na entrada e/ou na fila da UAN e apresentado o projeto de pesquisa com seus objetivos, juntamente com o pedido de assinatura do TCLE e o questionário impressos, e entregue junto uma caneta para motivar a participação na pesquisa. Ao final do almoço, os comensais depositaram o questionário/TCLE na saída da UAN.

Foram distribuídos1000questionários, sendo 603 respondidos, 100 deixados em branco e o restante não foi devolvido. Dos 603 respondidos, 47 não cumpriram os critérios de inclusão contemplados e foram excluídos, restando 556 questionários válidos.

\subsection{ANÁLISE E TRATAMENTO DE DADOS}

Todas as análises foram realizadas com o apoio do programa SPSS (Statistical Package for Social Sciences) versão 21.0. Foram realizados teste normalidade da amostra, não tendo sido confirmado esses pressupostos. Foram realizadas análises descritivas (medidas de tendência central e variância. Foi obtido o Odds Ratio (OR) de todos os dados, assim como o Intervalo de Confiança (IC) e o coeficiente de Correlação de Pearson, utilizando o valor de $\mathrm{p}<0,05$ como resultado significativo. 


\section{RESULTADOS E DISCUSSÃO}

Este capítulo está dividido em três artigos. O primeiro artigo intitulado "1 Intervenção Nutricional na Mudança do Consumo Alimentar em Adultos" está de acordo com as normas para publicação na revista Ciência \& Saúde Coletiva*. Trata-se de uma revisão de literatura sobre a influência da educação nutricional na mudança do consumo e das escolhas alimentares. O segundo e terceiro artigo estão de acordo com as normas para publicação na revista British Food Journal**, com título "2 - Estratégia de educação nutricional em restaurante self-service", que fala sobre a elaboração da metodologia de classificação nutricional de cardápios, e o terceiro artigo com título "3 Avaliação de estratégia de educação nutricional em restaurante self-service" apresenta os resultados empíricos da intervenção nutricional realizada neste trabalho.

\footnotetext{
*Revista Ciência \& Saúde Coletiva - Rio de Janeiro/RJ -classificação A1 na tabela Qualis Nutrição.

**British FoodJournal - Jornal internacional multidisciplinar do grupo de publicações Emerald para a disseminação das pesquisas relacionadas aos alimentos - classificação A1 na tabela Qualis Nutrição.
} 


\title{
4.1 ARTIGO 1 - INTERVENÇÃO NUTRICIONAL NA MUDANÇA DO CONSUMO ALIMENTAR EM ADULTOS
}

\author{
Larissa MAZOCCO
}

Raquel Bráz Assunção BOTELHO

Izabel Cristina Rodrigues da SILVA

Rita de Cássia Coelho Almeida AKUTSU

\section{Resumo}

O objetivo deste estudo é realizar uma revisão da literatura acerca dos impactos da intervenção nutricional através de estratégias educacionais sobre a mudança no consumo alimentar de adultos. O estudo é de revisão de literatura com foco principal na educação nutricional, comportamento alimentar e sua influência na escolha alimentar de adultos. A educação nutricional possui um papel importante e indispensável na formação de novas escolhas alimentares. Muitos estudos ainda precisam ser feitos para comprovar a associação positiva entre a influência da educação nutricional nas escolhas alimentares saudáveis de adultos, que já possuem hábitos e costumes alimentares formados. Essas estratégias precisam levar em consideração vários fatores e não se prender somente ao ato da educação nutricional.

Palavras-chave: Consumo alimentar, educação nutricional, comportamento alimentar, influência na alimentação, escolha alimentar de adultos.

\begin{abstract}
The aim of this study was to review the literature on the nutritional intervention impact through educational strategies, and its correlation with changes in the food intake of adults. The study is a literature review with main focus on nutrition education, eating behavior and its influence on food choice for adults. Nutrition education has an important and indispensable role in the formation of new food choices. Studies still need to be made to prove the positive association between the influence of nutrition education and healthy food choices for adults who already have formed their habits.
\end{abstract}


These strategies need to consider many factors and do not focus only in the act of nutrition education.

Keywords: Food intake, nutrition education, eating behavior, influence on eating, adults food choice.

\section{Introdução}

Uma alimentação equilibrada é um dos principais componentes do estilo de vida que pode ser modificado para se viver melhor e com qualidade. Quando inadequada, a alimentação pode ser um importante fator de risco para doenças e agravos crônicos não transmissíveis (DACNT) (Sousa, 2005).

Devido ao aumento da incidência das doenças oriundas da má alimentação e da falta de conhecimento de grande parte da população sobre formas de prevenção, elevase a demanda por estratégias de mudança de práticas e comportamentos individuais cujo objetivo seja a alimentação saudável (Cervato et al., 2005). Assim, o papel da promoção da saúde, incluindo principalmente a educação nutricional, como estratégia no combate as doenças oriundas da alimentação é essencial, sendo o Nutricionista o responsável pela promoção da saúde concretizada a partir de práticas educativas (CFN, 2006; Sousa, 2005).

A adoção de um estilo de vida saudável pode ser duas vezes mais efetivo do que o tratamento farmacológico no controle de doenças, como a diabetes (Costa et al., 2011; Vieira et al., 2011). O incentivo à alimentação saudável deve ser reforçado diariamente, mas isto é um desafio para todos os profissionais de saúde (Costa et al., 2011). Tais incentivos devem incluir o resgate dos hábitos alimentares saudáveis próprios da cultura alimentar brasileira e, ainda, identificar alimentos cujo consumo deva ser estimulado na alimentação cotidiana (Sichieri et al., 2000).

Propostas educativas em nutrição, como intervenções na coletividade, têm por objetivo tornar o ambiente interativo e facilitador de aprendizagem (Alvarez; Zanella, 2009). Do ponto de vista de sua importância, a educação nutricional é apontada como estratégia de ação, no campo da educação em saúde, a ser adotada prioritariamente em saúde pública para conter o avanço da ocorrência de DACNT uma vez que a alimentação de má qualidade é considerada um fator de risco para inúmeras doenças (Ramos, 2013). 
Além disso, a educação nutricional é um conjunto de estratégias sistematizadas para impulsionar a cultura e a valorização da alimentação, concebidas no reconhecimento da necessidade de respeitar, mas também de modificar, crenças, valores, atitudes, representações, práticas e relações sociais que se estabelecem em torno da alimentação, visando o acesso econômico e social de todo cidadão a uma alimentação quantitativa e qualitativamente adequada (Boog, 2010).

\section{Objetivo}

Existem poucos trabalhos científicos publicados que relatam sobre a efetividade na influência da educação nutricional no consumo alimentar em adultos, sendo que a maior parte da literatura discute sobre essa influência em crianças e adolescentes. Com isso, o objetivo deste estudo é realizar uma revisão da literatura sobre os impactos da intervenção nutricional através de estratégias educacionais sobre a mudança no consumo alimentar de adultos.

\section{REVISÃO DA LITERATURA}

\section{Metodologia}

Trata-se de uma revisão bibliográfica sobre a efetividade das intervenções nutricionais através da educação nutricional na escolha e consumo alimentar de adultos com busca de artigos publicados entre os anos de 2000 e 2013. Os temas "mudança no consumo alimentar", "educação nutricional" e "comportamento alimentar" e seus equivalentes e m inglês e espanhol, foram investigados em bases de dados e bibliotecas da área da saúde, sendo estas a Bireme (Biblioteca virtual da saúde), LILACS (Literatura Latino-Americana e do Caribe em Ciências da Saúde), Scielo (Biblioteca Científica Eletrônica Online), PubMed (Biblioteca de Medicina Americana) e Science Direct (plataforma do grupo de revistas Elsevier).

O material levantado (5 referências na Bireme, 4 referências na LILACS, 10 referências na Scielo, 11 referências no PubMed e 3 no ScienceDirect) e selecionado para o trabalho foi organizado de modo a permitir identificar as categorias que influenciam para o estudo da mudança do consumo alimentar. 


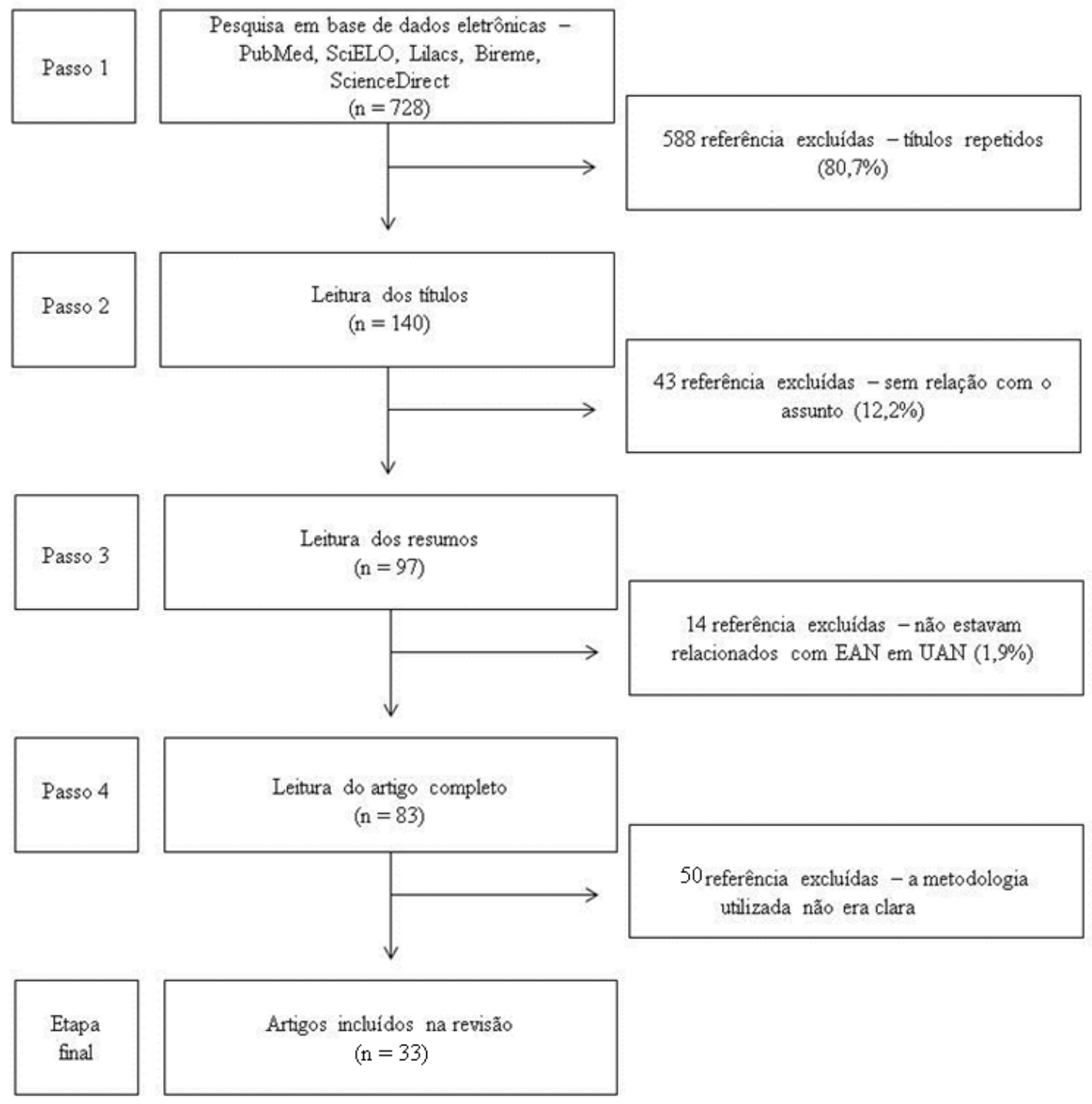

EAN: Educação Alimentar e nutricional; UAN: Unidade de Alimentação e Nutrição

Figura 1. Pesquisa, seleção e exclusão de estudos sobre estratégias de educação nutricional que modificam a escolha alimentar de adultos.

\section{Resultados}

A revisão bibliográfica permitiu dividir este trabalho em três tendências que compõem os estudos sobre intervenção nutricional: a educação nutricional, estudo sobre o comportamento alimentar, e as influências no consumo alimentar. A Tabela 1 mostra a relação dos artigos e as características de cada estudo. A contribuição de cada estudo está descrita ao longo do texto. 
Tabela 1. Características dos estudos sobre intervenção nutricional na mudança da escolha alimentar de adultos entre os anos de 2000 e 2013.

\begin{tabular}{|c|c|c|c|c|c|}
\hline Autores & $\begin{array}{c}\text { Local e } \\
\text { participantes }\end{array}$ & Ano & Desenho de estudo & Principais resultados & $\begin{array}{l}\text { Análise } \\
\text { estatística }\end{array}$ \\
\hline Buss & $\begin{array}{l}\text { Rio de } \\
\text { Janeiro }\end{array}$ & 2000 & $\begin{array}{c}\text { Estudo de revisão } \\
\text { de literatura }\end{array}$ & $\begin{array}{l}\text { As estratégias de educação nutricional se concretizam } \\
\text { através de seus próprios fundamentos e práticas, que } \\
\text { estão estreitamente relacionados com as inovações na } \\
\text { gestão pública para o desenvolvimento local integrado e } \\
\text { sustentável. }\end{array}$ & Ausente \\
\hline $\begin{array}{l}\text { Wardle et } \\
\text { al. }\end{array}$ & $\begin{array}{l}\text { Inglaterra, } \\
1040 \\
\text { participantes }\end{array}$ & 2000 & Não mencionado & $\begin{array}{c}\text { Os indivíduos que possuíam conhecimento sobre } \\
\text { nutrição tinham } 25 \text { vezes maior probabilidade de } \\
\text { consumir quantidades adequadas de frutas e verduras } \\
\text { diariamente. }\end{array}$ & Presente \\
\hline $\begin{array}{l}\text { Mills e } \\
\text { Clay }\end{array}$ & $\begin{array}{l}\text { Estados } \\
\text { Unidos }\end{array}$ & 2001 & Não mencionado & $\begin{array}{l}\text { A informação do valor nutricional do alimento } \\
\text { influencia a escolha alimentar do indivíduo, e é } \\
\text { denominada uma variável relacionada aos alimentos. }\end{array}$ & Presente \\
\hline Falk et al. & $\begin{array}{l}\text { Nova York, } \\
79 \\
\text { participantes }\end{array}$ & 2001 & Não mencionado & $\begin{array}{l}\text { Os indivíduos levam em consideração vários itens antes } \\
\text { de realizar a escolha alimentar, como seus ideais, } \\
\text { identidade, cultura e mudança de contextos e situações, } \\
\text { saúde, sabor, custo, relação tempo/conveniência e } \\
\text { organização de relacionamentos e experiências prévias } \\
\text { de escolha alimentar relacionadas à saúde. }\end{array}$ & Presente \\
\hline $\begin{array}{l}\text { Stables et } \\
\text { al. }\end{array}$ & $\begin{array}{c}\text { Estados } \\
\text { Unidos, } 5299 \\
\text { participantes }\end{array}$ & 2002 & $\begin{array}{l}\text { Duas pesquisas de } \\
\text { marcação aleatória } \\
\text { de dígitos } \\
\text { representativos a } \\
\text { nível nacional }\end{array}$ & $\begin{array}{l}\text { A consciência e o conhecimento sobre as recomendações } \\
\text { dietéticas são preditores significativos da mudança de } \\
\text { comportamento alimentar. }\end{array}$ & Presente \\
\hline
\end{tabular}




\begin{tabular}{|c|c|c|c|c|c|}
\hline Autores & $\begin{array}{c}\text { Local e } \\
\text { participantes }\end{array}$ & Ano & Desenho de estudo & Principais resultados & $\begin{array}{l}\text { Análise } \\
\text { estatística }\end{array}$ \\
\hline $\begin{array}{l}\text { Stevens et } \\
\text { al. }\end{array}$ & $\begin{array}{l}\text { Estados } \\
\text { Unidos, } 616 \\
\text { mulheres }\end{array}$ & 2002 & $\begin{array}{l}\text { Estudo controlado } \\
\text { e randomizado }\end{array}$ & $\begin{array}{l}\text { A redução das gorduras na dieta e aumento do consumo } \\
\text { de fruta e verduras em conjunto com o aconselhamento } \\
\text { comportamental provou-se eficaz no cenário dos } \\
\text { cuidados de saúde primários. }\end{array}$ & Presente \\
\hline Worsley & Austrália & 2002 & $\begin{array}{l}\text { Estudo de revisão } \\
\text { de literatura }\end{array}$ & $\begin{array}{c}\text { A educação nutricional precisa ser completada por outros } \\
\text { fatores para que haja melhor efetividade na ação, como } \\
\text { conhecimento das consequências da alimentação } \\
\text { saudável e objetivo do espectador em mudar o estilo de } \\
\text { vida. }\end{array}$ & Ausente \\
\hline $\begin{array}{l}\text { Scholderer } \\
\text { et al. }\end{array}$ & $\begin{array}{l}\text { Dinamarca, } \\
1000 \\
\text { participantes } \\
\text { por país }\end{array}$ & 2004 & $\begin{array}{l}\text { Estudo de } \\
\text { validação de } \\
\text { instrumento }\end{array}$ & $\begin{array}{l}\text { Os principais determinantes da escolha alimentar são a } \\
\text { aparência, sabor, variedade, valor nutricional e qualidade } \\
\text { dos alimentos. }\end{array}$ & Presente \\
\hline $\begin{array}{l}\text { Camossa } \\
\text { et al. }\end{array}$ & $\begin{array}{l}\text { Estudo de } \\
\text { revisão }\end{array}$ & 2005 & $\begin{array}{l}\text { Pesquisa } \\
\text { exploratória }\end{array}$ & $\begin{array}{l}\text { Sugere que a área de Educação Nutricional dispõe de } \\
\text { amplo campo teórico e prático a ser pesquisado. }\end{array}$ & Ausente \\
\hline $\begin{array}{l}\text { Triches e } \\
\text { Giugliani }\end{array}$ & $\begin{array}{l}\text { Rio Grande } \\
\text { do Sul, } 573 \\
\text { crianças }\end{array}$ & 2005 & Estudo transversal & $\begin{array}{c}\text { A promoção de hábitos alimentares saudáveis, e a } \\
\text { consequente diminuição dos índices de obesidade, têm } \\
\text { sido associadas aos conhecimentos sobre alimentação e } \\
\text { nutrição. }\end{array}$ & Presente \\
\hline Santos & Salvador & 2005 & $\begin{array}{l}\text { Estudo de revisão } \\
\text { de literatura }\end{array}$ & $\begin{array}{l}\text { Os instrumentos utilizados para as práticas de educação } \\
\text { nutricional que já foram testados e tiveram sua } \\
\text { efetividade comprovada foram a comunicação midiática, } \\
\text { inclusão da educação nutricional nos projetos } \\
\text { pedagógicos escolares. }\end{array}$ & Ausente \\
\hline
\end{tabular}




\begin{tabular}{|c|c|c|c|c|c|}
\hline Autores & $\begin{array}{c}\text { Local e } \\
\text { participantes }\end{array}$ & Ano & Desenho de estudo & Principais resultados & $\begin{array}{l}\text { Análise } \\
\text { estatística }\end{array}$ \\
\hline $\begin{array}{l}\text { Cervato et } \\
\quad \text { al. }\end{array}$ & $\begin{array}{l}\text { São Paulo, } 44 \\
\text { alunos }\end{array}$ & 2005 & $\begin{array}{l}\text { Estudo quase } \\
\text { experimental, do } \\
\text { tipo pré-teste/pós- } \\
\text { teste, sem grupo } \\
\text { controle }\end{array}$ & $\begin{array}{l}\text { O conhecimento nutricional está relacionado diretamente } \\
\text { com o comportamento sobre consumo alimentar. }\end{array}$ & Presente \\
\hline Lytle & $\begin{array}{l}\text { Estados } \\
\text { Unidos }\end{array}$ & 2005 & $\begin{array}{c}\text { Estudo de revisão } \\
\text { de literatura }\end{array}$ & $\begin{array}{c}\text { Participantes de estratégias de educação nutricional } \\
\text { aumentam sua auto-eficácia e há maior probabilidade de } \\
\text { mudança de comportamento }\end{array}$ & Ausente \\
\hline $\begin{array}{l}\text { Rodrigues } \\
\text { e Boog }\end{array}$ & $\begin{array}{l}\text { São Paulo, } 22 \\
\text { adolescentes }\end{array}$ & 2006 & $\begin{array}{l}\text { Estudo longitudinal } \\
\text { com entrevistas } \\
\text { semi-estruturadas }\end{array}$ & $\begin{array}{c}\text { A educação nutricional pode promover o } \\
\text { desenvolvimento da capacidade de compreender práticas } \\
\text { e comportamentos, e os conhecimentos ou as aptidões } \\
\text { resultantes desse processo }\end{array}$ & Ausente \\
\hline $\begin{array}{l}\text { Gaglione } \\
\quad \text { et al. }\end{array}$ & $\begin{array}{l}\text { São Paulo, } 8 \\
\text { escolas } \\
\text { públicas com } \\
\text { amostra de } \\
637 \text { alunos e } \\
51 \\
\text { professores }\end{array}$ & 2006 & $\begin{array}{l}\text { Estudo } \\
\text { randomizado } \\
\text { controlado }\end{array}$ & $\begin{array}{l}\text { Observou-se uma melhora na escolha alimentar dos } \\
\text { estudantes e redução no consumo de alimentos com alta } \\
\text { densidade energética. Também se observou melhora nos } \\
\text { conhecimentos e atitudes de professores em relação } \\
\text { à prevenção da obesidade. }\end{array}$ & Presente \\
\hline $\begin{array}{l}\text { Toral e } \\
\text { Slater }\end{array}$ & São Paulo & 2007 & $\begin{array}{l}\text { Estudo de revisão } \\
\text { de literatura }\end{array}$ & $\begin{array}{l}\text { O fornecimento de informações sobre qualquer } \\
\text { comportamento de saúde é fundamental nas atividades } \\
\text { educativas e contribui para sustentar ou desenvolver } \\
\text { novas atitudes sendo o componente racional necessário } \\
\text { para motivar uma ação desejada. }\end{array}$ & Ausente \\
\hline $\begin{array}{l}\text { Lassen } e t \\
\quad a l .\end{array}$ & $\begin{array}{l}\text { Dinamarca, } \\
12 \text { clientes }\end{array}$ & 2007 & Não mencionado & $\begin{array}{l}\text { As intervenções no local de trabalho podem eficientes } \\
\text { para mudança de escolha alimentar, como maior }\end{array}$ & Presente \\
\hline
\end{tabular}




\begin{tabular}{|c|c|c|c|c|c|}
\hline Autores & $\begin{array}{c}\text { Local e } \\
\text { participantes }\end{array}$ & Ano & Desenho de estudo & Principais resultados & $\begin{array}{l}\text { Análise } \\
\text { estatística }\end{array}$ \\
\hline & & & & $\begin{array}{c}\text { disponibilidade de alimentos saudáveis nos pontos de } \\
\text { venda. }\end{array}$ & \\
\hline $\begin{array}{l}\text { Oliveira e } \\
\text { Alves }\end{array}$ & $\begin{array}{c}\text { Santa } \\
\text { Catarina, } \\
\text { clientes de } \\
\text { uma Unidade } \\
\text { de } \\
\text { Alimentação } \\
\text { e Nutrição }\end{array}$ & 2008 & $\begin{array}{l}\text { Estudo descritivo } \\
\text { e transversal, do } \\
\text { tipo estudo de caso } \\
\text { com abordagem } \\
\text { qualiquantitativa de } \\
\text { caráter não- } \\
\text { experimental }\end{array}$ & $\begin{array}{l}\text { Os resultados demonstraram que as ações educativas } \\
\text { em nutrição realizadas (cartazes e folders) não surtiram } \\
\text { os efeitos desejados, pois o consumo de carne manteve- } \\
\text { se acima do recomendado. Outros fatores possivelmente } \\
\text { interferiram de forma negativa: falta de interesse dos } \\
\text { trabalhadores nas ações desenvolvidas, tempo de } \\
\text { duração, ausência de histórico de ações educativas no } \\
\text { local, tamanho das porções de carne servidas no local. }\end{array}$ & Ausente \\
\hline $\begin{array}{l}\text { Rodrigues } \\
\text { e Roncada }\end{array}$ & $\begin{array}{l}\text { Distrito } \\
\text { Federal }\end{array}$ & 2008 & $\begin{array}{l}\text { Estudo de revisão } \\
\text { de literatura }\end{array}$ & $\begin{array}{l}\text { A utilização de metodologias ativas de educação } \\
\text { nutricional contribui na formação de cidadãos } \\
\text { conscientes com relação à origem e produção dos } \\
\text { alimentos, tornando-os aptos a fazerem escolhas mais } \\
\text { saudáveis na alimentação diária, aspecto essencial na } \\
\text { promoção da saúde. }\end{array}$ & Ausente \\
\hline $\begin{array}{l}\text { Jomori et } \\
\text { al. }\end{array}$ & $\begin{array}{c}\text { Santa } \\
\text { Catarina }\end{array}$ & 2008 & $\begin{array}{l}\text { Estudo de revisão } \\
\text { de literatura }\end{array}$ & $\begin{array}{l}\text { As variáveis relacionadas aos alimentos que influenciam } \\
\text { na escolha alimentar de um indivíduo são apresentação } \\
\text { visual, o sabor, o valor nutricional, os tipos de } \\
\text { preparações e a variedade oferecida. }\end{array}$ & Ausente \\
\hline Boog & Porto Alegre & 2008 & $\begin{array}{l}\text { Estudo de revisão } \\
\text { de literatura }\end{array}$ & $\begin{array}{l}\text { O integrante dos processos de educação nutricional deixa } \\
\text { de ser espectador e passa a ser o sujeito da reconstrução } \\
\text { do saber, que, ao fazer, vai aprendendo, deixando de ser } \\
\text { aquele que recebe passivamente as informações. }\end{array}$ & Ausente \\
\hline
\end{tabular}




\begin{tabular}{|c|c|c|c|c|c|}
\hline Autores & $\begin{array}{c}\text { Local e } \\
\text { participantes }\end{array}$ & Ano & Desenho de estudo & Principais resultados & $\begin{array}{c}\text { Análise } \\
\text { estatística }\end{array}$ \\
\hline $\begin{array}{l}\text { Dollahite } \\
\text { et al. }\end{array}$ & $\begin{array}{l}\text { Estados } \\
\text { Unidos, } 5730 \\
\text { participantes } \\
\text { de baixa } \\
\text { renda }\end{array}$ & 2008 & Não mencionado & $\begin{array}{l}\text { As mudanças no comportamento alimentar decorrentes } \\
\text { de estratégias de educação nutricional são susceptíveis à } \\
\text { melhorara da saúde futura e reduzir os custos de saúde }\end{array}$ & Presente \\
\hline $\begin{array}{l}\text { Bernardon } \\
\quad \text { et al. }\end{array}$ & $\begin{array}{l}\text { Distrito } \\
\text { Federal, } 59 \\
\text { educadores }\end{array}$ & 2009 & Não mencionado & $\begin{array}{l}\text { A estratégia de construção das ações práticas de } \\
\text { alimentação saudável se mostrou efetiva e precisam ser } \\
\text { pautadas em aspectos metodológicos consistentes para } \\
\text { que possam alcançar seus objetivos. }\end{array}$ & Ausente \\
\hline $\begin{array}{l}\text { Carvalho } \\
\text { et al. }\end{array}$ & $\begin{array}{l}\text { Belo } \\
\text { Horizonte, } \\
136 \text { escolares }\end{array}$ & $2010 \mathrm{a}$ & $\begin{array}{l}\text { Estudo de } \\
\text { intervenção }\end{array}$ & $\begin{array}{l}\text { As ações de educação nutricional podem favorecer a } \\
\text { formação de hábitos alimentares adequados e, } \\
\text { consequentemente, prevenir o surgimento e o aumento } \\
\text { de patologias relacionadas a uma alimentação } \\
\text { inadequada, assim como garantir qualidade de vida. }\end{array}$ & Presente \\
\hline Boog & $\begin{array}{l}\text { São Paulo, } \\
155 \text { pré- } \\
\text { escolares }\end{array}$ & 2010 & Estudo qualitativo & $\begin{array}{l}\text { A metodologia ativa empregada despertou interesse pelas } \\
\text { atividades porque estas refletiam o cotidiano e } \\
\text { valorizavam o trabalho, a história, a identidade cultural, } \\
\text { fortalecendo a autoestima das famílias. }\end{array}$ & Ausente \\
\hline $\begin{array}{c}\text { Yokota et } \\
\text { al. }\end{array}$ & $\begin{array}{l}\text { Distrito } \\
\text { Federal, } 8 \\
\text { escolas, } 309 \\
\text { alunos e } 35 \\
\text { professores }\end{array}$ & 2010 & Não mencionado & $\begin{array}{l}\text { Observou-se que tanto a realização de oficinas de } \\
\text { capacitação sobre educação nutricional para professores, } \\
\text { como a realização direta de palestras e outras atividades } \\
\text { pedagógicas para a comunidade escolar pelo } \\
\text { nutricionista, são processos igualmente úteis de } \\
\text { intervenção nutricional no âmbito escolar, utilizando } \\
\text { recursos como o Guia Alimentar Brasileiro. }\end{array}$ & Presente \\
\hline
\end{tabular}




\begin{tabular}{|c|c|c|c|c|c|}
\hline Autores & $\begin{array}{c}\text { Local e } \\
\text { participantes }\end{array}$ & Ano & Desenho de estudo & Principais resultados & $\begin{array}{c}\text { Análise } \\
\text { estatística }\end{array}$ \\
\hline $\begin{array}{l}\text { Locarno e } \\
\text { Navarro }\end{array}$ & São Paulo & 2011 & $\begin{array}{l}\text { Estudo de revisão } \\
\text { de literatura }\end{array}$ & $\begin{array}{l}\text { Outros instrumentos utilizados foram o resgate da } \\
\text { culinária na prática, materiais impressos educativos. }\end{array}$ & Ausente \\
\hline Rezende & $\begin{array}{l}\text { São Paulo, } 27 \\
\text { profissionais } \\
\text { de saúde e } 22 \\
\text { pacientes }\end{array}$ & 2011 & $\begin{array}{l}\text { Estudo analítico- } \\
\text { descritivo de } \\
\text { natureza qualitativa }\end{array}$ & $\begin{array}{l}\text { Outros instrumentos utilizados foram as entrevistas semi- } \\
\text { estruturadas, ações de instrução e ensino planejadas. }\end{array}$ & Presente \\
\hline $\begin{array}{l}\text { Magalhães } \\
\quad \text { et al. }\end{array}$ & Minas Gerais & 2012 & $\begin{array}{l}\text { Estudo de revisão } \\
\text { de literatura }\end{array}$ & $\begin{array}{c}\text { O profissional nutricionista é o principal agente de } \\
\text { mudança de escolhas alimentares através das práticas de } \\
\text { educação nutricional }\end{array}$ & Ausente \\
\hline $\begin{array}{l}\text { Gardone } \\
\text { et al. }\end{array}$ & $\begin{array}{c}\text { Minas } \\
\text { Gerais, } 77 \\
\text { participantes }\end{array}$ & 2012 & Não mencionado & $\begin{array}{c}\text { A intervenção nutricional promoveu impacto positivo em } \\
\text { pacientes com perda de peso e melhoraram a qualidade } \\
\text { de sua alimentação }\end{array}$ & Presente \\
\hline $\begin{array}{l}\text { Miller e } \\
\text { Branscum }\end{array}$ & $\begin{array}{l}\text { Estados } \\
\text { Unidos, } 25 \\
\text { participantes }\end{array}$ & 2012 & $\begin{array}{l}\text { Estudo qualitativo } \\
\text { com entrevistas } \\
\text { semi-estruturadas }\end{array}$ & $\begin{array}{c}\text { As estratégias educativas em nutrição devem incluir } \\
\text { objetivos comerciais para poupar dinheiro, facilitar o } \\
\text { planejamento de cardápio e dos modos de preparo dos } \\
\text { alimentos na cozinha, e indicação de locais e } \\
\text { estabelecimentos para permitir aos participantes do } \\
\text { processo de mudança adquirirem alimentos suficiente e } \\
\text { nutricionalmente adequados. }\end{array}$ & Presente \\
\hline $\begin{array}{l}\text { Gomes et } \\
\quad \text { al. }\end{array}$ & $\begin{array}{l}\text { São Paulo, } 15 \\
\text { pacientes }\end{array}$ & 2013 & $\begin{array}{l}\text { Estudo longitudinal } \\
\text { de natureza } \\
\text { quantitativa }\end{array}$ & $\begin{array}{l}\text { A estratégia de educação nutricional parece ter } \\
\text { influenciado na boa evolução do estado nutricional dos } \\
\text { participantes, propiciando redução de medidas } \\
\text { antropométricas e ampliando os conhecimentos sobre } \\
\text { alimentação saudável. }\end{array}$ & Presente \\
\hline
\end{tabular}




\begin{tabular}{|c|c|c|c|c|c|}
\hline Autores & $\begin{array}{c}\text { Local e } \\
\text { participantes }\end{array}$ & Ano & Desenho de estudo & Principais resultados & $\begin{array}{l}\text { Análise } \\
\text { estatística }\end{array}$ \\
\hline $\begin{array}{l}\text { Rustad e } \\
\text { Smith }\end{array}$ & $\begin{array}{l}\text { Estados } \\
\text { Unidos, } 118 \\
\text { mulheres de } \\
\text { baixa renda }\end{array}$ & 2013 & $\begin{array}{l}\text { Estudo de } \\
\text { intervenção }\end{array}$ & $\begin{array}{l}\text { A intervenção nutricional utilizando conhecimentos } \\
\text { sobre nutrição através de aulas, atividades vivenciais e } \\
\text { interativas tem a capacidade de aumentar o } \\
\text { conhecimento de nutrição e favoravelmente mudar o } \\
\text { comportamento alimentar de mulheres de baixa renda. }\end{array}$ & Presente \\
\hline
\end{tabular}




\section{Educação Nutricional}

A educação nutricional é conceituada como um processo educativo que tem como objetivo principal tornar os sujeitos autônomos e seguros para realizarem suas escolhas alimentares de forma que garantam uma alimentação saudável e prazerosa, propiciando, então, o atendimento de suas necessidades fisiológicas, psicológicas e sociais (Camossa, 2005, p. 349).

Entre as diversas definições de educação nutricional, Rodrigues e Boog (2006, p. 924) afirmam que a educação nutricional pode promover o desenvolvimento da capacidade de compreender práticas e comportamentos, e os conhecimentos ou as aptidões resultantes desse processo. Gaglianone et al. (2006) mostra que a educação nutricional é um processo multidisciplinar que envolve transferência de informações, desenvolvimento da motivação e a mudança de hábitos, podendo reduzir os gastos públicos com o tratamento de doenças associadas aos maus hábitos alimentares.

O profissional Nutricionista é o importante difusor dessa prática educativa, com fundamentação teórica no campo da nutrição, capaz de traduzir esta ciência para a linguagem de seu público, orientando o comportamento alimentar dos indivíduos (CFN, 2006). Sua presença em ambientes que promovam atividades voltadas para aquisição e construção de conhecimento sistematizado, como as Unidades de Alimentação e Nutrição (UAN), é muito importante e capaz de contribuir na formação de hábitos alimentares duradouros.

Nessas UANs e também em outros ambientes que necessitem de estratégias de educação nutricional, é importante que o nutricionista desempenhe o papel de educador tanto para os seus funcionários quanto para seus clientes, além de oferecer uma refeição que atenda às exigências sanitárias e nutricionais estabelecidas e promover a realização de atividades educacionais através da transmissão de mensagens claras, coerentes, de fácil interpretação e de forma convincente que desperte o interesse do comensal em adquirir novos conhecimentos a respeito de alimentação e nutrição, uma vez que a mudança no hábito alimentar é uma questão de decisão e escolha individual (Oliveira; Alves, 2008).

Onde quer que o Nutricionista atue, deverá ser sempre um educador, suas ações deverão ser como agente de mudança num processo que ocorre, no mínimo entre duas pessoas: educando e educador. O contexto da educação nutricional no Brasil tem sido abordado através da difusão da noção de promoção das práticas alimentares saudáveis pode ser observada nas mais diversas ações políticas e estratégias relacionadas com alimentação e 
nutrição. O papel da promoção da saúde cresce em sua importância como uma estratégia fundamental para o enfrentamento dos problemas do processo de saúde, doença e cuidado e da sua determinação. A direção, nesse caso, é o fortalecimento do caráter promocional e preventivo, contemplando o diagnóstico e a detecção precoce das DACNT (Oliveira; Alves, 2008).

Segundo Buss (2000, p. 166), as duas principais definições de promoção de saúde são "atividades dirigidas centralmente à transformação dos comportamentos dos indivíduos, focando os seus estilos de vida e localizando-os no seio das famílias e, no máximo, no ambiente das 'culturas' da comunidade em que se encontram”. Essa primeira concepção, segundo o autor, tende a se centrar nos componentes educativos. Uma segunda concepção, e mais moderna, da promoção da saúde é caracterizada pela "constatação de que a saúde é produto de um amplo espectro de fatores relacionados com a qualidade de vida, incluindo um padrão adequado de alimentação e nutrição, de habitação e saneamento, boas condições de trabalho e renda, oportunidades de educação ao longo de toda a vida dos indivíduos e das comunidades".

A promoção de hábitos alimentares saudáveis, e a consequente diminuição dos índices de obesidade, têm sido associadas aos conhecimentos sobre alimentação e nutrição (Triches; Giugliani, 2005). Estas ações podem favorecer a formação de hábitos alimentares adequados e, consequentemente, prevenir o surgimento e o aumento de patologias relacionadas a uma alimentação inadequada, assim como garantir qualidade de vida (Carvalho et al., 2010).

Conforme Triches e Giugliani (2005), a educação nutricional apresenta-se como instrumento eficaz para a adoção de práticas alimentares saudáveis que irão determinar o peso saudável. Carvalho et al. (2010) também afirmam que a utilização da educação nutricional como estratégia para auxiliar a mudança dos hábitos alimentares e a promoção de estilos de vida saudáveis, tem sido apontada em diversos estudos como uma ferramenta eficaz para a aquisição de conhecimentos sobre nutrição, a adoção ou mudanças de atitude em relação à alimentação.

Com isso, a implementação de programas de educação nutricional e a consequente criação de um ambiente favorável à saúde e à promoção de práticas alimentares e estilo de vida saudáveis constituem-se em importantes estratégias para enfrentar problemas alimentares e nutricionais já citados anteriormente (Carvalho et al., 2010).

Os instrumentos utilizados para as práticas de educação nutricional que já foram testados e tiveram sua efetividade comprovada foram a comunicação midiática, inclusão da 
educação nutricional nos projetos pedagógicos escolares (Santos, 2005); resgate da culinária na prática, materiais impressos educativos (Locarno; Navarro; 2011); entrevistas semiestruturadas, ações de instrução e ensino planejadas (Rezende, 2011); questionário aberto de múltipla escolha (Gomes, 2013), metodologias ativas (Rodrigues; Roncada, 2008; Boog, 2010); cursos práticos de capacitação em alimentação e nutrição (Bernardon et al., 2009); ações educativas utilizando Guias Alimentares (Yokota et al., 2010), entre outros.

Em decorrência de novas demandas geradas pelo modo de vida urbano, é imposta ao comensal, a necessidade de adaptar sua vida segundo as condições das quais dispõe, como tempo, recursos financeiros e locais disponíveis para se alimentar. A condição atual urbana tem provocado mudanças significativas nos hábitos alimentares da população brasileira nos últimos anos (Oliveira; Alves, 2008).

A comensalidade contemporânea se caracteriza pela escassez de tempo para o preparo e consumo de alimentos, pela presença de produtos gerados com novas técnicas de conservação e preparo, pelo vasto leque de itens alimentares, pelos deslocamentos das refeições de casa para estabelecimentos que comercializam alimentos, pelo arsenal publicitário, pela flexibilização de horários para comer agregada à diversidade de alimentos e pela crescente individualização dos rituais alimentares (Oliveira; Alves, 2008).

\section{Comportamento Alimentar}

$\mathrm{O}$ interesse na investigação sobre o comportamento alimentar baseia-se na possibilidade de aumentar a efetividade de intervenções nutricionais. $\mathrm{O}$ aspecto mais importante na promoção da saúde é tornar o indivíduo capaz de traduzir as inúmeras informações sobre nutrição a que ele está exposto em informações práticas sobre quais alimentos deve escolher para garantir uma alimentação saudável. Contudo, é importante destacar que o fornecimento de informações sobre qualquer comportamento de saúde é fundamental nas atividades educativas. $\mathrm{O}$ conhecimento contribui para sustentar ou desenvolver novas atitudes sendo o componente racional necessário para motivar uma ação desejada (Toral; Slater, 2007).

O estudo de Stables et al. (2002) afirma que a consciência e o conhecimento sobre as recomendações dietéticas são preditores significativos da mudança de comportamento alimentar. Há evidências de que intervenções nutricionais apresentam maior efetividade quando são pautadas no comportamento, nas necessidades e crenças da população-alvo. 
Observa-se que há um relato mais frequente de fatores intrínsecos do que extrínsecos como motivação para modificações dietéticas. As dificuldades que se tem para motivar os indivíduos a alterar o seu consumo alimentar têm sido muito estudadas, devendo-se considerar a gama de fatores envolvidos nesse comportamento (Toral; Slater, 2007).

Para que a modificação no padrão alimentar aconteça, é preciso iniciar processos de intervenção para que se modifique o padrão alimentar a longo prazo. Um dos modelos mais indicados são as intervenções no local de trabalho. Ações como oferecer maior disponibilidade de alimentos saudáveis nos pontos de venda dos locais de trabalho (Lassen et al., 2007), ter simultaneamente em vista vários fatores dietéticos, tais como a redução das gorduras na dieta e aumento do consumo de fruta e verduras, provou-se eficaz no cenário dos cuidados de saúde primários. O aconselhamento comportamental, em conjunto com o nutricional, parece muito eficaz nesses cenários (Stevens et al., 2002).

A escolha alimentar humana está baseada, por um lado, na condição onívora do homem, isto é, apresentar a capacidade de comer de tudo e, por outro lado, na situação de que o indivíduo é determinado por diversas condições que irão influenciar essa decisão (Jomori et al., 2008). Dentre essas condições, expõem-se algumas variáveis relacionadas aos alimentos, por exemplo, a apresentação visual, o sabor, o valor nutricional, os tipos de preparações e a variedade oferecida.

Além disso, abordam-se os fatores individuais, como os biológicos, os econômicos, os socioculturais e os antropológicos. Destaca-se, contudo, que as diferenças na escolha alimentar entre homens e mulheres são determinadas por motivos que vão além das questões biológicas evidentes, já que o contexto histórico-cultural pode exercer certa influência na escolha dos indivíduos. Essa questão tem sido discutida nos estudos sobre gênero (Jomori et al., 2008).

Em relação aos alimentos, alguns determinantes de sua escolha podem ser citados em alguns estudos como a aparência, sabor, variedade, valor nutricional e qualidade (Mills; Clay, 2001; Scholderer et al., 2004). Esses aspectos foram referidos pelos autores acima em diferentes tipos de estudos e com diferentes abordagens que são demonstrados na temática 'variáveis relacionadas aos alimentos', mas possuem em comum o estudo sobre os motivos da procura do homem por determinado alimento (Jomori et al., 2008)

Existem na literatura alguns conceitos relativos ao estilo de vida no contexto alimentar. Jomori et al. (2008) discorre sobre essa abordagem, referindo ao conceito cognitivo do comportamento do consumidor, explicando que o estilo de vida é construído mentalmente, 
mas não é idêntico ao comportamento atual. Dessa forma, a escolha alimentar do consumidor é direcionada pela sua expectativa, ou seja, pelo valor dado ao alimento ou produto alimentício ou, por outro lado, pelo grau de liberdade dado ao indivíduo para realizar essas escolhas, conferindo a possibilidade de diferentes estilos de vida, relatados no contexto alimentar. Essas diferenças podem ser relacionadas às categorias cognitivas mencionadas (situações de compra, atributos do produto mais desejado, forma de preparação da refeição, hábito alimentar, consequências desejadas) relacionadas tanto aos produtos alimentícios em si quanto aos valores individuais.

As práticas alimentares declaradas são definidas como a ideia que os indivíduos possuem em relação à refeição apropriada, opiniões, atitudes e valores, transmitidos oralmente. As práticas observadas consistem em verificar as práticas alimentares atuais, que os indivíduos realizam e que são passíveis de observação (Poulain, 2004).

O estudo de Falk et al. (2001) empregou um método qualitativo e construtivista para coleta e análise dos dados para explicar o processo de escolha alimentar dos diferentes grupos estudados através de entrevistas e questionários. Assim, concluiu-se que esse método empregado nos estudos auxiliou o entendimento do processo de escolha alimentar. As entrevistas e questionários qualitativos proporcionam o surgimento de várias categorias para análise, importantes na definição de alguns dos fatores que determinam a escolha alimentar dos indivíduos.

Assim, os principais achados foram que os indivíduos levam em consideração vários itens antes de realizar a escolha alimentar, como seus ideais, identidade, cultura e mudança de contextos e situações, saúde, sabor, custo, relação tempo/conveniência e organização de relacionamentos e experiências prévias de escolha alimentar relacionadas à saúde (Falk et al., 2001).

Outros estudos verificaram a associação entre alguns fatores de escolha alimentar. Os participantes dos estudos realizados por Poulain (2004), Mills e Clay (2001) e Scholderer et al. (2004) afirmaram que a informação do valor nutricional do alimento influencia a escolha alimentar do indivíduo, e é denominada uma variável relacionada aos alimentos.

Mills e Clay (2001), numa pesquisa envolvendo consumidores de restaurantes dos Estados Unidos, membros de grupos de listas cadastradas, adultos, divididos entre homens e mulheres $(62 \%)$, avaliaram alguns fatores para se pesquisar sobre a lei que eles denominaram de 'verdade no cardápio' no momento da escolha dos itens, com informações nutricionais, de saúde, de tamanho e número da porção, da origem dos alimentos, da quantidade, qualidade, 
do método de preparo, entre outras questões de seguridade de produtos alimentícios. Esses fatores foram pontuados pelos sujeitos pesquisados dentro de uma escala de quatro pontos pelos graus de importância de 'não importante' a 'extremamente importante'. O conhecimento da porção foi considerado o mais importante fator pelos respondentes na escolha dos itens do cardápio. A conclusão do estudo foi que as informações contidas nos cardápios devem ser completas e acuradas, uma vez que elas são consideradas um meio pelo qual os frequentadores desses restaurantes se utilizam para fazerem suas escolhas.

\section{Influências no Consumo Alimentar}

Magalhães et al. (2012) aponta que a atuação do nutricionista para a promoção de práticas alimentares saudáveis baseia-se em prover intervenções que garantem mudanças de hábitos alimentares indesejáveis ou deletérios, principalmente por meio de atividades voltadas para grupos específicos. Além disso, a promoção de hábitos alimentares saudáveis pautada no trabalho de educação em saúde exige que o nutricionista tenha papel atuante de educador, sendo agente e propiciador de mudanças.

Nas estratégias de Educação Alimentar e Nutricional (EAN) definido por Boog (2008), essa aprendizagem mobiliza mudanças, e o integrante dos processos de educação nutricional deixa de ser espectador e passa a ser o sujeito da reconstrução do saber, que, ao fazer, vai aprendendo, deixando de ser aquele que recebe passivamente as informações.

Para que essas intervenções sejam satisfatórias, não se pode considerar apenas o fato de que todos os participantes estão cientes da necessidade da mudança no consumo alimentar. Assim, essas intervenções podem se beneficiar se forem considerados os diferentes estágios de mudança comportamental dos indivíduos - por exemplo, aqueles sugeridos pelo modelo transteórico. Nesse modelo, cada estágio corresponde a diferentes atitudes e percepções dos indivíduos diante da nutrição e da saúde, o que ratifica a necessidade de avaliar a prática educativa no final e em outros momentos posteriores à intervenção, modelo proposto por Toral e Slater (2007).

Muitos artigos encontrados na revisão de literatura assumem que o conhecimento nutricional está relacionado diretamente com o comportamento sobre consumo alimentar. Porém, existem variados tipos de abordagem que podem ou não ser efetivos nessa relação (Worsley, 2002). 
Estudos variados comprovam essa relação, como Cervato et al. (2005), que estudou a mudança no comportamento alimentar de adultos e idosos após práticas de educação nutricional e observou resultados positivos quanto a tendência às modificações nas práticas alimentares e nas noções conceituais sobre nutrição, em decorrência da intervenção educativa.

Outro estudo com objetivo de avaliar o impacto da intervenção nutricional nos hábitos alimentares, no perfil antropométrico e, consequentemente, nas condições de saúde de adultos e idosos observou que a intervenção nutricional promoveu impacto positivo entre aqueles que perderam peso, bem como entre os que melhoraram a qualidade de sua alimentação (Gardone et al.; 2012).

Rustad e Smith (2013) avaliaram o impacto de uma intervenção nutricional de curto prazo por meio da educação de uma gama de tópicos nutricionais e de saúde em mulheres de baixa renda, o que confirmou que a intervenção nutricional utilizando conhecimentos sobre nutrição através de aulas, atividades vivenciais e interativas tem a capacidade de aumentar o conhecimento de nutrição e favoravelmente mudar o comportamento alimentar.

Além de compor todas as características necessárias para melhor efetividade dos processos de educação nutricional, Miller e Branscum (2012) apontam que as estratégias educativas em nutrição devem incluir objetivos comerciais para poupar dinheiro, facilitar o planejamento de cardápio e dos modos de preparo dos alimentos na cozinha, e indicação de locais e estabelecimentos para permitir aos participantes do processo de mudança adquirirem alimentos suficiente e nutricionalmente adequados.

O estudo americano de Dollahite et al. (2008) sobre o custo x benefício de estratégias educacionais para diminuir os gastos governamentais com agravos na saúde, os resultados indicaram que as mudanças no comportamento alimentar decorrentes de estratégias de educação nutricional são susceptíveis à melhorara da saúde futura e reduzir os custos de saúde.

No estudo de Gomes et al. (2013) para avaliar o impacto de um programa de educação nutricional sobre o estado nutricional e conhecimento alimentar de pacientes com excesso de peso, viu-se que houve uma redução média de $1,51 \mathrm{~kg}$ do peso inicial; o valor médio de IMC passou de $37,41 \mathrm{~kg} / \mathrm{m}^{2}$ para $36,85 \mathrm{~kg} / \mathrm{m}^{2}$; o perímetro de cintura apresentou redução média de $5,6 \mathrm{~cm}$, afirmando que a estratégia de educação nutricional parece ter influenciado na boa evolução do estado nutricional dos participantes, propiciando redução de medidas antropométricas e ampliando os conhecimentos sobre alimentação saudável. 
No estudo realizado por Wardle et al. (2000) com um inquérito postal de 1040 participantes entre 18 e 75 anos selecionados a partir de listas obtidas em clínicas da Inglaterra, obteve resultados de que o conhecimento nutricional foi significativamente associado com alimentação saudável, como a maior ingestão de frutas e vegetais. Os autores afirmam que os indivíduos que possuíam conhecimento sobre nutrição tinham 25 vezes maior probabilidade de consumir quantidades adequadas de frutas e verduras diariamente. Através de análises de covariância os autores foram capazes de mostrar que o conhecimento de nutrição era um mediador parcial da variação na ingestão de alimentos, especialmente a ingestão de frutas e vegetais.

Lytle (2005) revisou a literatura e pontuou sua opinião sobre o uso e efetividade da educação nutricional feita como é hoje, baseada em achados teóricos e pautada por modelos práticos. O autor mostra que os profissionais responsáveis pela educação nutricional se inspiram em teorias de mudança de comportamento além da nutrição, começando a olhar para fatores além do conhecimento próprio para melhorar esses modelos, tais como auto-eficácia ou sentir-se confiante de que se pode fazer o que é necessário de mudar de comportamento.

Além disso, intervenções testadas e baseadas na literatura atual sobre educação nutricional tem mudado a abordagem prática dessas estratégias. Ao invés de apenas explicar às pessoas como o seu comportamento afeta o seu peso, o risco de câncer, o risco de doença cardiovascular, ou qualquer outro problema de saúde, educadores de nutrição concentram-se em comportamentos específicos que influenciam esses risco e ajudam as pessoas a alcançar o que procuram mudar, incentivando-os a definir pequenos e realizáveis objetivos. Essas habilidades relacionadas à prática em experiências de realização resultam no aumento da confiança na capacidade para ter sucesso na mudança de comportamento (aumento da autoeficácia), e uma maior probabilidade de mudança de comportamento (Lytle, 2005).

Worsley (2002) foi um dos poucos autores que estudou a relação entre conhecimentos sobre nutrição e mudanças no consumo alimentar. Ele aponta que as evidências de influência do conhecimento nutricional sobre os comportamentos alimentares é misto. No entanto, sugere que o conhecimento nutricional pode desempenhar um papel pequeno, mas fundamental na adoção de hábitos alimentares mais saudáveis. $\mathrm{O}$ autor também afirma que a educação nutricional precisa ser completada por outros fatores para que haja melhor efetividade na ação, como conhecimento das consequências da alimentação saudável e objetivo do espectador em mudar o estilo de vida. 


\section{Considerações finais}

Vê-se que a educação nutricional possui um papel importante e indispensável na formação de novas escolhas alimentares.

De acordo com a revisão da literatura, é visível que muitos estudos ainda precisam ser feitos para comprovar a associação positiva entre a influência da educação nutricional nas escolhas alimentares saudáveis de adultos, que já possuem hábitos e costumes alimentares formados. Essas estratégias precisam levar em consideração o desejo de mudança e objetivo dos participantes, o Estágio de Mudança em que se encontram e a cultura regional. Além disso, essas estratégias são mais efetivas quando aplicadas em médio e longo prazo, para que o processo de mudança das escolhas alimentares seja contínuo, para que os conhecimentos sobre nutrição sejam adquiridos na forma de um processo constante.

Além disso, outros estudos precisam apontar como os participantes utilizam esses conhecimentos no seu dia-a-dia e a sua nova relação com os alimentos, através de estudos longitudinais e intervenções experimentais. 


\section{Bibliografia}

ALVAREZ, T. S.; ZANELLA, M. T. Impacto de dois programas de educação nutricional sobre o risco cardiovascular em pacientes hipertensos e com excesso de peso. Rev. Nutr., Campinas, v. 22, n. 1, p. 71-79, 2009.

BERNARDON, R.; SILVA, J. R. M.; CARDOSO, G. T.; MONTEIRO, R. A.; AMORIM, N. F. A.; SCHMITZ, B. A. S.; RODRIGUES, M. L. C. F. Construction of a methodology to train educators in food and nutrition. Rev. Nutr., Brasília, v. 22, n. 3, p. 389 - 398, 2009.

BOOG, M. C. F. Atuação do nutricionista em saúde pública na promoção da alimentação saudável. Rev. Ciênc. Saúde. São Paulo, v. 1, p. 33-42, 2008.

BOOG, M. C. F. Nutrition education program in a rural elementary school. Rev. Nutri., São Paulo, v.23, n. 6, p. 1005-1017, 2010.

BUSS, P. M. Promoção da saúde e qualidade de vida. Ciênc. saúde coletiva, Rio de Janeiro, v. 5, n. 1, p. 163-177,2000.

CARVALHO, A. P. OLIVEIRA, V.B.; SANTOS, L.C. Hábitos alimentares e práticas de educação nutricional: atenção a crianças de uma escola municipal de Belo Horizonte, Minas Gerais. Pediatria (São Paulo), São Paulo, v. 32, n. 1, p. 20-7, 2010.

CERVATO, A. M.; DERNTL, A. M.; LATORRE, M. R. D. O.; MARUCCI, M. F. N. Educação nutricional para adultos e idosos: uma experiência positiva em Universidade Aberta para a Terceira Idade. Rev. Nutr. São Paulo, v.18, n.1, p. 41-52, 2005.

CFN - Conselho Federal de Nutricionistas. Inserção profissional dos nutricionistas no Brasil. Brasília: CFN, 2006.

COSTA, J. A.; BALGA, R. S. M.; ALFENAS, R. C. G.; COTTA, R. M. M. Promoção da saúde e diabetes: discutindo a adesão e a motivação de indivíduos diabéticos participantes de programas de saúde. Ciê.nc Saúde. Colet., Viçosa, v. 16, n. 3, p. 2001-2009, 2011.

DOLLAHITE, J.; KENKEL, D.; THOMPSON, S.An Economic Evaluation of the Expanded Food and Nutrition Education Program. J. Nutr. Educ. Behav. Estados Unidos, v. 40, p. 134143, 2008.

FALK, L. W.; SOBAL, J.; BISOGNI, C. A.; CONNORS, M.; DEVINE, C. M. Managing health eating: definitions, classifications and strategies. Health Educ. Behav., New York, v. 28, n. 4, p. 425-439, 2001. 
FALS-BORDA, O. Aspectos teóricos da pesquisa participante: considerações sobre o significado e o papel da ciência na participação popular.In: BRANDÃO, Carlos Rodrigues. Pesquisa participante. São Paulo: Brasiliense, 1988.

Gaglianone, C. P.; TAdDEI, J. A. A. C.; COlugnati, F. A. B.; MAGAlhães, C. G.; DAVANÇO, G. M.; MACEDO, L.; LOPEZ, F. A. Nutritional education in public elementary schools of São Paulo, Brazil: the reducing risks of illness and death in adulthood project. Rev. Nutr., Campinas, v. 19, n. 3, p. 309-320, 2006.

GARDONE, D. S.; RIBEIRO, S. M. R.; SILVA, R. R.; MARTINO, H. S. D. Impact of nutritional intervention on the anthropometric profile and dietary intake of participants of the Family Health Strategy (FHS). Nutrire, São Paulo, v. 37, n. 3, p. 245-258, 2012

GOMES, A. C. M.; DIAS, C. P.; GUERRA, R. O.; SAlVO, V. L. M. A. Impacto de estratégias de educação nutricional sobre variáveis antropométricas e conhecimento alimentar. Rev. Bras. Promo. Saúde, Fortaleza, v. 26, n. 4, p. 462-469, 2013.

JOMORI, M. M.; PROENÇA, R. P. C.; CALVO, M. C. M. Determinantes da escolha alimentar. Rev. Nutr., Campinas, v. 21, n. 1, p. 63-73, 2008.

KUNERT, C. S.; MORAIS, M. P.; CARVALHO, A. C. M. S. Salt and fat contents in preparations at commercial restaurants in Goiânia-GO. Rev. Bras. Promo. Saúde, Fortaleza, v. 26, n. 1, p. $18-25,2013$.

LASSEN, A.; HANSEN, K.; TROLLE, E. Comparison of buffet and a la carte serving at worksite canteens on nutrient intake and fruit and vegetable consumption. Pub. Health Nutr., Estados Unidos, v. 10, n. 3, p. 292-297, 2007.

LOCARNO, A. F. S.; NAVARRO, A. C.Educação nutricional como estratégia de prevenção e Tratamento da obesidade. Rev. Bras. Obes. Nutr. Emagrec., São Paulo, v. 5, n. 28, p. 314 323, 2011.

LYTLE, L. A. Nutrition Education, Behavioral Theories, and the Scientific Method: Another Viewpont. Journ. Nutr. Educ. Beh., Estados Unidos, v. 37, n. 2, p. 90-93, 2005.

MAGAlHÃES, A. P. A.; MARTINS, K. C.; CASTRO, T. G. Educação alimentar e nutricional: reflexões para intervenções em alimentação e nutrição na atenção primária à saúde. Rev. Min. Enferm., Minas Gerais, v. 16, n. 3, p. 463-470, 2012.

MILLER, C.; BRANSCUM, P. The Effect of a Recessionary Economy on Food Choice: Implications for Nutrition Education. J. Nutr. Educ. Behav. EstadosUnidos, v. 44, p. 100-106, 2012. 
MILLS, J. E.; CLAY, J. M.The truth-in-menu law and restaurant consumers. Foods. Res. Intern., Estados Unidos, v. 13, p. 69-82, 2001.

OLIVEIRA, C. S.; ALVES, F. S. Educação nutricional em unidade de alimentação e nutrição, direcionada para consumo de pratos protéicos: um estudo de caso. Alim. Nutr., Araraquara, v. 19, n. 4, p. 435-440, 2008.

POULAIN, J-P. Sociologias da Alimentação. Tradução: PROENÇA, R.P.C.; RIAL, C.S.; CONTE, J. Florianópolis: Ed. UFSC, 2004. (Série Nutrição)

RAMOS, F. P.; SANTOS, L. A. S.; REIS, A. B. C. Educação alimentar e nutricional em escolares: uma revisão de literatura. Cad. Saúde Pública, Rio de Janeiro, v. 29, n. $11,2013$.

REZENDE, A. M. B. Ação educativa na atenção básica à saúde de pessoas com diabetes mellitus e hipertensão arterial: avaliação e qualificação de estratégias com ênfase na educação nutricional, 2011, 220 p. il. (Tese de Doutorado). São Paulo: Faculdade de Saúde Pública. Universidade de São Paulo, 2011.

RODRIGUES, L. P. F.; RONCADA, M. L. Nutritional education in Brazil: evolution and description of a pedagogical proposal for schools. Comunic. Ciênc. Saúde, Brasília, v. 19, n. 4, p. 315-322, 2008.

RUSTAD, C.; SMITH, C. Nutrition Knowledge and Associated Behavior Changes in a Holistic, Short-term Nutrition Education Intervention with Low-income Women.J Nutr. Educ. Behav. EstadosUnidos, v. 45, p. 490-498, 2013.

SANTOS, L. A. S. Food and nutrition education in the context of promoting healthy food practices. Rev. Nutri., Campinas, v. 18, n. 5, p. 681 - 692, 2005.

SCHMIDT, M. I. et al. Doenças crônicas não transmissíveis no Brasil: carga e desafios atuais. The Lancet., Londres, v. 13, n. 3, p. 61-74, 2011.

SCHOLDERER, J. BRUNSO, K; BREDAHL, L; GRUNERT, K.G. Cross-cultural validity of the food-related lifestyles instrument (FRL) within Western Europe. Appetite, Dinamarca, v. 42, p. 197- 211, 2004.

SICHIERI, R.; COITINHO, D. C.; MONTEIRO, J. B.; COUTINHO, W. F. Recomendações de alimentação e nutrição saudável para a população brasileira. Arq. Bras. Endocrinol. Metab., São Paulo, v. 44,n. 3, p. 227-232, 2000.

SOUSA, A.A. et al. Qualidade Nutricional e Sensorial na Produção de Refeições. Nutr. Pauta, São Paulo, v. 3, n. 75, p. 04-16, 2005. 
STABLES, G. J. et al. Changes in vegetable and fruit consumption and awareness among US adults: results of the 1991 and 1997 - 5 A Day for Better Health Program surveys. J. Am. Diet. Assoc., EstadosUnidos, v. 102, n. 6, p. 809-817, 2002.

STEVENS, V. J.; GLASGOW, R. E.; TOOBERT, D. J. et al. Randomized trial of a brief dietary intervention to decrease consumption of fat and increase consumption of fruits and vegetables. Amer. Jour. Health Prom., Estados Unidos, v. 16, n. 3, p. 129-34, 2002.

TORAL, N.; SLATER, B.. Abordagem do modelo transteórico no comportamento alimentar. Ciênc. saúde coletiva, Rio de Janeiro, v. 12, n. 6, p. 1641 - 1650, 2007.

TRICHES, R. M.; GIUGLIANI, E. R. J. Obesidade, práticas alimentares e conhecimentos de nutrição em escolares. Rev. Saúde Pública, São Paulo, v. 39, n. 4, p.541-547, 2005.

VIEIRA, C. M.; CORDEIRO, S. N.; MAGDALENO JUNIOR, R.; TURATO, E. R. Significados da dieta e mudanças de hábitos para portadores de doenças metabólicas crônicas: uma revisão. Ciên. Saúde Coletiva, Rio de Janeiro, v. 16, n. 7, p. 3161-3168, 2011.

WARDLE, J.; PARMENTER, K.; WALLER, J. Nutrition knowledge and food intake. Appetite, Reino Unido, v. 34, p. 269-275, 2000.

WORSLEY, A. Nutrition knowledge and food consumption: can nutrition knowledge change food behaviour? Asia Pac. J. Clin. Nutr., Austrália, v. 11(Suppl), p. S579-S585, 2002.

YOKOTA, R. T. C.; VASCONCElOS, T. F.; PINHEIRO, A. R. O.; SCHMITZ, B. A. S.; COITINHO, D. C.; RODRIGUES, M. L. C. F. "Promotion of healthy eating habits by schools" study: comparison of two nutrition education strategies in the Federal District of Brazil. Rev. Nutr., Brasília, v. 23, n. 1, p. 37 - 47, 2010. 


\title{
4.2 ARTIGO 2 - ESTRATÉGIA DE EDUCAÇÃO NUTRICIONAL EM RESTAURANTE SELF-SERVICE
}

\author{
Larissa MAZOCCO
}

Raquel Bráz Assunção BOTELHO

Izabel Cristina Rodrigues da SILVA

Rita de Cássia Coelho Almeida AKUTSU

\section{RESUMO}

Proposta - O objetivo deste estudo é elaborar uma estratégia de educação nutricional de classificação de cardápios em restaurante self-service.

Metodologia - O desenvolvimento da metodologia foi realizado em sete etapas, desde a elaboração das Fichas Técnicas de Preparação de todos os alimentos servidos no buffet, classificação nutricional e disponibilização dessas informações ao comensal.

Resultados e discussão - Foram elaboradas 144 Fichas Técnicas de Preparação e classificadas com as cores verde, amarelo e vermelho de acordo com a densidade energética e teor de sódio. 88 Fichas Técnicas de Preparação $(61,1 \%)$ estavam inadequadas, sendo os molhos para salada, arroz, sobremesas, pratos principais e guarnições os que mais receberam as cores amarelas e vermelhas, com $40 \%$ em virtude do moderado ou alto teor de sódio e $33 \%$ pela moderada ou alta densidade energética.

Conclusão - Foi elaborada uma metodologia de educação nutricional que englobou a classificação das preparações servidas no buffet de almoço de um restaurante self-service. Os resultados devem incentivar os restaurantes a fornecerem preparações saudáveis aos clientes, utilizar as Fichas Técnicas de Preparação e suas respectivas informações nutricionais, abordando os pressupostos das metodologias ativas.

Palavras-chave: Educação nutricional, densidade energética, sódio, Ficha Técnica de Preparação, cardápio, restaurante, escolha alimentar, informação nutricional.

\section{ABSTRACT}

Proposal - The objective of this study is to develop a nutrition education strategy menus classification self-service restaurant. 
Methodology - The development of the methodology was carried out in seven stages, from preparation of Preparation Technical Files of all food served in the buffet, nutritional classification and such information available to consumer.

Results and Discussion - 144 Preparation Technical Files were prepared and classified with the colors green, yellow and red according to the energy density and sodium content. 88 Preparation Technical Files $(61.1 \%)$ were inadequate, and the salad dressings, rice, desserts, main dishes and side dishes that have received the yellow and red colors, with $40 \%$ under moderate or high sodium content and $33 \%$ for moderate or high density energy.

Conclusion - A nutrition education methodology that included the classification of meals served at the lunch buffet a self-service restaurant was developed. The results should encourage restaurants to provide healthy preparations to clients, use Preparation Technical Files and their nutritional information, addressing the conditions of active methodologies.

Keywords: nutrition education, energy density, sodium, Preparation Technical File, menu, restaurants, food choice and nutritional information. 


\section{INTRODUÇÃO}

A educação nutricional é conceituada como um processo educativo que tem como objetivo principal tornar os sujeitos autônomos e seguros para realizarem suas escolhas alimentares de forma que garantam uma alimentação saudável e prazerosa, propiciando, então, o atendimento de suas necessidades fisiológicas, psicológicas e sociais (Camossa, 2005). Sendo apontada como estratégia de ação, no campo da educação em saúde, a ser adotada prioritariamente na saúde da população com o objetivo de conter o avanço das doenças e agravos crônicos não-transmissíveis (DACNT), uma vez que a alimentação de má qualidade é considerada um fator de risco para inúmeras doenças (Carvalho et al., 2010a; Ramos, 2013).

O principal difusor das práticas educativas em restaurantes no Brasil é o Nutricionista. A sua presença em ambientes que promovam atividades voltadas para aquisição e construção de conhecimento sistematizado - como os restaurantes self-service (por quilo) - é muito importante e contribui na formação de hábitos alimentares saudáveis e duradouros (CFN, 2006).

Carvalho et al. (2010a) afirmam que a utilização da educação nutricional como estratégia para auxiliar a mudança dos hábitos alimentares e a promoção de estilos de vida saudáveis, tem sido apontada em diversos estudos como uma ferramenta eficaz para a aquisição de conhecimentos sobre nutrição, para adoção ou mudanças de atitude em relação à alimentação, uma vez que mudanças no hábito alimentar é uma questão de decisão e escolha individual (Paschoa, 2005; Oliveira; Alves, 2008).

Em restaurantes, é importante que ações de educação em saúde sejam privilegiadas como forma de promover hábitos alimentares saudáveis. Tais ações têm sido apontadas como um dos intervenientes nos índices de obesidade que está largamente associado aos conhecimentos sobre alimentação e nutrição (Triches; Giugliani, 2005).

O conhecimento decorrente do fornecimento de informações nutricionais dos alimentos contribui para sustentar e/ou desenvolver novas atitudes do comensal; é o componente racional necessário para motivar uma ação desejada (Toral; Slater, 2007). O estudo de Stables et al. (2002) afirma que a consciência e o conhecimento sobre as recomendações dietéticas são preditores significativos da mudança de comportamento alimentar. 
Para que a modificação no padrão alimentar aconteça, é preciso iniciar processos de intervenção para que essa modificação se instale e permaneça em longo prazo. Os modelos mais atuais adotam intervenções nos locais de trabalho com diversas ferramentas e metodologias (Jomori et al., 2008). Um tipo de restaurante que tem sido muito frequentado pelos brasileiros nos últimos anos é o restaurante self-service por quilo, onde o comensal escolhe o que deseja consumir pagando o equivalente ao peso do que foi colocado em seu prato (Proença, 2000).

Alguns trabalhos têm sido realizados utilizando características específicas das preparações que são determinantes da escolha, entre essas podem ser citados o valor nutricional, aparência, sabor, variedade e qualidade (Castelo Branco, 2000; Nield et al., 2000; Mills; Clay, 2001; Tse et al., 2002; Scholderer et al., 2004).

Cabe ressaltar que a informação nutricional tem sido apontada como uma das estratégias que mais influenciam nas escolhas alimentares (Poulain; 1999; 2002; 2004; Castelo Branco, 2000; Mills e Clay, 2001; Nield et al., 2000; Scholderer et al., 2004).

Em virtude disso, o objetivo deste estudo é elaborar uma estratégia Educação Nutricional em restaurantes self service.

\section{METODOLOGIA}

O desenho de estudo é de intervenção e randomizado (Pereira, 2008). Para aplicação da metodologia foi selecionado um restaurante por conveniência do tipo self-service por quilo. O restaurante escolhido está localizado no centro de Brasília - DF e atende em torno de 1000 comensais no almoço de segunda a sexta-feira, sendo a grande maioria de trabalhadores do local - o restaurante é do tipo institucional. A metodologia deste trabalho foi desenvolvida em sete etapas.

\section{1) Fichas Técnicas de Preparação}

Para realização do presente trabalho, foram elaboradas as Fichas Técnicas de Preparação (FTP) (Akutsu et al., 2005; Camargo; Botelho, 2012) do restaurante para todas as preparações servidas no cardápio semanal. Para o desenvolvimento destas, realizou-se o acompanhamento da produção dos alimentos de todos os dias de cardápio de uma semana completa de segunda a sexta-feira. Todos os dados foram computados no software dietWin Rótulos de Alimentos® versão 1 de 2003 - que utiliza uma compilação de dados das 
principais tabelas de composição de alimentos: TACO (2011), IBGE (2011) e USDA (2011) para análise da informação nutricional das preparações. Foram elaboradas 144 FTPs.

Para determinação da porção média de todas as preparações, foi utilizado o método descrito por Sávio et al. (2005). Para determinação do prato médio (PM) real e da porção média real, foi realizada uma observação direta de 50 comensais e assim determinada a frequência que cada comensal colocava em seu prato cada preparação, segundo fórmula abaixo.

$\left(\mathrm{N}^{\mathrm{o}}\right.$ de comensais que se serviram da preparação $\mathrm{x} \mathrm{n}^{\mathrm{o}}$ de porções servidas) $\mathrm{x}$ peso da porção em gramas/50 (número de comensais observados) = valor médio da porção em gramas.

Essa observação foi realizada para todos os Tipos de Preparações - pratos principais, acompanhamentos (feijão e arroz), guarnições, saladas, molhos para saladas e sementes. Também foram observadas as porções médias das sobremesas e frutas, sendo de $71 \mathrm{~g}$ de frutas sem casca e sem caroço (exceto a melancia, que permaneceu com caroço) e $104 \mathrm{~g}$ para sobremesas elaboradas. Esses valores não entram no cálculo do peso do PM em virtude de serem consumidos separados após a refeição.

Em relação à metodologia de classificação e avaliação das preparações culinárias produzidas no restaurante, foram escolhidos três critérios de acordo com a revisão de literatura.

\section{2) Primeiro critério de classificação - DE e TS}

Foram atribuídas às preparações cores verde, amarela e vermelha, de forma lúdica, associada à sinalização de trânsito - cores do semáforo. Essa classificação contempla a Densidade Energética (DE) e o Teor de Sódio (TS) da preparação e o uso das três cores refere-se à recomendação de consumo das preparações, conforme apresentado no Quadro I. A densidade energética (DE) expressa em kcal/g é classificada de acordo com o Centers of Disease Control and Prevention (CDC, 2005) em baixa (<1,5 kcal/g), média (1,5 - $4 \mathrm{kcal} / \mathrm{g}) \mathrm{e}$ alta $(>4 \mathrm{kcal} / \mathrm{g})$. 
Quadro I Legenda das cores das placas de identificação com classificação e recomendação de consumo das preparações de restaurantes self service

\begin{tabular}{|c|c|c|}
\hline Cor & Classificação & Recomendação de consumo \\
\hline Verde & Baixa quantidade de sódio e de gordura & Consumo diário \\
\hline Amarela & $\begin{array}{l}\text { Quantidade moderada de sódio e de } \\
\text { gordura }\end{array}$ & Consumo de 2 a 3 vezes na semana \\
\hline Vermelha & Alta quantidade de sódio e gordura & Consumo de 1 vez na semana \\
\hline
\end{tabular}

O teor de sódio (TS) foi calculado de acordo com o proposto por Zandonadi et al. (2014) utilizando a porcentagem de sódio que o tipo de preparação requer de acordo com o PM encontrado no estudo. Neste estudo considerou-se a recomendação do PAT (Brasil, 2006) de 920 mg de sódio (cerca de 40\% da quantidade diária, a semelhança do Valor Energético Total do almoço), essa quantidade de sódio ideal $(920 \mathrm{mg}$ ) foi distribuída pelas porções dos Tipos de Preparações como mostra a Tabela I.

Tabela I. Determinação de sódio ideal na porção por Tipos de Preparações em restaurantes self service no Brasil, 2015.

\begin{tabular}{cccc}
\hline Tipos de Preparações & $\begin{array}{c}\text { Média da } \\
\text { porção }(\mathrm{g})\end{array}$ & $\begin{array}{c}\text { Distribuição \% do sódio na } \\
\text { preparação* }\end{array}$ & $\begin{array}{c}\text { Sódio ideal na } \\
\text { porção em mg }\end{array}$ \\
\hline Prato principal & $69 \mathrm{~g}$ & $32,5 \%$ & $299 \mathrm{mg}$ \\
Guarnição & $63 \mathrm{~g}$ & $13,5 \%$ & $124,2 \mathrm{mg}$ \\
Arroz & $103 \mathrm{~g}$ & $33 \%$ & $303,6 \mathrm{mg}$ \\
Feijão & $69 \mathrm{~g}$ & $18,5 \%$ & $170,2 \mathrm{mg}$ \\
Saladas e molhos para & $102+22 \mathrm{~g}$ & $18,5 \%$ & $23 \mathrm{mg}$ \\
salada & $4,5 \mathrm{~g}$ & - & - \\
Sementes & $432 \mathrm{~g}$ & $100 \%$ & $920 \mathrm{mg}$ \\
\hline Total & & &
\end{tabular}

Fonte: *ZANDONADI et al., 2014.

Para classificar o teor de sódio (miligramas de sódio em 100 g de alimento) das preparações em Baixo (adequado), Médio e Alto, foram utilizados parâmetros encontrados na revisão de literatura (Cobcroft et al., 2008; AWASH, 2011; Brasil, 2014; Zandonadi et al., 2014). De início, o teor de sódio ideal (Baixo) do conjunto de preparações que compõem o PM do almoço, corresponde até 920 mg de sódio (Brasil, 2006), e porcentagens distribuídas nos Tipos de Preparações conforme o apresentado na Tabela I.

O teor de sódio Médio considerou o consumo atual de sódio (4600 mg de sódio/dia que de acordo com a POF 2008/2009 do IBGE é em média o dobro de sal recomendado, aproximadamente $12 \mathrm{~g} \mathrm{sal} / \mathrm{dia}$ ) (Brasil, 2011) e permaneceu atribuindo-se os $40 \%$ do almoço 
conforme PAT (Brasil, 2006), ou seja, o consumo atual de sódio é em torno de $1840 \mathrm{mg}$ para o almoço. Desse valor foi debitado $30 \%$ da quantidade de sódio por porção, em virtude dos estudos apontarem que não há percepção na aceitabilidade neste percentual de distribuição, quantidade essa que já pode ser retirada de imediato dos pratos, como mostra a revisão de literatura (Cobcroft et al., 2008; AWASH, 2011; Brasil, 2014). O número final para teor de sódio Médio do almoço nessa classificação foi em torno de $1288 \mathrm{mg}$. Este valor foi distribuído nas porções do PM considerando-se as recomendações de Zandonadi et al. (2014).

O teor de sódio Alto, por fim, assume valores maiores de $1288 \mathrm{mg}$, ou seja, valores maiores que o teor de sódio Médio. A classificação do teor de sódio em Baixo, Médio e Alto está apresentada na Tabela II.

Tabela II. Classificação do Teor de sódio por Tipos de Preparações de restaurantes self service no Brasil, 2015.

\begin{tabular}{cccc}
\hline \multirow{2}{*}{ Tipos de preparações } & \multicolumn{3}{c}{ Teor de sódio (por 100 g) } \\
\cline { 2 - 4 } & Baixo & Moderado & Alto \\
\hline Prato principal & $<433 \mathrm{mg}$ & $433-607 \mathrm{mg}$ & $>607 \mathrm{mg}$ \\
Guarnição & $<197 \mathrm{mg}$ & $197-276 \mathrm{mg}$ & $>276 \mathrm{mg}$ \\
Arroz & $<295 \mathrm{mg}$ & $295-413 \mathrm{mg}$ & $>413 \mathrm{mg}$ \\
$\begin{array}{c}\text { Feijão } \\
\text { salada }\end{array}$ & $<247 \mathrm{mg}$ & $247-345 \mathrm{mg}$ & $>345 \mathrm{mg}$ \\
$\begin{array}{c}\text { Saladas e molhos para } \\
\text { Total correspondente } \\
\text { ao consumo total de } \\
\text { sódio no almoço }\end{array}$ & $<19 \mathrm{mg}$ & $19-26 \mathrm{mg}$ & $>26 \mathrm{mg}$ \\
\hline
\end{tabular}

3) Segundo critério de classificação - Grupos de Alimentos e Recomendação

O segundo critério classificatório está associado aos quatro princípios da alimentação saudável descritos por Pedro Escudero, sendo eles: quantidade, qualidade, harmonia e adequação de alimentos e nutrientes (Landabure, 1968). Para que os quatro princípios sejam adotados na composição do prato do almoço, além de classificá-los em cores, como no primeiro critério, trabalhando os nutrientes que influenciam na Densidade Energética e no Teor de Sódio, é preciso dividir os Tipos de Preparações em grupos alimentares para contemplar o consumo de diferentes tipos de nutrientes e adequar o prato à necessidade da clientela ao tamanho e a quantidade de porções de cada Grupo Alimentar.

Para contemplar esses critérios foram usados como referência, o Guia Alimentar que categoriza todos os alimentos que devem ser consumidos durante o todo o dia em grupos de 
alimentos (Brasil, 2008; 2014) e o My Plate que categoriza os grupos de que devem ser consumidos no almoço (USDA, 2011).

Para facilitar o entendimento dos comensais quanto ao agrupamento de alimentos indicados para o prato de almoço, a classificação foi ajustada em grupos que tenham relação com a refeição do almoço. Cada grupo deste ajuste ganhou um código - uma letra - para facilitar o cálculo das porções. A divisão dos grupos está disposta na Tabela III. 
Tabela III. Classificação dos Grupos de Alimentos de acordo com o Guia Alimentar para a População Brasileira, de acordo com o My Plate e a classificação final ajustada para restaurantes self service no Brasil, 2015.

\begin{tabular}{|c|c|c|c|c|c|c|c|c|}
\hline \multicolumn{4}{|c|}{ Classificação de acordo com o Guia (BRASIL, 2008) } & \multicolumn{2}{|c|}{$\begin{array}{c}\text { Classificação de acordo com o } M y \\
\text { Plate (USDA, 2011) }\end{array}$} & \multicolumn{3}{|c|}{ Classifcação ajustada } \\
\hline $\begin{array}{c}\text { Grupos de } \\
\text { Alimentos do } \\
\text { Guia }\end{array}$ & $\begin{array}{l}\text { Recomendação } \\
\text { calórica média } \\
\text { do grupo para o } \\
\text { almoço (kcal)* }\end{array}$ & $\begin{array}{l}\text { Número de } \\
\text { porções do } \\
\text { grupo para o } \\
\text { almoço }\end{array}$ & $\begin{array}{c}\text { Valor } \\
\text { energético } \\
\text { médio por } \\
\text { porção (kcal) }\end{array}$ & $\begin{array}{l}\text { Grupos de } \\
\text { Alimentos do } \\
\text { My Plate }\end{array}$ & $\begin{array}{c}\text { Recomendação } \\
\text { média em \% do } \\
\text { grupo para o } \\
\text { almoço }\end{array}$ & $\begin{array}{c}\text { Reclassificação } \\
\text { dos grupos } \\
\text { (novos grupos) }\end{array}$ & $\begin{array}{l}\text { Recomendação } \\
\text { calórica média } \\
\text { dos novos grupos } \\
\text { para o almoço } \\
\text { (kcal)*** }\end{array}$ & $\begin{array}{c}\text { Número de } \\
\text { porções dos } \\
\text { novos grupos } \\
\text { para o almoço }\end{array}$ \\
\hline $\begin{array}{l}\text { Cereais, } \\
\text { tubérculos, } \\
\text { raízes e } \\
\text { derivados }\end{array}$ & 375 & 2,5 & 150 & Grãos & $30 \%$ & $\begin{array}{c}\text { Grupo dos } \\
\text { Carboidratos }(\mathrm{C})\end{array}$ & 180 & 2 \\
\hline Feijões & 55 & 1 & 55 & & & $\begin{array}{l}\text { Grupo dos Feijões } \\
\text { (F) }\end{array}$ & 55 & 1 \\
\hline $\begin{array}{c}\text { Frutas e sucos } \\
\text { de frutas } \\
\text { naturais }\end{array}$ & 70 & 1 & 70 & Frutas & $10 \%$ & 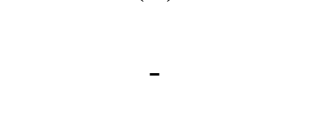 & 70 & 1 \\
\hline Hortaliças & 45 & 3 & 15 & Vegetais & $40 \%$ & $\begin{array}{c}\text { Grupo dos } \\
\text { Vegetais (V) }\end{array}$ & 15 & 3 \\
\hline $\begin{array}{c}\text { Leite e } \\
\text { derivados } \\
\text { Carnes e Ovos }\end{array}$ & $\begin{array}{c}144 \\
76\end{array}$ & $\begin{array}{l}3 \\
1\end{array}$ & $\begin{array}{l}48 \\
76\end{array}$ & $\begin{array}{l}\text { Laticínios } \\
\text { Proteínas }\end{array}$ & $\begin{array}{c}1 \text { copo } \\
10 \%\end{array}$ & $\begin{array}{c}\text { Grupo das } \\
\text { Proteínas }(\mathrm{P})\end{array}$ & 140 & 1,5 \\
\hline $\begin{array}{l}\text { Óleos, gorduras } \\
\text { e castanhas } \\
\text { Sementes } \\
\text { (linhaça e } \\
\text { gergelim) }\end{array}$ & 73 & 1 & 73 & 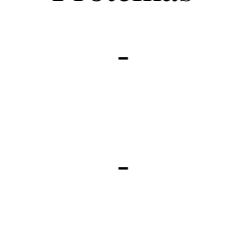 & - & - & 72 & 1 \\
\hline
\end{tabular}

*Esta distribuição atingiu 838 kcal e **Esta distribuição atingiu $842 \mathrm{kcal}$ 
Cabe ressaltar que a recomendação do Valor Energético Total (VET) do almoço é diferente para homens e mulheres. De acordo com Cervato et al. (1997) e Bonomo et al. (2003), as mulheres consomem em média um VET 29\% menor que os homens, pois em virtude de suas características antropométricas e biológicas, necessitam de menos energia para manter o corpo em equilíbrio. Com isso, a recomendação de porções do almoço foi reduzida em $29 \%$ para mulheres considerando à classificação apontada na Tabela III.

Os Grupos Alimentares foram convertidos de acordo com o tamanho e VET da porção média real das preparações, cuja recomendação está disposta na Tabela IV.

Tabela IV Recomendação das quantidades de porções dos grupos alimentares para homens e mulheres no almoço em restaurantes self service no Brasil, 2015.

\begin{tabular}{cccc}
\hline \multicolumn{2}{c}{ Grupo alimentar } & \multicolumn{2}{c}{ Quantidades de porções recomendadas } \\
\hline Nome do grupo & $\begin{array}{c}\text { Símbolo na placa de } \\
\text { identificação }\end{array}$ & Homem & Mulher \\
\hline Carboidratos & $\mathrm{C}$ & 2 porções & 1 porção \\
Proteínas & $\mathrm{P}$ & 1 porção & 1 porção \\
Feijão & $\mathrm{F}$ & 1 porção & 1 porção \\
Vegetais & $\mathrm{V}$ & 3 porções & 2 porções \\
Itens extras & Azeite de oliva & 1 fio pequeno & 1 fio pequeno \\
& Sementes & 1 colher de chá & 1 colher de chá \\
\hline
\end{tabular}

4) Terceiro critério de classificação - Ingredientes

O terceiro e último critério de classificação das preparações contempla a adição dos símbolos referentes ao glúten e à lactose, em virtude do crescimento da população com doença celíaca e intolerância à lactose (Zandonadi, 2012; Almada, 2013). Além disso, foram listados todos os itens inclusos na preparação como forma de esclarecer ao comensal a presença de possíveis ingredientes alergênicos como castanhas, crustáceos e corantes (Peyerl; De Matos, 2012).

Para classificar as preparações, cada placa recebeu dois símbolos. Um deles é com a letra "L" de lactose envolta em um círculo. Se o círculo estiver cortado com um traço na transversal, significa que não contém lactose. Caso não esteja com esse traço, contém lactose. O mesmo para o glúten, representado pela letra "G". Ambos os símbolos estavam explicados e detalhados em painéis expostos à frente do buffet, e as placas de identificação contendo essas informações estão dispostas na Figura I. 

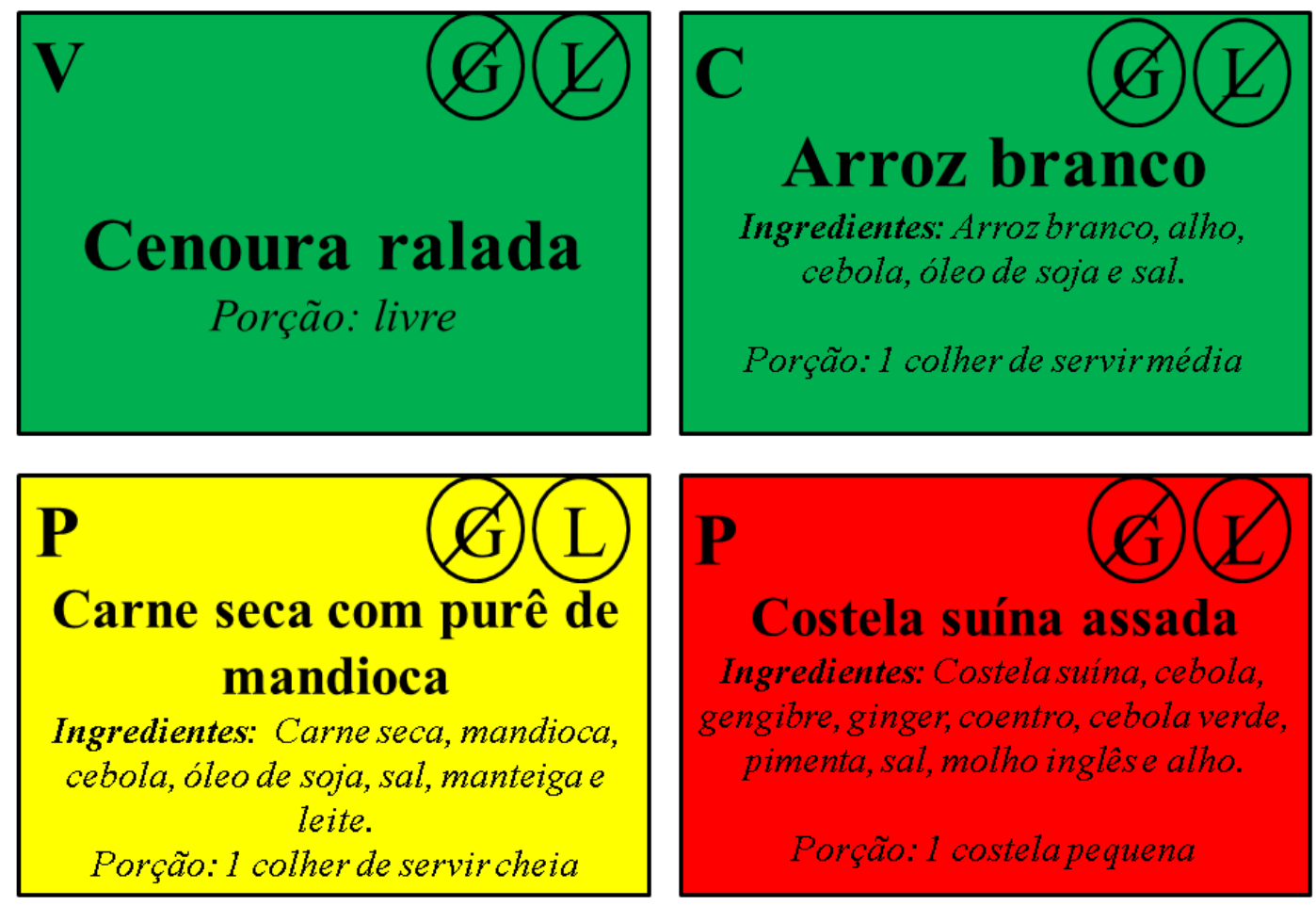

Figura I Modelos de placas de identificação das preparações

\section{5) Estratégias Educacionais}

Para divulgar a classificação das preparações, foram confeccionadas placas de identificação para cada alimento servido, impressas e plastificadas, medindo aproximadamente $7 \mathrm{~cm} \times 11 \mathrm{~cm}$ e posicionadas no buffet em local de fácil visibilidade, à frente de sua respectiva preparação. Essas placas levam uma das três cores - verde, amarelo ou vermelho, um código em letra caracterizando o grupo dos alimentos que se encontra, o nome da preparação, os ingredientes, o tamanho da porção que equivale a um código previamente adequado aos utensílios do restaurante e os símbolos "G" e "L".

Com o objetivo de explicar ao comensal essa medida de educação nutricional, dois painéis explicativos foram elaborados e posicionados próximo ao buffet do restaurante para orientar e explicar ao comensal como interpretar as informações dadas.

O primeiro painel continha: a imagem de uma placa de identificação modelo e a legenda de todos os itens que compuseram essa placa, sendo eles o grupo alimentar, o nome da preparação, os ingredientes, a porção ideal, a cor da placa e se continha ou não glúten e lactose. Além disso, continha a explicação do conceito associado a cada cor; as legendas sobre o que cada símbolo do grupo alimentar e de glúten e lactose representavam, a quantidade de “C, F, V e P" que poderiam ser consumidos para se 
obter um prato nutricionalmente equilibrado, de acordo com as necessidades energéticas da clientela em questão dividida por gênero.

A informação incentivando o consumo livre de folhosos também foi adicionada ao primeiro painel. Esse primeiro painel foi impresso colorido em folha de tamanho A4 e colocada uma cópia em todas as mesas do refeitório da UAN durante todo o período da metodologia.

O segundo painel foi formulado para incentivar a participação na pesquisa. Foram elaboradas frases curtas (quiz) e de impacto que mobilizasse o comensal - "Você sabia que diminuir o consumo de sódio e gordura reduz o risco de infartos e de obesidade?". O painel também direcionava os comensais a observarem o buffet e destacava as mudanças realizadas.

Cabe destacar que foram elaborados e registrados em fotografia quatro pratos de almoço, de acordo com a recomendação de porções apresentada na Tabela IV, para estimular os comensais a elaborarem seus pratos a semelhança do proposto.

Ainda no painel, foi informada aos leitores que no final da semana em questão seria realizada a aplicação dos questionários e que a adesão à participação era de grande importância. Para tal ação, dois Nutricionistas que trabalhavam no local e dois estagiários de Nutrição abordavam ativamente os comensais durante destacando e incentivando a leitura e adesão às práticas saudáveis.

\section{6) Análise e Tratamento de Dados}

Todas as análises foram realizadas com o apoio do programa SPSS (Statistical Package for Social Sciences) versão 21.0. Foram realizados teste normalidade da amostra, não tendo sido confirmado esses pressupostos $(\mathrm{p}<0,05)$. Foram realizadas análises descritivas (medidas de tendência central e variância.

\section{RESULTADOS}

Foram elaboradas 144 Fichas Técnicas de Preparação (FTPs), todas foram classificadas com as cores verde, amarelo e vermelho como descrito na metodologia. Os tipos de preparações que mais obtiveram parâmetros inadequados (cores amarelo e vermelho) foram os molhos para salada (100\%), arroz (71\%), sobremesas (68\%), pratos principais $(65 \%)$, e guarnições (64\%). Todas as sementes e frutas receberam a cor verde 
para incentivar o consumo, o feijão obteve $40 \%$ das FTPs inadequadas e as saladas 47\%. Os resultados estão dispostos na Tabela V.

Tabela V. Medidas de tendência central e variância da Densidade Energética, Teor de Sódio e porção por Tipo de Preparação de um restaurante self-service no Brasil, 2015.

\begin{tabular}{ccccc}
\hline $\begin{array}{c}\text { Tipos de } \\
\text { Preparações }\end{array}$ & $\begin{array}{c}\text { FTPs } \\
(\mathbf{n})\end{array}$ & $\begin{array}{c}\text { Densidade } \\
\text { energética } \\
(\mathbf{k c a l} / \mathbf{g})\end{array}$ & $\begin{array}{c}\text { Teor de sódio } \\
(\mathbf{m g} / \mathbf{1 0 0} \mathbf{g})\end{array}$ & $\begin{array}{c}\text { Porção } \\
(\mathbf{g})\end{array}$ \\
\cline { 2 - 5 } & & Média $\pm \mathbf{D P}$ & Média $\pm \mathbf{D P}$ & Média $\pm \mathbf{D P}$ \\
\hline Molhos para salada & 5 & $1,76 \pm 0,45$ & $876,26 \pm 805,70$ & 22,00 \\
Sementes & 2 & $0,34 \pm 0,08$ & $4,50 \pm 0,70$ & 4,50 \\
Sobremesas & 19 & $2,31 \pm 0.91$ & $61,34 \pm 48,47$ & 150,00 \\
Frutas & 4 & $0,38 \pm 0,09$ & $4,50 \pm 4,35$ & 75,00 \\
Pratos principais & 29 & $1,56 \pm 0,56$ & $439,60 \pm 260,75$ & 69,00 \\
Arroz & 7 & $1,61 \pm 0,34$ & $308,40 \pm 271,53$ & 103,00 \\
Feijão & 5 & $1,96 \pm 1,22$ & $330,80 \pm 286,82$ & 69,00 \\
Guarnição & 50 & $1,44 \pm 0,89$ & $282,30 \pm 263,89$ & 63,00 \\
Saladas & 23 & $0,83 \pm 0,55$ & $37,11 \pm 44,57$ & 102,00 \\
\hline Prato médio* & - & $\mathbf{1 , 3 5} \pm \mathbf{0 , 5 7}$ & $\mathbf{2 6 0 , 5 4} \pm \mathbf{2 8 2 , 7 5}$ & $\mathbf{4 3 2 , 0 0}$ \\
\hline
\end{tabular}

*As frutas e sobremesas não entraram no cálculo do prato médio total por não fazerem parte do conteúdo do prato médio do almoço do restaurante.

No geral, 88 FTPs (61\% das FTPs) obtiveram parâmetros inadequados (moderada e alta DE e TS). Destas 88 FTPs, 40\% $(n=35)$ estavam inadequadas exclusivamente pelo TS e 33\% ( $\mathrm{n}=29)$ estavam inadequadas exclusivamente pela DE. As demais $(\mathrm{n}=24)$ foram classificadas inadequadas pelos dois fatores.

De acordo com cada Tipo de Preparação, a inadequação das FTPs (por TS e/ou DE) era de $60 \%$ dos molhos para salada $(n=3), 40 \%$ dos feijões $(n=2), 21 \%$ das sobremesas $(n=4), 18 \%$ das guarnições $(n=9), 14 \%$ dos pratos principais $(n=4)$ e $13 \%$ das saladas $(\mathrm{n}=3)$.

O TS do prato médio (PM) é de 260,54 $\pm 282,75 \mathrm{mg} / 100 \mathrm{~g}$ de alimento, sendo que, para o peso do PM de 432 g, a quantidade de sódio total do PM é 1122,50 mg, um valor $22 \%$ acima do recomendado pelo PAT $(920 \mathrm{mg})$ no almoço. Sobre a quantidade de energia do PM, utilizando a DE para calcular o Valor Energético Total (VET) do PM encontrado neste estudo, obteve-se $593 \mathrm{kcal}$ (30\% do recomendado pelo PAT - 2000 kcal, $10 \%$ a menos). 


\section{DISCUSSÃO}

A quantidade excessiva de sódio em algumas preparações deveu-se aos ingredientes industrializados adicionados. Itens como molho shoyu, que possui um Teor de Sódio = $5453 \mathrm{mg} / 100 \mathrm{~g}$, linguiça calabresa $(1456 \mathrm{mg} / 100 \mathrm{~g})$, presunto $(1039 \mathrm{mg} / 100$ $\mathrm{g})$, maionese $(787 \mathrm{mg} / 100 \mathrm{~g})$, tomate seco $(655 \mathrm{mg} / 100 \mathrm{~g})$, queijo mussarela (581 $\mathrm{mg} / 100 \mathrm{~g})$, palmito enlatado $(563 \mathrm{mg} / 100 \mathrm{~g})$, extrato de tomate $(498 \mathrm{mg} / 100 \mathrm{~g})$, atum em lata (362 mg/100 g), milho e ervilha enlatados (260 mg/100 g e $372 \mathrm{mg} / 100 \mathrm{~g})$ e outros, eram ingredientes das preparações coletadas neste trabalho. Tais alimentos possuem grande quantidade de sódio em virtude deste nutriente ser tradicionalmente usado como conservante (TACO, 2011).

Cabe destacar que preparações características do consumo do brasileiro como feijão e arroz, embora não sejam acrescidos dos ingredientes mencionados anteriormente, tiveram seus teores de sódio majorados em virtude da excessiva quantidade de Cloreto de Sódio adicionado.

Os altos TS encontrados também foram observados por Ginani (2011) na análise da qualidade nutricional de cardápios de restaurante populares brasileiros. A autora apontou que $98,2 \%$ das preparações estudadas apresentavam alto TS e que a quantidade de sódio do almoço ofertado era 264\% maior que a recomendada pela WHO (920 mg) (WHO, 2005). O encontrado pela referida autora está acima do encontrado neste trabalho, que foi de $40 \%(\mathrm{n}=35)$ de FTPs inadequadas pelo quesito TS, possivelmente por conta do perfil dos comensais dos restaurantes populares ser diferente do perfil dos comensais deste trabalho, com alto nível educacional.

Sendo a quantidade total de sódio do PM de 1122,50 mg - 22\% acima do recomendado pelo PAT (920 mg) no almoço, os resultados para o sódio do presente trabalho indicam que a redução desse excedente $(24 \%)$ pode ser realizada de imediato sem nenhum prejuízo para a manutenção do consumo dos demais nutrientes conforme apontam os estudos que indicam uma redução de $30 \%$ no sódio como imperceptível ao paladar (Cobcroft et al., 2008; AWASH, 2011; Brasil, 2014).

O World Cancer Research Found recomenda como meta de saúde pública que o almoço deve oferecer em torno de 1,25 kcal/g de DE (WCRF, 2007), já o Centers of Disease Control and Prevention (CDC, 2005) classifica a DE ideal como abaixo de 1,5 $\mathrm{kcal} / \mathrm{g}$, valor que foi utilizado para classificação da metodologia. O valor da média 
dessas duas fontes é de $1,37 \mathrm{kcal} / \mathrm{g}$, valor muito próximo do encontrado neste estudo $(1,35 \pm 0,57)$, apontado que o PM servido no restaurante está adequada, no que tange a DE.

Os autores ingleses Cox e Mela (2000) encontraram valores semelhantes de DE ao do presente trabalho $(1,36 \mathrm{kcal} / \mathrm{g})$, com consumo alimentar por Recordatório Alimentar de 24 horas de 75 adultos durante quatro dias de pesquisa. A DE encontrada no estudo de Canella (2011), que calculou a DE do cardápio do almoço (1,43 kcal/g) de 21 restaurantes de São Paulo também se aproximou dos Parâmetros do WCRF (2007) e do CDC (2005).

Diferentemente, estudos realizados em São Paulo por Lipi (2008) obteve $\mathrm{DE}=1,94 \mathrm{kcal} / \mathrm{g}$ na dieta de funcionários de uma indústria, próximo do encontrado por Stella (2008) $(\mathrm{DE}=1,98 \mathrm{kcal} / \mathrm{g})$, estudo realizado com 710 adultos através de recordatório alimentar de 24 horas. Os autores norte-americanos Kant e Graubard (2005) encontraram $\mathrm{DE}=1,92 \mathrm{kcal} / \mathrm{g}$ no seu estudo com 13.400 consumidores de Nova York. Esses estudos encontraram um valor de DE maior que o encontrado neste trabalho, mostrando a inadequação do cardápio dessas localidades, além da preocupação com a oferta inadequada de nutrientes, em virtude de DE elevada no consumo diário está diretamente relacionada com o consumo também alto de gorduras totais, o que está ligado com o aparecimento de DACNT (Bells; Rolls, 2001; Drewnoski, 2003).

Em relação ao VET do PM encontrado nesse estudo estar $10 \%$ abaixo da recomendação, uma das razões possíveis para este resultado é que o perfil dos participantes deste trabalho é diferente do perfil dos trabalhadores do PAT, em virtude de terem nível educacional elevado, necessitando de menor valor energético no prato de almoço. Cabe notar que os estudos citados anteriormente não contemplam o valor do VET do PM e por isto não foram comparados aos resultados deste estudo.

Cabe destacar que 37\% $(\mathrm{n}=53)$ das FTPs estavam inadequadas no quesito DE, os macronutrientes que mais contribuíram para a densidade energética das preparações foram as gorduras e carboidratos de ingredientes como azeite de oliva e de dendê, creme de leite, iogurte integral, mel, manteiga, maionese, queijo mussarela, molho bechamel, linguiça calabresa, amendoim, uvas passas e açúcar. Tais ingredientes estão presentes em virtude do cardápio analisado ser do tipo Médio com algumas preparações formais. Podem-se usar estratégias de redução de gordura e carboidrato retirando ou substituindo os ingredientes de alguns tipos de preparação, como saladas e guarnições menos elaboradas, usando-se artifícios como substituição de itens, modificação de técnicas de 
preparo e associação das duas coisas. Além disso, o treinamento dos manipuladores é essencial para incorporação de técnicas que favorecem a adoção de FTPs saudáveis.

Algumas carnes utilizadas têm alto teor de gordura intrínseca como bisteca e costela suínas, contra-filé bovino e coxa e sobrecoxa de frango com pele (TACO, 2011). Essas carnes necessitam ter a gordura aparente retirada no pré-preparo, associada, na oferta aos comensais a alimentos de baixo teor de gordura e, quando possível, ofertadas com menos frequência no cardápio. Cabe destacar que houve adição excessiva de óleo de soja em algumas dessas preparações com o intuito de melhorar o sabor e facilitar o processo de cocção.

Apesar das saladas estarem relacionadas com a alimentação saudável, algumas saladas elaboradas continham ingredientes industrializados que aumentavam a DE e o TS desses pratos, como maionese, tomate seco, e o sal em excesso previamente adicionado nos processos de cocção (cozidos e assados). Um exemplo é a salada de abobrinha italiana assada, que levou azeite de oliva e sal e assim obteve a cor vermelha na sua placa de identificação por conta do elevado TS para aquele tipo de preparação.

Como discutido anteriormente, o TS recomendado para saladas é menor que o de pratos principais e guarnições, em virtude de não necessitarem desses aditivos para realçarem o sabor (Araújo et al., 2011). Já as saladas cruas e cozidas sem adição de nenhum ingrediente rico em sódio ou DE, ganharam a cor verde por serem naturalmente baixas em DE e TS. As sementes e as frutas foram classificadas pelo mesmo critério, obtiveram TS e DE baixos por não serem acrescidas de outro ingrediente.

Sabe-se, então, que um maior consumo de refeições fora do domicílio está positivamente associado com excesso de peso e obesidade entre adultos no Brasil (Canella et al., 2011). O sobrepeso, obesidade, diabetes, hipertensão, infartos e demais DACNT são cada vez mais frequentes no Brasil, e têm sido relacionadas ao aumento da oferta alimentar e ao consumo crescente de alimentos com alta DE e TS (Marchioni et al., 2012). Em virtude disso, as preparações ofertadas em um restaurante precisam ser modificadas para que se reduza o TS e DE e evite a consequente piora do quadro de DACNT no Brasil e em todo o mundo.

A quantidade de sódio excessiva encontrada nas preparações do restaurante deixa em evidência a importância de se promover estratégias que substituam estes ingredientes ricos em sódio sem prejudicar o sabor e a aceitação das preparações, como a utilização de temperos naturais (cebola, alho, ervas frescas - tomilho, orégano, louro, sálvia, cheiro verde, entre outros), a substituição dos vegetais enlatados por naturais 
(milho e ervilha in natura), do extrato de tomate pelo molho de tomate caseiro feito no próprio restaurante, diminuir a frequência da oferta de tomate seco, palmito, molho shoyu, preferir a utilização de peixes frescos ao invés de atum em lata, dessalgar a linguiça calabresa com cocção prévia, entre outras estratégias.

Para confirmar a validade dessas substituições, Menezes et al. (2013), em São Paulo, avaliou o impacto de substituir 1720 produtos tipicamente consumidos pela dieta brasileira por produtos de acordo com critérios que utilizam a alimentação saudável como parâmetro, apenas comparando os rótulos desses produtos (por exemplo, trocar o extrato de tomate industrializado pelo molho de tomate caseiro). A pesquisa apontou que essas substituições podem diminuir em 52\% o consumo de gordura saturada, $92 \%$ das gorduras trans, $14 \%$ da densidade energética e $47 \%$ do sódio, além de um aumento de $87 \%$ do consumo de fibras, melhorando o perfil nutricional da dieta.

Portanto, a técnica dietética associada a técnicas culinárias adequadas são estratégias eficazes para incrementar tais mudanças. Algumas dessas estratégias foram testadas e publicadas por diversos autores (Araújo et al., 2011; Camargo; Botelho, 2012; Frantz et al., 2013) e o Guia de Boas Práticas Nutricionais para Restaurantes Coletivos da ANVISA (Brasil, 2014).

\section{CONCLUSÃO}

Este artigo elaborou uma metodologia de educação nutricional que englobou a classificação das preparações servidas no buffet de almoço de um restaurante selfservice e a exposição das informações de qualidade nutricional de cada preparação.

$\mathrm{Na}$ classificação das preparações do buffet (cores amarelo e vermelho), observou-se que as preparações com maiores parâmetros inadequados foram os molhos para salada, arroz, sobremesas, pratos principais e guarnições, e menores no feijão e saladas. No geral, mais da metade das FTPs obtiveram parâmetros inadequados (moderada e alta DE e TS), sendo a maioria por conta do TS. A média da DE foi adequada quando comparada com a média da recomendação. Já a média do TS encontrado foi elevada quando comparada às recomendações do PAT e da OMS, apontando a necessidade de redução do teor de sódio das preparações e podendo ser reduzida em $30 \%$ de imediato, como aponta a literatura. 
Como limitações de estudo, este trabalho desenvolveu as FTPs de uma semana de cardápio por conta da grande variedade de preparações servidas diariamente, sendo que o cardápio do restaurante era mensal.

Com isso, os resultados deste estudo devem incentivar os restaurantes a elaborarem as FTPs de todo o seu cardápio para que o público conheça o alimento que está sendo ofertado, utilizar as FTPs como itens permanentes e de suporte na produção de alimentos e fornecer informações nutricionais cuja abordagem deve adotar os pressupostos das metodologias ativas.

\section{REFERENCIAL BIBLIOGRÁFICO}

AKUTSU, R. C., BOTElho, R. A., CAMARgo, E. B., SÁViO, K. E. O., ARAÚJO, W. C. A ficha técnica de preparação como instrumento de qualidade na produção de refeições. Revista de Nutrição, Campinas, v. 18, n. 2, p. 277-9, 2005.

ALMADA, Eid da Rosa. Substitutos de leite condensado a partir de extratos vegetais. 2013. 39 f., il. Monografia (Bacharelado em Nutrição)—Universidade de Brasília, Brasília, 2013.

AWASH - Australian Division of the World Action on Salt \& Health. The George Institute for Global Health: Interim Australian targets for sodium levels in 85 food categories. Camperdown, NSW: George Institute for Global Health; 2011.

BONOMO, É.; CAIAFFA, W. T.; CÉSAR, C. C.; LOPES, A. C. S.; LIMA-COSTA, M. F. Consumo alimentar da população adulta segundo perfil sócio-econômico e demográfico: Projeto Bambuí. Cad. Saúde Pública, Rio de Janeiro, v. 19, n. 5, p. 14611471, 2003.

BRASIL, Instituto Brasileiro de Geografia e Estatística. Pesquisa de Orçamentos Familiares 2008-2009: Análise do consumo alimentar pessoal no Brasil. Rio de Janeiro: IBGE, 2011.

BRASIL. Agência Nacional de Vigilância Sanitária - ANVISA. Guia de Boas Práticas Nutricionais: Restaurantes Coletivos. Brasília, 2014, 44 p.

BRASIL. Ministério da Saúde. Secretaria de Atenção à Saúde. Guia alimentar para a população brasileira: promovendo a alimentação saudável / Ministério da Saúde, Secretaria de Atenção à Saúde. - Brasília: Ministério da Saúde, 2008. 210 p. - (Série A. Normas e Manuais Técnicos). 
BRASIL. Ministério da Saúde. Secretaria de Atenção à Saúde. Guia alimentar para a população brasileira: promovendo a alimentação saudável / Ministério da Saúde, Secretaria de Atenção à Saúde. - Brasília: Ministério da Saúde, 2014. 151 p. - (Série A. Normas e Manuais Técnicos).

BRASIL. Portaria Interministerial no 66, de 25 de agosto de 2006. Altera os parâmetros nutricionais do Programa de Alimentação do Trabalhador - PAT. Publicada no D. O. U. de 28 de agosto de 2006.

CAMARGO, E; BOTELHO, R.B.A.; Técnica Dietética - Pré-preparo e preparo de alimentos. São Paulo: Editora Atheneu, 2012.

CAMOSSA, A. C. A.; COSTA, F. N. A.; OliveIRA, P. F. O.; FIGUEIREDO, T. P. Educação nutricional: uma área em desenvolvimento. Alimentação e Nutrição, São Paulo, v. 16, p. 349-54, 2005.

CARVALHO, A. P. OLIVEIRA, V.B.; SANTOS, L.C. Hábitos alimentares e práticas de educação nutricional: atenção a crianças de uma escola municipal de Belo Horizonte, Minas Gerais. Pediatria (São Paulo), São Paulo, v. 32, n. 1, p. 20-7, 2010.

CASTELO-BRANCO, N.S.D. Análise da alimentação fora do domicílio de consumidores do centro comercial do Município do Rio de Janeiro - RJ. 2000, 100 f. il. Tese (Doutorado em Ciências da Nutrição) - Faculdade de Engenharia de Alimentos da Universidade Estadual de Campinas. Campinas, 2000.

CDC - Centers Of Disease Control And Prevention. Can eating fruits and vegetables help people to manage their weight? National Center for Chronic Disease Prevention and Health Promotion. Division of Nutrition and Physical Activity. (Research to pratice series, $\left.n^{\circ} 1\right)$. USA, 2005.

CERVATO, A. M., MAZZILLI, R. N., MARTINS, I. S., MARUCCI, M. F. N. Dieta habitual e fatores de risco para doenças cardiovasculares. Rev. Saúde Pública, São Paulo, v. 31, n. 3, p. 227-35, 1997.

CFN - CONSELHO FEDERAL DE NUTRICIONISTAS. Inserção profissional dos nutricionistas no Brasil. Brasília: CFN, 2006.

COBCROFT, M.; TIKELLIS, K.; BUSCH, J.L.H.C. Salt reduction - a technical overview. Food Australia, Sydney, v. 60, p. 83-86, 2008.

FRANTZ, C. B.; VEIROS, M. B.; PROENÇA, R. P. C.; SOUSA, A. A. Development of a method for controlling salt and sodium use during meal preparation for food services. Rev. Nutr., Campinas, v. 26, n. 1, p. 75-87, 2013. 
IBGE - Instituto Brasileiro de Geografia e Estatística. Pesquisa de orçamentos familiares 2008-2009: tabelas de composição nutricional dos alimentos consumidos no Brasil. Rio de Janeiro; 2011.

LANDABURE, P. B. Pedro Escudero: his thoughts, his doctrine and his works. Med. Argent, Argentina, v. 55, p. 1983-9, 1968.

LEVIN, J. Estatística Aplicada às Ciências Humanas. São Paulo: Harper \& Row do Brasil, 1987. 520 p.

LIPI, M. Densidade energética da dieta de trabalhadores de uma indústria da região metropolitana de São Paulo [dissertação de mestrado]. São Paulo: Faculdade de Saúde Pública da Universidade de São Paulo; 2008.

MAGNEÉ, H.M. Manual do self-service. São Paulo: Livraria Varela, 1996. 242p.

MILLS, J. E.; CLAY, J. M. The truth-in-menu law and restaurant consumers. Foodservice Research International, Estados Unidos, v. 13, p. 69-82, 2001.

NIELD, K.; KOZAK, M.; LEGRYS, G. The role of food service in tourist satisfaction. Hospitality Management, Estados Unidos, v. 19, p. 375-384, 2000.

OLIVEIRA, C. S.; ALVES, F. S. Educação nutricional em unidade de alimentação e nutrição, direcionada para consumo de pratos protéicos: um estudo de caso. Alim. Nutr., Araraquara, v. 19, n. 4, p. 435-440, 2008.

PASCHOA, M. F. Alimentação Escolar: Um Enfoque em Alimentos Funcionais. Revista Nutrição Profissional, São Paulo, v. 1, n. 1, p. 31-36, 2005.

PEREIRA, M. G. Epidemiologia: Teoria e prática. $4^{\mathrm{a}}$ ed. Guanabara Koogan: Rio de Janeiro; 2008.

PEYERL, F. F.; DE MATOS, K. H. O. Avaliação da legislação aplicada a rotulagem de alimentos embalados no Brasil e na Nova Zelância. Revista E-Tech: Tecnologias para Competitividade Industrial, Florianópilis, e. Esp. Alimentos, p. 14-25, 2012.

PROENÇA, R.P.C. Inovação tecnológica na produção de alimentação coletiva. 2.ed. Florianópolis: Editora Insular, 2000.

RAMOS, F. P.; SANTOS, L. A. S.; REIS, A. B. C. Educação alimentar e nutricional em escolares: uma revisão de literatura. Cad. Saúde Pública, Rio de Janeiro, v. 29, n. $11,2013$.

SAVIO, K. E. O.; COSTA, T. H. M.; MIAZAKI, E.; SCHMITZ, B. A. S. Avaliação do almoço servido a participantes do programa de alimentação do trabalhador. Rev. Saúde Pública, São Paulo, v. 39, n. 2, 2005. 
SCHOLDERER, J. BRUNSO, K; BREDAHL, L; GRUNERT, K.G. Cross-cultural validity of the food-related lifestyles instrument (FRL) within Western Europe. Appetite, Dinamarca, v. 42, p. 197- 211, 2004.

STABLES, G. Changes in vegetable and fruit consumption and awareness among US adults: results of the 1991 and 1997 - 5 A Day for Better Health Program surveys. $J$ Am Diet Assoc, Estados Unidos, v. 102, n. 6, p. 809-817, 2002.

TACO. Tabela Brasileira de Composição de Alimentos (2011) Nepa-Unicamp. 4nd Edition, NEPA-UNICAMP, Campinas.

TORAL, N.; SLATER, B.. Abordagem do modelo transteórico no comportamento alimentar. Ciênc. saúde coletiva, Rio de Janeiro, v. 12, n. 6, 2007.

TRICHES, R. M.; GIUGLIANI, E. R. J. Obesidade, práticas alimentares e conhecimentos de nutrição em escolares. Rev. Saúde Pública, São Paulo, v. 39, n. 4, p.541-547, 2005.

TRIOLA, M. F. Introdução à Estatística. Rio de Janeiro: LTC, 1999. 576 p.

TSE, A. C. B.; SIN, L.; YIN, F. H. K. How a crowded restaurant affects consumers' attribuition behavior. Hospit Manag.; Estados Unidos, v. 21, n. 4, p. 449-54, 2002.

USDA - Department of Agriculture, Foreign Agricultural Service (USDA), 2011. Production, Supply and Distribution Online Database. 2011.

ZANDONADI, R. P.; BOTELHO, R. A.; GANDOLFI, L.; GINANI, J. S.; MONTENEGRO, F.; PRATESI, R. Green Banana Pasta: An Alternative for GlutenFree Diets. Journal of the American Dietetic Association, Brasília, v. 11, p. 1068-72, 2012.

ZANDONADI, R. P.; BOTELHO, R. B. A.; GINANI, V. C.; AKUTSU, R. C. C. A.; SÁVIO, K. E. O.; ARAÚJO, W. M. C. Sodium and health: New proposal of distribution for major meals. Health, Brasília, v. 6, n. 3, p. 195-201, 2014. 


\title{
4.3 ARTIGO 3 - AVALIAÇÃO DE ESTRATÉGIA DE EDUCAÇÃO NUTRICIONAL EM RESTAURANTE SELF-SERVICE
}

\author{
Larissa MAZOCCO
}

Raquel Bráz Assunção BOTELHO

Izabel Cristina Rodrigues da SILVA

Rita de Cássia Coelho Almeida AKUTSU

\section{RESUMO}

Objetivo - O objetivo deste estudo é avaliar a estratégia educativa de classificação de cardápios em restaurante self-service.

Metodologia - $\mathrm{O}$ desenho de estudo é de intervenção e randomizado. O trabalho foi dividido em três etapas, sendo elas a aplicação de uma metodologia de classificação de cardápios, desenvolvimento e aplicação do instrumento de percepção e análise dos dados.

Resultados e discussão - Os participantes da pesquisa eram 52,5\% do sexo feminino, com média de idade de $37 \pm 15,2$ anos e 52,1\% com pós-graduação. Foram elaboradas 144 Fichas Técnicas de Preparação e classificadas com as cores verde, amarelo e vermelho de acordo com a DE e TS, com 61,1\% de inadequação. Dos participantes, $86,3 \%$ observaram a metodologia no restaurante e 54,5\% mudaram suas escolhas alimentares. Houve diferença significativa entre os que afirmaram que mudaram a escolha alimentar e os que não mudaram comparados ao número de itens que mais chamaram atenção na metodologia $(\mathrm{p}=0,033)$, favorecendo a mudança da escolha alimentar.

Conclusão: A metodologia proposta foi validada, afirmando que a mudança da escolha alimentar pode estar associada às informações nutricionais fornecidas.

Palavras-chave: Educação nutricional, densidade energética, sódio, Ficha Técnica de Preparação, cardápio, restaurante, escolha alimentar, informação nutricional.

Tipo do Artigo: Pesquisa original 


\section{ABSTRACT}

Purpose - The purpose of this study is to evaluate the educational strategy of menus classification self-service restaurant.

Methodology - The study design is randomized intervention. The work was divided into three stages, these being the application of menus rating methodology, development and application of the instrument of perception and analysis of data.

Results and discussion - Survey participants were 52.5\% female, with a mean age of $37 \pm 15.2$ years and $52.1 \%$ with graduate degrees. 144 Preparation Technical Files preparation were prepared and classified with the colors green, yellow and red according to the density energy and sodium content, with $61.1 \%$ of inadequacy. Of the participants, $86.3 \%$ noted the methodology in the restaurant and $54.5 \%$ changed their food choices. There was a significant difference between those who said they changed the food choice and those who have not changed compared to the number of items that most drew attention in the methodology $(\mathrm{p}=0.033)$, favoring the change in food choice.

Conclusion - The proposed methodology has been validated, stating that the change in food choice may be associated with nutritional information provided.

Keywords - nutrition education, energy density, sodium, Preparation Technical File, menu, restaurant, food choice and nutritional information.

Article Type - Original Research 


\section{INTRODUÇÃO}

O sobrepeso e a obesidade, segundo dados atuais da Vigilância de Fatores de Risco e Proteção para Doenças Crônicas por Inquérito Telefônico - VIGITEL (VIGITEL, 2011) têm sua porcentagem em ascendência no Brasil, sendo de $43 \%$ na população em 2006 e de 49\% em 2011. É um dado alarmante, visto que essa comorbidade também pode levar ao aparecimento de outras doenças, como a hipertensão, diabetes mellitus, entre outras. A hipertensão arterial atinge adultos cada vez mais jovens, chegando a um quarto da população adulta mundial, podendo chegar a 1,56 bilhões de pessoas até 2025 (BRITO et al., 2011).

No Brasil estima-se que existem cerca de 17 milhões de portadores de hipertensão arterial, dos quais 35\% possuem idade igual ou superior a 40 anos. O sódio, quando consumido em excesso, é considerado um grande contribuinte dessa doença (BRITO et al., 2011).

Devido ao aumento da incidência das doenças oriundas da má alimentação e da falta de conhecimento de grande parte da população sobre formas de prevenção, eleva-se a demanda por estratégias de mudança de práticas e comportamentos individuais cujo objetivo seja a alimentação saudável (CERVATO et al., 2005). Assim, o papel da promoção da saúde, incluindo a educação nutricional, como estratégia no combate a esses problemas é essencial, sendo o nutricionista o responsável pela promoção da saúde por meio da realização de práticas educativas (CFN, 2006; SOUSA, 2005).

Atualmente, a sociedade moderna industrializada pouco facilita ao trabalhador o seu deslocamento até sua residência para a realização de suas refeições, por isto os trabalhadores buscam se alimentar ou no próprio local de trabalho ou em restaurantes próximos. Sendo assim, os restaurantes precisam ofertar uma alimentação equilibrada, de acordo com as recomendações nutricionais e adotar estratégias para que o cliente escolha uma alimentação saudável (CAMOSSA et al., 2005; CFN, 2006; SOUSA, 2005).

Propostas educativas em nutrição para atendimentos em grupos têm por objetivo tornar o ambiente interativo e facilitador de aprendizagem. No trabalho em grupo é possível observar a reflexão dos membros do grupo sobre as suas práticas, com a possibilidade de intervenções lúdicas que facilitem e consolidem as mudanças de 
práticas, proporcionando assim melhor qualidade de vida (ALVAREZ; ZANELLA, 2009).

Os restaurantes necessitam adotar estratégias para formular cardápios que atendam a coletividade favorecendo a adoção de práticas alimentares saudáveis. Uma dessas estratégias é o Guia Alimentar para a População Brasileira (BRASIL, 2008)e por se tratar de um documento gerado pelo Ministério da Saúde e indicado para esse fim. Esse instrumento também permite que sejam realizadas boas escolhas alimentares, com base em princípios comprovados pela ciência da nutrição e de fácil entendimento por parte de profissionais e leigos (BRASIL, 2008).

Nos Estados Unidos, o guia alimentar para americanos do norte foi revisado em 2010, tendo a pirâmide alimentar sido substituída pelo My Plate, figura que apresenta as recomendações de porções alimentares em função da idade e das necessidades energéticas da população. O My Plate também é usado como apoio para estratégias de educação nutricional desta mesma a população (USDA, 2011).

Na prática, o porcionamento apresentado pelo Guia Alimentar brasileiro e pelo My Plate se refere à equivalência entre alimentos, determinando uma quantidade necessária de certo gênero alimentício ou preparação a fim de que seja possível sua substituição, mantendo o mesmo fornecimento qualitativo e quantitativo de nutriente. Entretanto, a quantificação das porções é dependente da necessidade energética do indivíduo. Em restaurantes esta quantificação é definida por meio das necessidades energéticas advindas da média obtida a partir da avaliação nutricional da clientela.

No Brasil, além do Guia Alimentar, também são usadas as normas do Programa de Alimentação do Trabalhador (BRASIL, 2006) para referenciar a porcentagem de energia necessária nas refeições de trabalhadores em restaurantes. Além disso, são necessários outros aliados para que o trabalho do Nutricionista ganhe maior qualidade, como a utilização das Fichas Técnicas de Preparação - FTPs, baseada sempre os quatro princípios de Pedro Escudero de qualidade, quantidade, harmonia e adequação dos nutrientes dos alimentos (LANDABURE, 1968; AKUTSU et al., 2005; BRASIL, 2008; CAMARGO; BOTELHO, 2012). Em virtude disso, o objetivo deste estudo é avaliar a estratégia educativa de classificação de cardápios em restaurante selfservice. 


\section{METODOLOGIA}

O desenho de estudo é de intervenção e randomizado (PEREIRA, 2008). Para aplicação da metodologia foi selecionado um restaurante por conveniência do tipo selfservice por quilo. O restaurante escolhido está localizado no centro de Brasília - DF e atende em torno de 1000 comensais no almoço de segunda a sexta-feira, sendo a grande maioria de trabalhadores do local - o restaurante é do tipo institucional. A amostra da população do restaurante foi de 600 comensais utilizando um nível de confiança de $95 \%$ e um erro amostral de 4\% (LEVIN, 1987; TRIOLA, 1999; PEREIRA, 2008).

Os critérios de inclusão dos comensais para participarem da pesquisa foram almoçar no restaurante pelo menos uma vez na semana ou mais e ter idade maior ou igual a 18 anos; foram excluídos da pesquisa os comensais que trazem seu próprio almoço para o trabalho e aqueles que optam pela marmita vendida pelo restaurante. Para avaliar a intervenção foi aplicado um instrumento de percepção aos comensais, o questionário. Os comensais foram abordados aleatoriamente no horário de almoço na entrada do restaurante e apresentado ao projeto de pesquisa com seus objetivos, e com o pedido de assinatura do Termo de Consentimento Livre e Esclarecido (TCLE) e o questionário impresso. O projeto foi aprovado pelo Comitê de Ética em Pesquisa da Faculdade de Ciências da Saúde da Universidade de Brasília - CEP/FS - UnB com Termo de Aprovação de Projeto de Pesquisa Parecer n ${ }^{\circ}$ 1.081.189. A metodologia deste trabalho foi desenvolvida em três etapas.

\section{1) Aplicação da metodologia de classificação de cardápios}

Para realização do presente trabalho, foi utilizada a metodologia de classificação de cardápios desenvolvida por Mazocco et al. (No prelo, 2015). Foram elaboradas 144 Fichas Técnicas de Preparação e classificadas de acordo com o Teor de Sódio e Densidade Energética (contemplados na FTP através de uma das cores do semáforo), Grupo Alimentar, Porção Recomendada e se contém ou não glúten e lactose, e disponibilizados através de estratégias educacionais descritas na metodologia (placas de identificação, painéis e metodologia ativa de educação nutricional).

\section{2) Desenvolvimento e Aplicação do Instrumento de Percepção}


Foi desenvolvido um instrumento de acordo com a necessidade da pesquisa no formato de questionário Este contempla os dados demográficos, a frequência que o comensal almoça no restaurante, a percepção acerca da intervenção, a clareza dos instrumentos de educação, a intensidade de mudança na escolha alimentar e os itens observados pelo comensal durante a pesquisa.

Durante uma semana de segunda a sexta-feira, todas as preparações e itens do buffet foram identificados com suas respectivas placas de identificação. No último dia da semana, foi aplicado o questionário impresso junto com o TCLE no horário do almoço. Foram distribuídos 1000 questionários, sendo 603 respondidos, 100 deixados em branco e o restante não foi devolvido. Dos 603 respondidos, 47 não cumpriram os critérios de inclusão contemplados e foram excluídos, restando 556 questionários válidos.

\section{3) Análise e Tratamento de Dados}

Todas as análises foram realizadas com o apoio do programa SPSS (Statistical Package for Social Sciences) versão 21.0. Foram realizados teste normalidade da amostra, não tendo sido confirmado esses pressupostos. Foram realizadas análises descritivas (medidas de tendência central e variância. Foi obtido o Odds Ratio (OR) de todos os dados, assim como o Intervalo de Confiança (IC) e o coeficiente de Correlação de Pearson, utilizando o valor de $\mathrm{p}<0,05$ como resultado significativo.

\section{RESULTADOS}

\section{Sujeitos de pesquisa}

Os dados sócio demográficos dos participantes revelaram que 52,5\% ( $\mathrm{n}=252)$ eram do sexo feminino e $44 \%$ tinham idade até 35 anos $(n=211)$. A média de idade foi de $37 \pm 15,2$ anos, $52,1 \%$ têm pós-graduação $(n=250), 61,9 \%$ têm companheiro(a) $(n=$ 297) e 48,1\% têm filhos $(\mathrm{n}=128)$.

\section{Respostas do questionário}

No total, foram respondidos 556 questionários. Desses, 86,3\% $(\mathrm{n}=480)$ observaram as estratégias de educação nutricional adotadas. Todas as respostas do questionário foram comparadas estatisticamente com a reposta da pergunta principal 
"você mudou sua escolha alimentar do seu prato de almoço depois de ler as placas de identificação dos pratos servidos no buffet?", denominada "pergunta-chave". Dos 480 participantes que notaram a estratégia, 54,5\% marcaram a opção "sim" a perguntachave.

Houve diferença significativa entre os que afirmaram que mudaram a escolha alimentar e os que não mudaram a escolha quando comparado ao número de itens que mais chamaram atenção na metodologia em questão, como apresenta a Tabela I. Esses itens eram a informação da porção ideal de cada preparação, o uso das cores (vermelho, amarelo e verde) como indicador, a indicação da quantidade de porções de proteína, carboidrato, vegetal e sobremesa por pessoa, avisos de contém ou não glúten e lactose a opção 'outros' para descrever mais algum item. O fato de três ou mais itens terem chamado a atenção dos indivíduos favoreceu a mudança da escolha alimentar. Esse favorecimento foi significante $(\mathrm{p}=0,033)$ e aumentou a chance da mudança da escolha alimentar ocorrer em 1,7 vezes. 
Tabela I. Variáveis sóciodemográficas e educacionais comparadas à mudança da escolha alimentar dos participantes através da Odds Ratio, Intervalo de Confiança e Coeficiente de Pearson de um restaurante self-service no Brasil, 2015

\begin{tabular}{|c|c|c|c|c|c|c|c|c|}
\hline & \multicolumn{4}{|c|}{ Mudou a escolha alimentar } & \multirow[b]{3}{*}{ OR* } & \multirow[b]{3}{*}{ IC** } & \multirow[b]{3}{*}{$\mathbf{P}^{* * * *}$} \\
\hline & & \multicolumn{2}{|c|}{ Não } & \multicolumn{2}{|c|}{ Sim } & & & \\
\hline & & $\mathbf{N}$ & $\%$ & $\mathbf{N}$ & $\%$ & & & \\
\hline \multirow{3}{*}{ Sexo } & Feminino & 113 & $52,07 \%$ & 139 & $53,46 \%$ & 1,06 & $0,73-1,54$ & 0,783 \\
\hline & Masculino & 104 & $47,93 \%$ & 121 & $46,54 \%$ & & & \\
\hline & Total & 217 & & 260 & & & & \\
\hline \multirow{3}{*}{ Faixa etária } & Até 35 anos & 93 & $50,00 \%$ & 118 & $54,63 \%$ & 1,2 & $0,79-1,82$ & 0,369 \\
\hline & 36 ou mais & 93 & $50,00 \%$ & 98 & $45,37 \%$ & & & \\
\hline & Total & 186 & & 216 & & & & \\
\hline \multirow{3}{*}{ Escolaridade } & Graduado & 91 & $42,72 \%$ & 131 & $50,58 \%$ & 1,37 & $0,94-2,01$ & 0,096 \\
\hline & Pós-graduado & 122 & $57,28 \%$ & 128 & $49,42 \%$ & & & \\
\hline & Total & 213 & & 259 & & & & \\
\hline \multirow{3}{*}{ Estado civil } & Com companheiro & 143 & $67,45 \%$ & 154 & $61,35 \%$ & 0,77 & $0,51-1,15$ & 0,175 \\
\hline & Sem companheiro & 69 & $32,55 \%$ & 97 & $38,65 \%$ & & & \\
\hline & Total & 212 & & 251 & & & & \\
\hline \multirow{3}{*}{ Filhos } & Com filhos & 108 & $51,67 \%$ & 120 & $48,00 \%$ & 0,86 & $0,59-1,27$ & 0,454 \\
\hline & Sem filhos & 101 & $48,33 \%$ & 130 & $52,00 \%$ & & & \\
\hline & Total & 209 & & 250 & & & & \\
\hline \multirow{3}{*}{$\begin{array}{l}\text { Frequência que } \\
\text { almoça no local }\end{array}$} & Até $2 x$ na semana & 23 & $10,75 \%$ & 45 & $17,51 \%$ & 1,76 & $1-3,13$ & 0,051 \\
\hline & De 3 a $5 x$ na sem. & 191 & $89,25 \%$ & 212 & $82,49 \%$ & & & \\
\hline & Total & 214 & & 257 & & & & \\
\hline \multirow{3}{*}{$\begin{array}{l}\mathrm{N}^{\circ} \text { de itens da } \\
\text { metodol. que } \\
\text { chamou atenção }\end{array}$} & Até 2 itens & 184 & $85,58 \%$ & 202 & $77,69 \%$ & 0,59 & $0,35-0,97$ & $\mathbf{0 , 0 3 3}$ \\
\hline & 3 itens ou mais & 31 & $14,42 \%$ & 58 & $22,31 \%$ & & & \\
\hline & Total & 215 & & 260 & & & & \\
\hline \multirow{3}{*}{$\begin{array}{l}\text { Clareza da } \\
\text { metodologia }\end{array}$} & $\begin{array}{l}\text { Não entendi nada a } \\
\text { entendi moderad. }\end{array}$ & 79 & $36,41 \%$ & 76 & $29,34 \%$ & 0,73 & $0,49-1,09$ & 0,116 \\
\hline & $\begin{array}{c}\text { Entendi muito a } \\
\text { entendi completam. }\end{array}$ & 138 & $63,59 \%$ & 183 & $70,66 \%$ & & & \\
\hline & Total & 217 & & 259 & & & & \\
\hline \multirow{3}{*}{$\begin{array}{l}\text { O que mudou } \\
\text { no prato após a } \\
\text { metodologia }\end{array}$} & Até 1 item & 9 & $100,00 \%$ & 188 & $74,90 \%$ & 0 & $0-1,82$ & 0,119 \\
\hline & 2 itens ou mais & 0 & $0,00 \%$ & 63 & $25,10 \%$ & & & \\
\hline & Total & 9 & & 251 & & & & \\
\hline \multirow{3}{*}{$\begin{array}{l}\text { O que faltou na } \\
\text { metodologia }\end{array}$} & Até 1 item & 61 & $77,22 \%$ & 130 & $84,42 \%$ & 1,59 & $0,76-3,33$ & 0,208 \\
\hline & 2 itens ou mais & 18 & $22,78 \%$ & 24 & $15,58 \%$ & & & \\
\hline & Total & 79 & & 154 & & & & \\
\hline
\end{tabular}

*OR: Odds Ratio ; IC: Intervalo de Confiança; P: Coeficiente de Pearson.

Sobre os itens que mais chamaram atenção na metodologia, 34\% das respostas mostraram que o que mais chamou a atenção dos comensais foi o uso das cores (verde, amarelo e vermelho) como indicador de qualidade nutricional, relacionando os valores de DE e TS. Em segundo lugar, 29\% dos comensais marcaram que a informação da porção ideal também chamou atenção, seguido de 20,5\% que marcaram que os símbolos de contém ou não glúten e lactose também chamaram atenção. Nessa questão, os comensais podiam marcar mais de uma opção caso desejasse, resultando que $78 \%$ dos 
comensais que mudaram sua escolha alimentar marcaram até dois itens que mais chamaram atenção. Essa porcentagem alta também ocorreu para quem não mudou a escolha alimentar, e $86 \%$ dos comensais marcaram que até dois itens chamaram atenção na metodologia. No entanto, as variáveis sociodemográficas não interferiram significativamente na resposta da pergunta-chave.

Sobre a intensidade da mudança da escolha alimentar, 62\% dos participantes marcaram uma das opções "mudei moderadamente", "mudei muito" e "mudei completamente". O principal item marcado sobre o que mudou no prato do almoço foi "coloquei mais salada do que geralmente me sirvo" (27\%) seguido de "o meu prato está mais leve (mais barato)" com 22\% e por fim, "escolhi os com menos sal (verdes)" com $21 \%$, totalizando $70 \%$ das respostas.

Em relação à clareza da metodologia, 67\% dos participantes entenderam a metodologia com facilidade. A frequência com que o comensal almoçava no restaurante também não teve relação com a pergunta-chave, mesmo com o valor de $p=0,051$. A grande maioria (84\%) dos participantes almoçava no restaurante de três a cinco vezes na semana, mostrando que a frequência não influenciou na resposta da pergunta-chave.

$\mathrm{O}$ instrumento abordava ainda o participante e indagava sobre itens que eles identificavam como ausentes na metodologia, sendo eles informações sobre outros nutrientes (vitaminas, minerais, etc), o tamanho da letra estava pequeno, as cores não deixaram claro o que deve escolher, poderia usar outras cores e a opção 'outros' para descrever mais algum item.

Sendo assim, $41 \%$ das respostas (com 51,4\% de absenteísmo) marcaram apenas um item, sendo que $38,7 \%(n=110)$ optaram pelo item "falta de informação sobre vitaminas e minerais". Para o item "o tamanho da letra estava pequeno", 29,6\% (n=84) marcaram esta opção.

\section{DISCUSSÃO}

A partir dos dados de que houve diferença significativa entre a mudança da escolha alimentar e o número de itens que mais chamaram atenção do participante, observa-se que a informação nutricional associada a metodologia ativa está relacionada com a mudança na escolha alimentar, assim como encontrado nos estudos de Jomori, (2006); Hwang; Lorenzen, (2008); Yang et al., (2009); Caliskan; Ozdemir, (2013). Essas pesquisas mostram que quando um cardápio contém as informações nutricionais 
pertinentes às suas preparações, isso aumenta as percepções de sabor, valor, qualidade e aspectos saudáveis da comida, o que influencia diretamente o comportamento do comensal sobre aquele alimento.

Um estudo americano semelhante a este trabalho objetivou identificar as informações nutricionais preferidas em um cardápio e se a exposição dessas informações teria influência nas escolhas alimentares saudáveis com 180 participantes com média de idade de 43 anos e que almoçavam fora de casa cerca de 2,44 vezes por semana. Os pesquisadores identificaram que os participantes preferiam alimentos que continham a informação "baixo em gordura" e de quantidade de calorias e de macronutrientes. Os autores comprovaram que quando os restaurantes fornecem a informação nutricional para escolhas mais saudáveis de preparações, os comensais estão mais propensos a reconhecer esses itens saudáveis e trocarem as opções não-saudáveis (HWANG; LORENZEN, 2008).

Outro estudo americano semelhante realizado com 304 participantes em dois restaurantes objetivou analisar a relação entre as pessoas que geralmente leem os rótulos de alimentos industrializados e as atitudes sobre as informações nutricionais dadas em cardápios de restaurantes, juntamente com o conteúdo calórico desses pratos do cardápio, e concluiu que os consumidores que têm costume de ler o rótulo dos alimentos já estão propensos a fazerem escolhas mais saudáveis em restaurantes. Em complemento, os autores também afirmam que se a informação nutricional for dada nesses restaurantes, os consumidores serão capazes de fazer escolhas mais saudáveis (ROSEMAN et al., 2013).

Apesar desses estudos apontarem a efetividade da metodologia ativa de educação nutricional, a mudança da escolha alimentar desses estudos não foi verificada estatisticamente, para que houvesse comparação com este trabalho, que alcançou 54,5\% de resultado positivo.

Em relação à clareza da metodologia, observou-se que os participantes entenderam a metodologia com facilidade, o que é explicada pela maior presença de comensais pós-graduados $(52,1 \%)$ sendo que, dos que não tinham pós-graduação, $63,2 \%$ tinham ensino superior completo e $24,2 \%$ incompleto. A grande maioria dos participantes almoçava no restaurante de três a cinco vezes na semana, mostrando que a frequência não influenciou na resposta da pergunta-chave. 
$\mathrm{Na}$ literatura, não foram encontrados estudos semelhantes a este, que tenham participantes voluntários com o mesmo perfil sóciodemográfico para possíveis comparações.

Em relação aos itens que os participantes identificaram como ausentes na metodologia, o item "falta de informação sobre vitaminas e minerais" aponta que os dados não foram apresentados nas placas de identificação. Isso ocorreu em virtude de nem todos os alimentos contidos no software DietWin ${ }^{\circledR}$ apresentarem os dados para esses micronutrientes, ocasionando uma informação errada ou incompleta para os comensais, mas que deve ser incluído na metodologia quando esta for realizada novamente. Acredita-se que os comensais marcaram este item em virtude desses micronutrientes serem os ingredientes principais dos alimentos denominados de funcionais e estarem cada vez mais bem posicionados na mídia e nos rótulos de alimentos, com as palavras 'rico em um nutriente, fonte de nutriente', fatores que estão despertando maior interesse por parte dos consumidores (TEIXEIRA; OSELAME, 2014).

Houve também a escolha do item "o tamanho da letra estava pequeno", considerando que a maior parte da população é adulta, é necessário que o tamanho da letra da placa de identificação dos alimentos seja maior.

Assim, os estudos apresentados fortalecem a resposta positiva à questão de pesquisa deste trabalho, apontando que metodologias ativas de educação nutricional apresentam resultados efetivos na mudança da escolha alimentar dos indivíduos e que a informação nutricional é o item cognitivo a ser mantido.

É preciso que as estratégias de educação nutricional sejam permanentes, para que haja maior percepção por parte dos comensais e essa mudança na escolha alimentar seja cada vez mais efetiva, visto que houve uma pequena porcentagem de participantes que não observaram a metodologia. Além disso, as FTPs do restaurante precisam ser elaboradas para todo o cardápio e permanentes, para que seja possível a modificação dessas preparações e disponibilização das informações nutricionais de todas as preparações ofertadas no restaurante.

Outra limitação do estudo foi a realização do trabalho em apenas um restaurante, com população de nível elevado de escolaridade, que correspondem a apenas uma pequena porcentagem da população, apesar das variáveis sóciodemográficas não interferirem na mudança da escolha alimentar. 


\section{CONCLUSÃO}

Este artigo validou uma metodologia de educação nutricional que englobou a classificação das preparações servidas no buffet de almoço de um restaurante selfservice e a exposição das informações de qualidade nutricional de cada preparação, para avaliar o impacto desta exposição na escolha alimentar dos comensais adultos através de um instrumento de percepção. A população deste trabalho possuía nível educacional elevado, de forma que os dados sócio-demográficos neste estudo não interferiram na mudança da escolha alimentar.

Para a avaliação da metodologia ativa, o número de itens com informação nutricional expostos no buffet aos comensais obtiveram diferença significativa em relação à mudança ou não da escolha alimentar dos comensais, respondendo positivamente a questão de pesquisa deste trabalho de que a informação nutricional dada ao comensal intervém na sua escolha alimentar. Os itens que os comensais consideraram de maior impacto para sua mudança de comportamento alimentar foi o uso das cores como indicador de qualidade nutricional (TS e DE), a informação da porção ideal e os avisos de contém ou não glúten e lactose. O item que os comensais acreditam ter faltado na metodologia são as informações acerca dos micronutrientes presentes e o tamanho da letra ser pequeno.

Como limites do estudo aponta-se o tempo de execução, que possivelmente se ampliado incluiria um número maior de participantes que efetivamente percebessem e adotassem práticas alimentares saudáveis. A homogeneidade da escolaridade da amostra que não permite identificar se para grupos com menor escolaridade a metodologia obteria os mesmos resultados. Outro ponto importante apontado pelos próprios comensais é a introdução de informações que tenham sido previamente identificadas como de interesse da população atendida.

Assim, os resultados deste estudo devem incentivar os restaurantes a fornecerem preparações saudáveis aos clientes, utilizar as FTPs como itens permanentes e de suporte na produção de alimentos e fornecer informações nutricionais cuja abordagem deve adotar os pressupostos das metodologias ativas. 


\section{REFERENCIAL BIBLIOGRÁFICO}

AKUTSU, R. C., BOTElho, R. A., CAMARGO, E. B., SÁVIO, K. E. O., ARAÚJO, W. C. A ficha técnica de preparação como instrumento de qualidade na produção de refeições. Revista de Nutrição, Campinas, v. 18, n. 2, p. 277-9, 2005.

ALMADA, Eid da Rosa. Substitutos de leite condensado a partir de extratos vegetais. 2013. 39 f., il. Monografia (Bacharelado em Nutrição)—Universidade de Brasília, Brasília, 2013.

AWASH - Australian Division of the World Action on Salt \& Health. The George Institute for Global Health: Interim Australian targets for sodium levels in 85 food categories. Camperdown, NSW: George Institute for Global Health; 2011.

BONOMO, É.; CAIAFFA, W. T.; CÉSAR, C. C.; LOPES, A. C. S.; LIMA-COSTA, M. F. Consumo alimentar da população adulta segundo perfil sócio-econômico e demográfico: Projeto Bambuí. Cad. Saúde Pública, Rio de Janeiro, v. 19, n. 5, p. 14611471, 2003.

BRASIL, Instituto Brasileiro de Geografia e Estatística. Pesquisa de Orçamentos Familiares 2008-2009: Análise do consumo alimentar pessoal no Brasil. Rio de Janeiro: IBGE, 2011.

BRASIL. Agência Nacional de Vigilância Sanitária - ANVISA. Guia de Boas Práticas Nutricionais: Restaurantes Coletivos. Brasília, 2014, 44 p.

BRASIL. Ministério da Saúde. Secretaria de Atenção à Saúde. Guia alimentar para a população brasileira: promovendo a alimentação saudável / Ministério da Saúde, Secretaria de Atenção à Saúde. - Brasília: Ministério da Saúde, 2008. 210 p. - (Série A. Normas e Manuais Técnicos).

BRASIL. Portaria Interministerial n ${ }^{\circ}$ 66, de 25 de agosto de 2006. Altera os parâmetros nutricionais do Programa de Alimentação do Trabalhador - PAT. Publicada no D. O. U. de 28 de agosto de 2006.

CAMARGO, E; BOTELHO, R.B.A.; Técnica Dietética - Pré-preparo e preparo de alimentos. São Paulo: Editora Atheneu, 2012.

CAMOSSA, A. C. A.; COSTA, F. N. A.; OLIVEIRA, P. F. O.; FIGUEIREDO, T. P. Educação nutricional: uma área em desenvolvimento. Alimentação e Nutrição, São Paulo, v. 16, p. 349-54, 2005. 
CARVALHO, A. P. OLIVEIRA, V.B.; SANTOS, L.C. Hábitos alimentares e práticas de educação nutricional: atenção a crianças de uma escola municipal de Belo Horizonte, Minas Gerais. Pediatria (São Paulo), São Paulo, v. 32, n. 1, p. 20-7, 2010.

CASTELO-BRANCO, N.S.D. Análise da alimentação fora do domicílio de consumidores do centro comercial do Município do Rio de Janeiro - RJ. 2000, 100 f. il. Tese (Doutorado em Ciências da Nutrição) - Faculdade de Engenharia de Alimentos da Universidade Estadual de Campinas. Campinas, 2000.

CDC - Centers Of Disease Control And Prevention. Can eating fruits and vegetables help people to manage their weight? National Center for Chronic Disease Prevention and Health Promotion. Division of Nutrition and Physical Activity. (Research to pratice series, $\left.n^{\circ} 1\right)$. USA, 2005.

CERVATO, A. M., MAZZILli, R. N., MARTINS, I. S., MARUCCI, M. F. N. Dieta habitual e fatores de risco para doenças cardiovasculares. Rev. Saúde Pública, São Paulo, v. 31, n. 3, p. 227-35, 1997.

CFN - CONSELHO FEDERAL DE NUTRICIONISTAS. Inserção profissional dos nutricionistas no Brasil. Brasília: CFN, 2006.

COBCROFT, M.; TIKELLIS, K.; BUSCH, J.L.H.C. Salt reduction - a technical overview. Food Australia, Sydney, v. 60, p. 83-86, 2008.

FRANTZ, C. B.; VEIROS, M. B.; PROENÇA, R. P. C.; SOUSA, A. A. Development of a method for controlling salt and sodium use during meal preparation for food services. Rev. Nutr., Campinas, v. 26, n. 1, p. 75-87, 2013.

LANDABURE, P. B. Pedro Escudero: his thoughts, his doctrine and his works. Med. Argent, Argentina, v. 55, p. 1983-9, 1968.

LEVIN, J. Estatística Aplicada às Ciências Humanas. São Paulo: Harper \& Row do Brasil, 1987. 520 p.

LIPI, M. Densidade energética da dieta de trabalhadores de uma indústria da região metropolitana de São Paulo [dissertação de mestrado]. São Paulo: Faculdade de Saúde Pública da Universidade de São Paulo; 2008.

MAGNEÉ, H.M. Manual do self-service. São Paulo: Livraria Varela, 1996. 242p.

MILLS, J. E.; CLAY, J. M. The truth-in-menu law and restaurant consumers. Foodservice Research International, Estados Unidos, v. 13, p. 69-82, 2001.

NIELD, K.; KOZAK, M.; LEGRYS, G. The role of food service in tourist satisfaction. Hospitality Management, Estados Unidos, v. 19, p. 375-384, 2000. 
OLIVEIRA, C. S.; ALVES, F. S. Educação nutricional em unidade de alimentação e nutrição, direcionada para consumo de pratos protéicos: um estudo de caso. Alim. Nutr., Araraquara, v. 19, n. 4, p. 435-440, 2008.

PASCHOA, M.F. Alimentação Escolar: Um Enfoque em Alimentos Funcionais. Revista Nutrição Profissional, São Paulo, v. 1, n. 1, p. 31-36, 2005.

PEREIRA, M. G. Epidemiologia: Teoria e prática. 4a ed. Guanabara Koogan: Rio de Janeiro; 2008.

PEYERL, F. F.; DE MATOS, K. H. O. Avaliação da legislação aplicada a rotulagem de alimentos embalados no Brasil e na Nova Zelância. Revista E-Tech: Tecnologias para Competitividade Industrial, Florianópilis, e. Esp. Alimentos, p. 14-25, 2012.

PROENÇA, R.P.C. Inovação tecnológica na produção de alimentação coletiva. 2.ed. Florianópolis: Editora Insular, 2000.

RAMOS, F. P.; SANTOS, L. A. S.; REIS, A. B. C. Educação alimentar e nutricional em escolares: uma revisão de literatura. Cad. Saúde Pública, Rio de Janeiro, v. 29, n. $11,2013$.

SAVIO, K. E. O.; COSTA, T. H. M.; MIAZAKI, E.; SCHMITZ, B. A. S. Avaliação do almoço servido a participantes do programa de alimentação do trabalhador. Rev. Saúde Pública, São Paulo, v. 39, n. 2, 2005.

SCHOLDERER, J. BRUNSO, K; BREDAHL, L; GRUNERT, K.G. Cross-cultural validity of the food-related lifestyles instrument (FRL) within Western Europe. Appetite, Dinamarca, v. 42, p. 197- 211, 2004.

STABLES, G. Changes in vegetable and fruit consumption and awareness among US adults: results of the 1991 and 1997 - 5 A Day for Better Health Program surveys. J Am Diet Assoc, Estados Unidos, v. 102, n. 6, p. 809-817, 2002.

TACO. Tabela Brasileira de Composição de Alimentos (2011) Nepa-Unicamp. 4nd Edition, NEPA-UNICAMP, Campinas.

TORAL, N.; SLATER, B.. Abordagem do modelo transteórico no comportamento alimentar. Ciênc. saúde coletiva, Rio de Janeiro, v. 12, n. 6, 2007.

TRICHES, R. M.; GIUGLIANI, E. R. J. Obesidade, práticas alimentares e conhecimentos de nutrição em escolares. Rev. Saúde Pública, São Paulo, v. 39, n. 4, p.541-547, 2005.

TRIOLA, M. F. Introdução à Estatística. Rio de Janeiro: LTC, 1999. 576 p.

TSE, A. C. B.; SIN, L.; YIN, F. H. K. How a crowded restaurant affects consumers' attribuition behavior. Hospit Manag.; Estados Unidos, v. 21, n. 4, p. 449-54, 2002. 
USDA - Department of Agriculture, Foreign Agricultural Service (USDA), 2011. Production, Supply and Distribution Online Database. 2011.

ZANDONADI, R. P.; BOTELHO, R. A.; GANDOLFI, L.; GINANI, J. S.; MONTENEGRO, F.; PRATESI, R. Green Banana Pasta: An Alternative for GlutenFree Diets. Journal of the American Dietetic Association, Brasília, v. 11, p. 1068-72, 2012.

ZANDONADI, R. P.; BOTELHO, R. B. A.; GINANI, V. C.; AKUTSU, R. C. C. A.; SÁVIO, K. E. O.; ARAÚJO, W. M. C. Sodium and health: New proposal of distribution for major meals. Health, Brasília, v. 6, n. 3, p. 195-201, 2014. 


\section{CONSIDERAÇÕES FINAIS}

Este trabalho criou e validou uma metodologia de educação nutricional que englobou a classificação das preparações servidas no buffet de almoço de uma UAN institucional avaliadas a partir da percepção dos comensais e adotando metodologias ativas de educação.

Sobre a classificação das preparações do buffet (cores amarelo e vermelho), identificou-se que as preparações com maior quantidade de parâmetros inadequados foram os molhos para salada, arroz, sobremesas, pratos principais e guarnições, e menores no feijão e saladas nesta sequência. No geral, mais da metade das FTPs obtiveram parâmetros inadequados (moderada e alta DE e TS), sendo a maioria por conta do TS. A média da DE foi baixa quando comparada a estudos semelhantes nacionais e internacionais, porém adequada quando comparada com a média da recomendação. Já a média do TS encontrado foi elevada quando comparada às recomendações do PAT e da OMS, apontando a necessidade de redução do teor de sódio das preparações.

Quanto à avaliação da metodologia ativa, o número de itens com informação nutricional expostos no buffet aos comensais obtiveram diferença significativa em relação à mudança ou não da escolha alimentar dos comensais, respondendo positivamente a questão de pesquisa deste trabalho de que a informação nutricional dada ao comensal intervém na sua escolha alimentar. Os itens que os comensais consideraram de maior impacto para sua mudança de comportamento alimentar foi o uso das cores como indicador de qualidade nutricional (TS e DE), a informação da porção ideal e os avisos de contém ou não glúten e lactose. O item que os comensais acreditam ter faltado na metodologia são as informações acerca dos micronutrientes presentes e o tamanho da letra ser pequeno.

Como limites do estudo aponta-se o tempo de execução, que possivelmente se ampliado incluiria um número maior de participantes que efetivamente percebessem e adotassem práticas alimentares saudáveis. A homogeneidade da escolaridade da amostra que não permite identificar se para grupos com menor escolaridade a metodologia obteria os mesmos resultados. Outro ponto importante apontado pelos próprios comensais é a introdução de informações que tenham sido previamente identificadas como de interesse da população atendida. 
Assim, os resultados deste estudo devem incentivar as UANs a preparações saudáveis aos clientes, utilizar as FTPs como itens permanentes e de suporte na produção de alimentos e fornecer informações nutricionais cuja abordagem deve adotar os pressupostos das metodologias ativas. 


\section{REFERÊNCIAS BIBLIOGRÁFICAS}

ABREU, E. S.; TORRES, E. A. F. S. Restaurante "por quilo": vale quanto pesa? Uma avaliação do padrão alimentar em restaurantes em São Paulo, SP. Nutrire: Rev. Soc. Bras. Alim. Nutr., São Paulo, v. 25, p. 19-34, 2003.

AKUTSU, R. C.; BOTELHO, R. A.; CAMARGO, E. B.; SÁVIO, K. E. O.; ARAÚJO, W. C. A. ficha técnica de preparação como instrumento de qualidade na produção de refeições. Revista de Nutrição, Campinas, v. 18, n. 2, p. 277-9, 2005.

ALMADA, E. R. Substitutos de leite condensado a partir de extratos vegetais. 2013. 39 f., il. Monografia (Bacharelado em Nutrição)—Universidade de Brasília, Brasília, 2013.

ALVAREZ, T. S.; ZANELLA, M. T. Impacto de dois programas de educação nutricional sobre o risco cardiovascular em pacientes hipertensos e com excesso de peso. Rev. Nutr., Campinas v. 22, n. 1, p. 71-79, 2009.

AMARAL, T. P. Análise de uma intervenção educativa de alimentação e nutrição em servidores da Administração Regional de Planaltina-DF. 2013. Trabalho de Conclusão de Curso em Nutrição - Faculdade de Ciências da Educação e Saúde, Centro Universitário de Brasília, Brasília, 2013.

ANDRADE, J. P.; PIVA-MATTOS, L. A.; CARVAlHO, A. C.; MACHADO, C. A.; OLIVEIRA, G. M. National physician qualification program in cardiovascular disease prevention and integral care. Arq. Bras. Cardiol., São Paulo, v. 100, n. 3, p. 203-211, 2013.

ANILAKUMAR, K. R.; PAL, A.; KHANUM, F.; BAWA, A. S. Nutritional, Medicialand Industrial Uses os Sesame (Sesamumindicum L.) Seeds - an overview. Agric. Consp. Scienti., Reino Unido, v. 75, n. 4, p. 159-168, 2010.

AQUINO, W. F. S.; CAMPOS, S. A. S. O olhar dos profissionais de saúde e de usuários de uma unidade básica de saúde sobre a educação nutricional. Rev. Eletr. Com.Inform. Inov. Saúde, Rio de Janeiro, v. 1, n. 2, p. 215-223, 2007.

ARAUJO, M. F. M.; BESERRA, E. P.; CHAVES, E. S. O papel da amamentação ineficaz na gênese da obesidade infantil: um aspecto para a investigação de enfermagem. Acta paul. enferm., São Paulo, v. 19, n. 4, p. 450-455, 2006.

ARAÚJO, W. M; MONTEBello, N. P.; BOtelho, R. B. A.; BORGO L. A. (ORGS). Alquimia dos alimentos. Brasília: EditoraSenac-DF, 2011.

AUSTRALIAN DIVISION OF THE WORLD ACTION ON SALT AND HEALTH AWASH.The George Institute for Global Health: Interim Australian targets for sodium levels in 85 food categories. Camperdown, NSW: George Institute for Global Health; 2011.

BARBIERI, T.; RODRIGUES, K. S.; SILVA, S. F.; MEDEIROS, L. B.; SACCOL, A. L. F. Consumer attitudes toward information displayed at food buffets in commercial restaurants. Ciênc. Tecnol. Aliment, Campinas, v. 32, n. 4, p. 798-803, 2012. 
BEZERRA, I. N.; SICHIERI, R. Características e gastos com alimentação fora do domicílio no Brasil. Ver. Saúde Pública, São Paulo, v. 44, n. 2, p. 221-9, 2010.

BISSOLI, M. C.; LANZILLOTTI, H. S. Educação nutricional como forma de intervenção: avaliação de uma proposta para pré-escolares. Rev. Nutr., Campinas, v. 10, n. 2, p. 107-113, 1997.

BONOMO, É.; CAIAFFA, W. T.; CÉSAR, C. C.; LOPES, A. C. S.; LIMA-COSTA, M. F. Consumo alimentar da população adulta segundo perfil sócio-econômico e demográfico: Projeto Bambuí. Cad. Saúde Pública, Rio de Janeiro, v. 19, n. 5, p. 14611471, 2003.

BOOG, M. C. F. Educação nutricional: por que e para quê? J. UNICAMP, São Paulo, v. 260, p. 2-8, 2004.

BOOG, M. C. F. Nutrition education program in a rural elementar school. Rev. Nutri., Brasil, v. 23, n. 6, p. 1005-1017, 2010.

BRASIL, INSTITUTO BRASILEIRO DE GEOGRAFIA E ESTATÍSTICA. Pesquisa de Orçamentos Familiares 2008-2009: aquisição alimentar domiciliar per capita. Rio de Janeiro: IBGE, 2010a.

BRASIL, INSTITUTO BRASILEIRO DE GEOGRAFIA E ESTATÍSTICA. Pesquisa de Orçamentos Familiares 2008-2009: Análise do consumo alimentar pessoal no Brasil. Rio de Janeiro: IBGE, 2011.

BRASIL, MINISTÉRIO DA SAÚDE. Marco de Referência de Educação Alimentar e Nutricional para as Políticas Públicas. Brasília: Ministério da Saúde, da Educação e do Desenvolvimento Social e Combate à Fome; 2012.

BRASIL, MINISTÉRIO DA SAÚDE. Sistema de Planejamento do SUS (PlanejaSUS): uma construção coletiva. Plano Nacional de Saúde 2008/2009. Brasília: Ministério da Saúde; 2010b. (Série Cadernos de Planejamento, volume 9).

BRASIL, MINISTÉRIO DA SAÚDE. Vigitel Brasil 2014: vigilância de fatores de risco e proteção para doenças crônicas por inquérito 57 telefônico. Estimativas sobre frequência e distribuição sóciodemográfica de fatores de risco e proteção para doenças crônicas nas capitais dos 26 Estados brasileiros e no Distrito Federal em 2013. Brasília: Secretaria de Vigilância em Saúde, Secretaria de Gestão Estratégica e Participativa, 2014.

BRASIL. Agência Nacional de Vigilância Sanitária - ANVISA. Guia de Boas Práticas Nutricionais: Restaurantes Coletivos. Brasília, 2014, 44 p.

BRASIL. Agência Nacional de Vigilância Sanitária- ANVISA. Resolução de Diretoria Colegiada RDC - ANVISA n. 360, de 23 de dezembro de 2003. Aprova Regulamento Técnico sobre Rotulagem Nutricional de Alimentos Embalados, tornando obrigatória a rotulagem nutricional. Brasília: DOU, 2003. 
BRASIL. MINISTÉRIO DA SAÚDE. Secretaria de Atenção à Saúde. Guia alimentar para a população brasileira : promovendo a alimentação saudável / Ministério da Saúde, Secretaria de Atenção à Saúde, . - Brasília : Ministério da Saúde, 2014. 210 p. - (Série A. Normas e Manuais Técnicos)

BRASIL. Portaria Interministerial $n^{o}$ 66, de 25 de agosto de 2006. Altera os parâmetros nutricionais do Programa de Alimentação do Trabalhador-PAT. D. O. U. 28 de agosto de 2006.

BRITO, E. S.; PANTAROTTO, R. F. R.; COSTA, L. R. L. G. A hipertensão arterial sistêmica como fator de risco ao acidente vascular encefálico (AVE). Health Sci Inst., Araçatuba - São Paulo, v. 29, n. 4, p. 265-8, 2011.

BRUG, J.; STEENHUIS, I.; VAN-ASSEMA, P.; DE-VRIES, H.The impact of a computer-tailored nutrition intervention.Prev. Med, v. 25, p. 236-242, 1996.

BUSS, P. M. Promoção da saúde e qualidade de vida. Ciênc. saúde coletiva, Rio de Janeiro, v. 5, n. 1, p. 163-177, 2000.

BUTTRISS, J. L. Food and nutrition: attitudes, beliefs, and knowledge in the United Kingdom. Am J Clin Nutr. Reino Unido, v. 65, p. 1985S-1995S, 1997.

CAMARGO, E; BOTELHO, R. B. A. Técnica Dietética - Pré-preparo e preparo de alimentos. São Paulo: Editora Atheneu, 2012.

CAMOSSA, A. C. A.; COSTA, F. N. A.; OLIVEIRA, P. F. O.; FIGUEIREDO, T. P. Educação nutricional: uma área em desenvolvimento. Alim e Nut, São Paulo, v. 16, p. 349-54, 2005.

CANELLA, D. S.; BANDONI, D. H.; JAIME, P. C. Densidade energética de refeições oferecidas em empresas inscritas no Programa de Alimentação do Trabalhador no município de São Paulo. Rev. Nutr., Campinas, v. 24, n. 5, p. 715-724, 2011.

CAPALONGA, R. Avaliação da quantidade de sal oferecida no almoço dos funcionários de um Hospital Público de Porto Alegre. Revista HCPA, Porto Alegre, v. 30 , n. 3, p. 204-20, 2010.

CARVALHO, A. P.; OLIVEIRA, V.B.; SANTOS, L.C. Hábitos alimentares e práticas de educação nutricional: atenção a crianças de uma escola municipal de Belo Horizonte, Minas Gerais. Pediatria (São Paulo), São Paulo, v. 32, n. 1, p. 20-7, 2010a.

CARVALHO, L. M. F. Avaliação da eficácia de um modelo de intervenção educativa, voltado para escolares do ensino fundamental, Teresina-PI, 2010b, 86 f. il. Dissertação (Mestrado em Alimentos e Nutrição) - Universidade Federal do Piauí. Teresina, 2010b.

CENTERS OF DISEASE CONTROL AND PREVENTION - CDC. Can eating fruits and vegetables help people to manage their weight? National Center for Chronic Disease Prevention and Health Promotion.Division of Nutrition and Physical Activity.(Researchtopratice series, $\left.n^{\circ} 1\right)$. USA, 2005. 
CERVATO, A. M.; MAZZILLI, R. N.; MARTINS, I. S.; MARUCCI, M. F. N. Dieta habitual e fatores de risco para doenças cardiovasculares. Rev. Saúde Pública,São Paulo, v. 31, n. 3, p. 227-35, 1997.

CERVATO, A. M; DERNTL, A. M.; LATORRE, M. R. D. O.; MARUCCI, M. F. N. Educação nutricional para adultos e idosos: uma experiência positiva em Universidade Aberta para a Terceira Idade. Rev. Nutr., São Paulo, v.18, n.1, p. 41-52, 2005.

COBCROFT, M.; TIKELLIS, K.; BUSCH, J.L.H.C. Salt reduction - a technical overview.FoodAustralia, Sydney, v. 60, p. 83-86, 2008.

CONCEIÇÃO, T. C.; AMORIM, M. M. A. Avaliação do consumo alimentar de um restaurante self-service por peso de Belo Horizonte, Brasil. EFDesportes.com, Revista Digital, Buenos Aires, v. 18, n. 190, 2014.

CONNORS, M.; BISOGNI, C. A.; SOBAL, J.; DEVINE, C. M. Managing values in personal food systems. Dinamarca, Appetite, v. 36, p. 189-200; 2001.

CONSELHO FEDERAL DE NUTRICIONISTAS - CFN. Inserção profissional dos nutricionistas no Brasil. Brasília: CFN, 2006.

COUTINHO, J. G.; RECINE, E. Experiências internacionais de regulamentação das alegações de saúde em rótulos de alimentos Internacional. Rev PanamSaludPublica, São Paulo, v. 22, n. 6, p. 432-7, 2007.

COX, D. N.; MELA, D. J. Determination of energy density of freely selected diets: methodological issues and implications. Int J Obes, EstadosUnidos, v. 24, n. 1, p. 49$54,2000$.

CROWE, T. C.; LA FONTAINE, H. A.; GIBBONS, C. J.; CAMERON-SMITH, D.; SWINBURN, B. A. Energy density of foods and beverages in the Australian food supply: influence of macronutrients and comparison to dietary intake. Eur J ClinNutr, Austrália, v. 58, n. 11, p. 1485-91, 2004.

DEVINE, C. M.; SOBAL, J.; BISOGNI, C. A.; CONNORS, M. Food choices in three ethnic groups: interactions of ideals, identities, and roles. Journal of Nutrition Education, EstadosUnidos, vv.33, p.6-93, 1999.

DICKINSON, B. D.; HAVAS, S. Reducing the population burden of cardiovascular disease by reducing sodium intake: a report of the Council on Science and Public Health. Arch Intern Med., EstadosUnidos, v. 167, n. 14, p. 1460-8, 2007.

DREWNOWSKI, A.The role of energy density.Lipids, Estados Unidos, v. 38, n. 2, p. 109-15, 2003.

ELLO-MARTIN, J. A.; LEDIKWE, J. H.; ROLLS, B. J. The influence of food portion size and energy density on energy intake: implications for weight management. Am. J. Clin. Nutr., Estados Unidos, v. 82, n. 1, p. 236S-241S, 2005. 
ELLO-MARTIN, J. A.; ROE, L. S.; LEDIKWE, J. H.; BEACH, A. M.; ROLLS, B. J. Dietary energy density in the treatment of obesity: a year-long trial comparing 2 weightloss diets. Am J Clin Nutr., Estados Unidos, v. 85, n. 6, p. 1465-77, 2007.

ESTRUCH, R. Primary Prevention of Cardiovascular Disease with a Mediterranean Diet. The New England Journal of Medicine, New England, v. 368, n. 14, p. 1279-90, 2013.

FALK, L. W.; SOBAL, J.; BISOGNI, C. A.; CONNORS, M.; DEVINE, C. M. Managing health eating: definitions, classifications and strategies. Health Education \& Behavior,EstadosUnidos, v. 28, n. 4, p. 425-439, 2001.

FALK, L.W.; BISOGNI, C.A; SOBAL, J. Food choice process in older adults: a qualitative investigation. JournalofNutritionEducation, Estados Unidos, v. 28, p. 257265, 1996.

FALS-BORDA, O. Aspectos teóricos da pesquisa participante: considerações sobre o significado e o papel da ciência na participação popular.In: BRANDÃO, Carlos Rodrigues. Pesquisaparticipante. São Paulo: Brasiliense, 1988.

FREIRE, P. Pedagogia da autonomia: saberes necessários à prática educativa. $25^{\mathrm{a}}$ ed. São Paulo: Paz e Terra, 2002.

GAGLIANONE, C.P. Nutritional education in public elementary schools of São Paulo, Brazil: the reducing risks of illness and death in adulthood project. Rev. Nutr., Campinas, v. 19, n. 3, p. 309-320, 2006.

GERALDO, A. P. G.; BANDONI, D. H.; JAIME, P. C. Aspectos dietéticos das refeições oferecidas por empresas participantes do Programa de Alimentação do Trabalhador na Cidade de São Paulo, Brasil. Rev PanamSaludPublica, São Paulo, v. 23, n. 1, p. 19-25, 2008.

GRUNERT, K. G. Towards a concept of Food-Related Life Style. Appetite, Dinamarca, v.21, p. 151-155, 1993.

HE, F. J.; MACGREGOR, G. A. A comprehensive review on salt and health and current experience of worldwide salt reduction programmes. J Hum Hypertens, EstadosUnidos, v. 23, n. 6, p. 363-84, 2009.

HOLMAN, H. R. Qualitative Inquiry in medical research.J of Clin Epidemiology, EstadosUnidos, v. 46, n. 1, p. 29-36, 1993.

HWANG, J.; LORENZEN, C. L. Effective nutrition labeling of restaurant menu and pricing of healthy menu.JournalofFoodservice, New York, v. 19, n. 5, p. 270-276, 2008.

INSTITUTO BRASILEIRO DE GEOGRAFIA E ESTATÍSTICA. Pesquisa de Orçamentos Familiares 2002-2003: análise da disponibilidade domiciliar de alimentos e do estado nutricional no Brasil. Rio de Janeiro, Instituto Brasileiro de Geografia e Estatística, 2004. 
JOMORI, M. M. Escolha alimentar do comensal de um restaurante por peso. 2006, 80 f. il. Dissertação (Mestrado em nutrição) - Centro de Ciências da Saúde, Universidade Federal de Santa Catarina. Santa Catarina, 2006.

JOMORI, M. M.; PROENÇA, R. P. C.; CALVO, M. C. M. Determinantes da escolha alimentar. Rev Nutr, Campinas, v. 21, n. 1, p. 63-73, 2008.

LANDABURE, P. B. Pedro Escudero: his thoughts, his doctrine and his works. Med. Argent, Argentina,v. 55, p. 1983-9, 1968.

LANDO, A. M.; LABINER-WOLFE, J. Helping consumers make more healthful food choices: consumer views on modifying food labels and providing point-of-purchase nutrition information at quick-service restaurants. Journal of Nutrition Education Behavior, New York, v. 3, n. 39, p. 157-163, 2007.

LASSEN, A.; HANSEN, K.; TROLLE, E. Comparison of buffet and a la carte serving at worksite canteens on nutrient intake and fruit and vegetable consumption. Public Health Nutrition, Estados Unidos, v. 10, n. 3, p. 292-297, 2007.

LEVIN, J. Estatística Aplicada às Ciências Humanas. São Paulo: Harper \&Row do Brasil, 1987. 520 p.

LEVY, R. B.; CLARO, R. M.; MONTEIRO, C. A. Sugar and total energy content of household food purchases in Brazil. Public Health Nutr, EstadosUnidos, v. 12, p. 208491, 2009.

LEWIS, J. E. Food label use and awareness of nutritional information and recommendations among persons with chronic disease. Am. J. Clin. Nutr, Estados Unidos, v. 90, n. 5, p. 1351-7, 2009.

BOURDIEU, P. A Distinção - crítica social dos julgamentos. Porto Alegre: Zouk, $2^{\mathrm{a}}$ edição, 2011.

LÜDKE, M.; ANDRÉ, M. E. D. A. Pesquisa em Educação: abordagens qualitativas. São Paulo: E.P.U., 1986.

MAESTRO, V.; SALAY, E. Informações nutricionais e de saúde disponibilizadas aos consumidores por restaurantes comerciais, tipo fastfoode fullservice. Ciênc. Tecnol. Aliment., Campinas, v. 28, p. 208-216, 2008.

MAGNÉE, H.M. Manual do self-service. São Paulo: Livraria Varela, 1996. 242p.

MARTINS, J.; BICUDO, M. A. V.A pesquisa qualitativa em Psicologia: fundamentos e recursos básicos. São Paulo: EDUC/Moraes, 1989. 200p.

MILLS, J. E.; CLAY, J. M.The truth-in-menu law and restaurant consumers.FoodserviceResearchInternational, Austrália, v. 13, p. 69-82, 2001.

MOREIRA, M. A.; CABRAL, P. C.; FERREIRA, H. S.; LIRA, P. I. C. Excesso de peso e fatores associados em crianças da região nordeste do Brasil. J. Pediatr., Rio de Janeiro, v. 88, n. 4, p. 347-352, 2012. 
NASCIMENTO, S. M. Perfil sociodemográfico e fatores associados a desfechos desfavoráveis entre pacientes hipertensos e diabéticos em um serviço de Atenção Primária à Saúde de Porto Alegre.2013, 100 f. il. Dissertação (Mestrado Profissional) - Programa de Pós-Graduação em Epidemiologia, Universidade Federal do Rio Grande do Sul, Porto Alegre. 2013.

NIELD, K.; KOZAK, M.; LEGRYS, G.The role of food service in tourist satisfaction.Hospitality Management, Estados Unidos, v. 19, p. 375-384, 2000.

NILSON, E. A. F.; JAIME, P. C.; RESENDE, D. O. Iniciativas desenvolvidas no Brasil para a redução do teor de sódio em alimentos processados. Rev Panam Salud Publica, Washington, v. 32, n. 4, 2012.

NILSON, E. A. F.; JAIME, P. C.; RESENDE, D. O. Iniciativas desenvolvidas no Brasil para a redução do teor de sódio em alimentos processados. Rev Panam Salud Publica, Brasil, v. 34, n. 4, p. 287-92, 2012.

OLIVEIRA, C. S.; ALVES, F. S. Educação nutricional em unidade de alimentação e nutrição, direcionada para consumo de pratos protéicos: um estudo de caso. Alim. Nutr., Araraquara, v. 19, n. 4, p. 435-440, 2008.

PASCHOA, M.F. Alimentação Escolar: Um Enfoque em Alimentos Funcionais. Revista Nutrição Profissional, São Paulo, v. 1, n. 1, p. 31-36, 2005.

PELlANDA, L. C.; ECHENIQUE, L.; BARCELlOS, L. M. A.; MACCARI, J.; BORGES, F. K.; ZEN, B. L. Doença cardíaca isquêmica: a prevenção inicia durante a infância. J Pediatr, Rio de Janeiro, v. 78, n. 2, p. 91-6, 2002.

PEREIRA, M. G. Epidemiologia: Teoria e prática. $4^{\mathrm{a}}$ ed. Guanabara Koogan: Rio de Janeiro; 2008.

PEYERL, F. F.; DE MATOS, K. H. O. Avaliação da legislação aplicada a rotulagem de alimentos embalados no Brasil e na Nova Zelância. Revista E-Tech: Tecnologias para Competitividade Industrial, Florianópilis, e. Esp. Alimentos, p. 14-25, 2012.

POULAIN, J. P.; PROENÇA, R. P. C. O espaço social alimentar: um instrumento para o estudo dos modelos alimentares. Revista de Nutrição, Campinas, v.16, n.3, p.245-256, 2003a.

POULAIN, J. P.; PROENÇA, R. P. C. Reflexões metodológicas para o estudo das práticas alimentares. Revista de Nutrição, Campinas, v.16, n.4, p.365-386, 2003b.

POULAIN, J-P. La consctrutionduchoixalimentaire. Dossier - La Revue, Paris, p. 60-73, 1999.

POULAIN, J-P. Les modèles alimentaires. In: Manger aujourd'hui: attitudes, normes et pratiques. ÉditionsPrivat: Toulouse, (2002).

POULAIN, J-P. Sociologias da Alimentação. Tradução: PROENÇA, R.P.C.; RIAL, C.S.; CONTE, J. Florianópolis: Ed. UFSC, 2004. (Série Nutrição) 
PROENÇA, R.P.C. Inovação tecnológica na produção de alimentação coletiva. 2.ed. Florianópolis: Editora Insular, 2000.

RAMOS, F. P.; SANTOS, L. A. S.; REIS, A. B. C. Educação alimentar e nutricional em escolares: uma revisão de literatura. Cad. Saúde Pública, Rio de Janeiro, v. 29, n. 11, 2013.

RODRIGUES, E.M.; BOOG, M.C.F. Problematização como estratégia de educação nutricional com adolescentes obesos. Cad.SaúdePublica, Rio de Janeiro, v. 22, n. 5, p. 923-931, 2006.

RODRIGUES, L. P. F.; RONCADA, M. J. Nutritional education in Brazil: evolution and description of a pedagogical proposal for schools. Comunic. Ciênc. Saúde, Brasil, v. 19, n. 4, p. 315-322, 2008.

ROLLS, B. J. The relationship between dietary energy density and energy intake.PhysiolBehav, Estados Unidos, v. 97, n. 5, p. 609-15, 2009.

SALAS, C. K. T. S.; SPINELLI, M. G. N.; KAWASHIMA, L. M.; UEDA, A. M. Teores de sódio e lipídios em refeições almoço consumidas por trabalhadores de uma empresa do município de Suzano, SP. Rev Nutri., São Paulo, v. 22, n. 3, p. 331-0, 2009.

SANCHES, M. Alimentação fora do domicílio: a atitude do consumidor frente à informação nutricional dos alimentos disponibilizada por restaurantes, Campinas-SP. 2007. 186 f. il. Tese (Doutorado em Alimentos e Nutrição) - Faculdade de Engenharia de Alimentos, Universidade Estadual de Campinas, Campinas, 2007.

SANCHES, M. Z.; CANELlA, D. S.; DURAN, A. C. F. L.; JAIME, P. C. Disponibilidade de informação nutricional em restaurantes no município de São Paulo. Demetra, São Paulo, v. 8, n. 1, p. 9-22, 2013.

SANTOS, L. A. S. O fazer educação alimentar e nutricional: algumas contribuições para reflexão. Ciênc. saúde coletiva, Rio de Janeiro, v. 17, n. 2, 2012.

SANTOS, M. G. Educação alimentar e nutricional. EFDesportes, Revista Digital, Buenos Aires, v. 16, n. 156, 2011.

SANTOS, R.D. et al. I Diretriz sobre o consumo de gorduras e saúde cardiovascular. Arq. Bras. Cardiol., São Paulo, v. 100, n. 1, supl. 3, p. 1-40, 2013.

SARNO, F. Estimativas do consumo de sódio no Brasil, revisão dos benefícios relacionados à limitaçao do consumo deste nutriente na Síndrome Metabólica e avaliação de impacto de intervenção no local de trabalho.2010, 100 f. il. Tese (Doutorado em Ciências) - Programa de Pós-Graduação em Saúde Pública, Universidade de São Paulo. São Paulo, 2010.

GINANI, V. C. Avaliação da qualidade nutricional, sensorial e cultural de cardápios populares. 2011, 131 f. il. Tese (Doutorado em Nutrição Humana) - Programa de PósGraduação em Nutrição Humana, Universidade de Brasília. Brasília, 2011. 
SARNO, F.; CLARO, R. M.; LEVY, R. B. Estimated sodium intake by the Brazilian population, 2002-2003. Rev Saúde Pública, v. 43, p. 219-25, 2009.

SAVIO, K. E. O.; COSTA, T. H. M.; MIAZAKI, E.; SCHMITZ, B. A. S. Avaliação do almoço servido a participantes do programa de alimentação do trabalhador. Rev. Saúde Pública, São Paulo, v. 39, n. 2, 2005.

SCHMIDT, M. I. Doenças crônicas não transmissíveis no Brasil: carga e desafios atuais. The Lancet.Londres, v. 13, n. 3, p. 61-74, 2011.

SCHOLDERER, J.; BRUNSO, K; BREDAHL, L; GRUNERT, K. G. Cross-cultural validity of the food-related lifestyles instrument (FRL) within Western Europe. Appetite, Dinamarca, v. 42, p. 197- 211, 2004.

SILVA, V. S. Prevalência de sobrepesolobesidade e fatores associados em adultos no brasil. 2010, 100 f. il. Dissertação (Mestrado em Educação Física) - Universidade Federal de Santa Catarina. Santa Catarina, 2010.

SONDA, F. K. Educação Nutricional no ambiente escolar. 2011, 100 f. il. Dissertação (Especialização em Ensino de Ciências) - Universidade Tecnológica do Paraná. Medianeira, Paraná, 2011.

SOUSA, A. A. Qualidade Nutricional e Sensorial na Produção de Refeições. Nutrição em Pauta, São Paulo, v. 3, n. 75, p. 04-16, 2005.

SOUSA, F. A.; SILVA, R. C. O.; FERNANDES, C. E. Avaliação nutricional de cardápios em Unidades de Alimentação e Nutrição: adequação ao programa de alimentação do trabalhador.Rev. Eletr. Ciênc., Pernambuco, v. 2, n. 1 e 2, p. 43-50, 2009.

SOUZA, S. M. F. C.; LIMA, K. C.; MIRANDA, H. F.; CAVALCANTI, F. I. D. Utilização da informação nutricional de rótulos por consumidores de Natal - Brasil. Rev PanamSaludPublica, EstadosUnidos, v. 29, n. 5, p. 337-43, 2011.

SPENCER, J. C. The usefulness of qualitative methods in rehabilitation: issues of meaning, of context and of change. Archives of Physical Medicine and Rehabilitation, EstadosUnidos, v. 74, p. 119-126, 1993.

STABLES, G. J. Changes in vegetable and fruit consumption and awareness among US adults: results of the 1991 and 1997 - 5 A Day for Better Health Program surveys. J Am Diet Assoc, EstadosUnidos, v. 102, n. 6, p. 809-817, 2002.

STEPOE, A.; POLLARD, T. M.; WARDLE, J. Development of a mesure of the motives underlying the selection of food: The food choice questionnaire. Appetite, Dinamarca, v.25, p. 267-284, 1995.

STEVENS, V. J.; GLASGOW, R. E.; TOOBERT, D. J. Randomized trial of a brief dietary intervention to decrease consumption of fat and increase consumption of fruits and vegetables. Amer. Jour. Health Prom., EstadosUnidos, v. 16, n. 3, p. 129-34, 2002. 
THOMAS, J. R. L.; MILLS, J. E. Consumer knowledge and expectations of restaurant menus and their governing legislation: a qualitative assessment. JournalofFoodservice, Estados Unidos, v. 17, n. 1, p. 6-22, 2006.

TORAL, N. A alimentação saudável na ótica dos adolescentes e o impacto de uma intervenção nutricional com materiais educativos baseados no Modelo Transteórico entre escolares de Brasília-DF. 2010, 153 f. il. Tese (Doutorado em Saúde Pública) Programa de Pós-Graduação em Saúde Pública, Universidade de São Paulo, São Paulo, 2010.

TORAL, N.; SLATER, B.. Abordagem do modelo transteórico no comportamento alimentar. Ciênc. saúde coletiva, Rio de Janeiro, v. 12, n. 6, 2007.

TRICHES, R. M.; GIUGLIANI, E. R. J. Obesidade, práticas alimentares e conhecimentos de nutrição em escolares. Rev. Saúde Pública, São Paulo, v. 39, n. 4, p.541-547, 2005.

TRIOLA, M. F. Introdução à Estatística. Rio de Janeiro: LTC, 1999. 576 p.

USDA - Department of Agriculture, Foreign Agricultural Service (USDA), 2011. Production, Supply and Distribution Online Database. 2011.

VADIVELOO, M. K.; DIXON, L. B.; ELBE, B. Consumer purchasing patterns in response to calorie labeling legislation in New York City. Int $J$ BehavNutrPhyAct.,Estados Unidos, v. 8, p. 51, 2011.

VANIN, M.; SOUTHIER, N.; NOVELLO, D.; FRANCISCHETTI, V. A. Adequação nutricional do almoço de uma unidade de alimentação e nutrição de Guarapuava - PR. Revista Salus, Guarapuava - Paraná, v. 1, n. 1, 2007.

VAN-WEEL, C. Nutritional guidance in general practice a conceptual framework.Eur $J$ ClinNutr, Estados Unidos, v. 53, Suppl, 2, p. S108-S111, 1999.

VELLOSO, L.A. O controle hipotalâmico da fome e da termogênese: implicações no desenvolvimento da obesidade. Arquivos Brasileiros de Endocrinologia \& Metabologia, v. 50, n. 2, p. 165-176, 2006.

VERDE, S.; OLINDA, Q. B. Educação nutricional: uma ferramenta para alimentação saudável. RBPS, Fortaleza - Ceará, v. 23, n. 3, p. 197-198, 2010.

WEBSTER, J.; DUNFORD, E.; HUXLEY, R.; LI, N.; NOWSON, C. A.; NEALON, B. The Development of a National Salt Reduction Strategy for Australia.Asia Pacific Journal of Clinical Nutrition, Sydney, Australia, v. 18, n. 3, p. 303-309, 2009.

OMS - Organização Mundial da Sáude. Preventing chronic diseases: a vital investment. Geneva: World Health Organization, 2005.

WHO - World Health Organization. Preventing chronic diseases: a vital investment. Geneva: World Health Organization, 2005. 
WORLD CANCER RESEARCH FUND - WCRF.A closer look at: salt. Registered in London, England No: 2536180. Registered with the Charity Commission in England and Wales (Registered Charity No: 1000739) Registered Office: 22 Bedford Square, London WC1B 3HH. 2012.

YAMAMOTO, J. A. Adolescent fast food and restaurant ordering behavior with and without calorie and fat content menu information.Journal of Adolescent Health, v. 37, n. 1, p. 397-402, 2005.

ZANDONADI, R. P.; BOTELHO, R. A.; GANDOLFI, L.; GINANI, J. S.; MONTENEGRO, F.; PRATESI, R. Green Banana Pasta: An Alternative for GlutenFree Diets. Journal of the American Dietetic Association, Brasília, v. 11, p. 1068-72, 2012.

ZANDONADI, R. P.; BOTELHO, R. B. A.; GINANI, V. C.; AKUTSU, R. C. C. A.; SAVIO, K. E. O.; ARAÚJO, W. M. C. Sodium and health: New proposal of distribution for major meals. Health, Brasil, v. 6, n. 3, p. 195-201, 2014. 
APÊNDICE 1 - Instrumento de Percepção

\section{QUESTIONÁRIO}

Caso você tenha aceitado participar do projeto: "Avaliação de estratégia de educação nutricional em Unidade de Alimentação e Nutrição", responda essas questões marcando com um "X" na opção escolhida dentro dos parênteses "( )". Na "idade" e nas opções "outros" contém um traço " " para que você escreva a resposta.
a. Sexo: ( ) Feminino
( ) Masculino
b. Idade: anos
c. Escolaridade:

( ) 2o grau incompleto ( ) $2^{\circ}$ grau completo ( ) Superior incompleto

( ) Superior completo ( ) Especialização

d. Estado civil: ( ) com companheiro (a) ( ) sem companheiro (a)

e. Tem filhos? ( ) Sim ( ) Não

1. Quantas vezes na semana você almoça nesse restaurante?
( ) 1
( ) 2
( ) 3
( ) 4
( ) 5

2. Você observou que houve mudança na identificação e informação (plaquinha) dos pratos servidos no restaurante no horário do almoço?

$$
\text { ( ) } \operatorname{Sim} \text { ( ) Não }
$$

3. O que mais lhe chamou atenção nessa metodologia? (Pode marcar mais de uma opção se desejar)

a. ( ) Informação da porção ideal

b. ( ) Uso das cores (vermelho, amarelo e verde) como indicador

c. ( ) Indicação da quantidade de porções de proteína, carboidrato, vegetal e sobremesa por pessoa

d. ( ) Avisos de contém ou não glúten e lactose

e. ( ) Outros:

4. Você achou a metodologia clara, fácil de entender? Marque na escala de 1 a 5 o nível de clareza que você achou da metodologia:
( ) 1 - não entendi nada
( ) 2 - entendi pouco
( ) 3 - entendi moderadamente
( ) 4 - entendi muito
( ) 5 - entendi completamente

5. Você mudou sua escolha alimentar do seu prato de almoço depois de ler as plaquinhas de identificação dos pratos servidos no buffet?

$$
\text { ( ) } \operatorname{Sim} \text { ( ) Não }
$$

6. Caso você tenha marcado "sim", marque na escala de 1 a 5 qual a intensidade da mudança que você fez na sua escolha alimentar ao se servir:
( ) 1 - mudei muito pouco
( ) 2 - mudei pouco
( ) 3 - mudei moderadamente
( ) 4 - mudei muito
( ) 5 - mudei completamente 
7. O que mudou no seu prato?
a. ( ) Está mais leve (mais barato)
b. ( ) Coloquei mais salada do que geralmente me sirvo
c. ( ) escolhi os com menos sal
d. ( ) escolhi os amarelos
e. ( ) escolhi os verdes
f. ( ) Escolhi os vermelhos
g. Outros:

8. Você acha que faltaram informações? Se sim, quais? (Pode marcar mais de uma opção se desejar):
a. ( ) Informações sobre outros nutrientes (vitaminas, minerais, etc)
b. ( ) O tamanho da letra é pequeno
c. ( ) as cores não deixam claro o que deve escolher
d. ( ) poderia usar outras cores
e. Outros:

Muito obrigada por participar! 
APÊNDICE 2 - Termo de Consentimento Livre e Esclarecido (TCLE)

\section{Termo de Consentimento Livre e Esclarecido - TCLE}

O (A) Senhor (a) está sendo convidado a participar do projeto de mestrado e, Nutrição Humana da UnB: "Avaliação de estratégia de educação nutricional em Unidade de Alimentação e Nutrição". O objetivo dessa pesquisa é avaliar a estratégia educativa de classificação de cardápios em Unidade de Alimentação e Nutrição.

O (A) Senhor (a) receberá todos os esclarecimentos necessários antes e no decorrer da pesquisa e lhe asseguramos que seu nome não aparecerá, sendo mantido o mais rigoroso sigilo atavés da omissão total de quaisquer informações que permitam identificá-lo (a). Informamos que o Senhor (a) poderá se recusar a responder qualquer questão (ou participar de qualquer procedimento) que the traga constrangimento, podendo desistir de participar da pesquisa em qualquer momento sem nenhum prejuízo para o (a) Senhor (a) e nenhum comprometimento no seu almoço. O (a) Senhor (a) será ressarcido por todas as despesas que venha a ter com a participação nesse estudo, sendo garantida a existência de recursos e que poderá ser indenizado por qualquer dano que venha a sofrer com a participação na pesquisa.

A sua participação consiste em preencher um questionário, que leva em torno de 10 minutos para ser preenchido, para que seja avaliado se houve ou não mudança na sua escolha alimentar depois de disponibilizadas as informações nutricionais das preparações. Os resultados da pesquisa serão divulgados na Universidade de Brasília, podendo ser publicados posteriormente. Os dados e materiais utilizados na pesquisa ficarão sobre a guarda do pesquisador.

A pesquisa pode levar benefícios aos participantes como mudança da escolha alimentar; educação nutricional; conhecimento das informações nutricionais dos alimentos; facilitação da escolha por alimentos mais saudáveis; introdução à alimentação saudável; controle do consumo de sódio e gorduras; diminuir o risco de comensais que possuem alergias alimentares consumirem alimentos alergênicos, entre outros. A pesquisa apresenta riscos mínimos aos participantes da pesquisa, podendo ser algum constrangimento através da leitura de algum item do questionário, mesmo estes sendo elaborados para agredir o mínimo possível a privacidade do indivíduo. Todas as medidas para que não ocorram riscos foram tomadas, como treinamento dos Nutricionistas que irão aplicar o questionário, revisão do questionário por um grupo de professores da área, entre outros.

Se o (a) Senhor (a) tiver qualquer dúvida em relação à pesquisa, por favor telefone para Larissa Mazocco, (61) 99838097 (e-mail: mazoccolarissa@gmail.com) aluna de Mestrado; ou Prof ${ }^{-}$Dr ${ }^{\text {a }}$ Rita de Cássia Akutsu (61) 81070622 (e-mail rita.akutsu@gmail.com) - Orientadora de Mestrado. Este projeto foi aprovado pelo Comitê de Ética em Pesquisa da Faculdade de Ciências da Saúde da Universidade de Brasília. As dúvidas em relação à assinatura do TCLE ou os seu direitos, o senhor (a) pode obter mais informações através do telefone (61) 31071947 de $10 \mathrm{h00}$ às $12 \mathrm{~h}$ e de $13 \mathrm{~h} 30$ às 15h30, de segunda à sexta-feira, localizado na Faculdade de Ciências da Saúde, Campus Universitário Darcy Ribeiro, Universidade de Brasília, Asa Norte, ou pelos emails cepfs@unb.br ou cepfsunb@gmail.com. O objetivo do Comitê de Ética em Pesquisa (CEP/FS-UnB) é proteger o bem-estar dos indivíduos pesquisados e é um comitê interdisciplinar e independente, responsável pela avaliação e acompanhamento dos aspectos éticos de todas as pesquisas que envolvam a participação de seres humanos 
Este documento foi elaborado em duas vias, uma ficará com o pesquisador responsável e a outra com o participante da pesquisa.

Se você estiver de acordo, por favor, assine esta folha.

Assinatura do participante da pesquisa

Assinatura do Pesquisador

Larissa Mazocco

Brasília, __ de Maio de 2015. 
APÊNDICE 3 - Modelos de placas de identificação das preparações
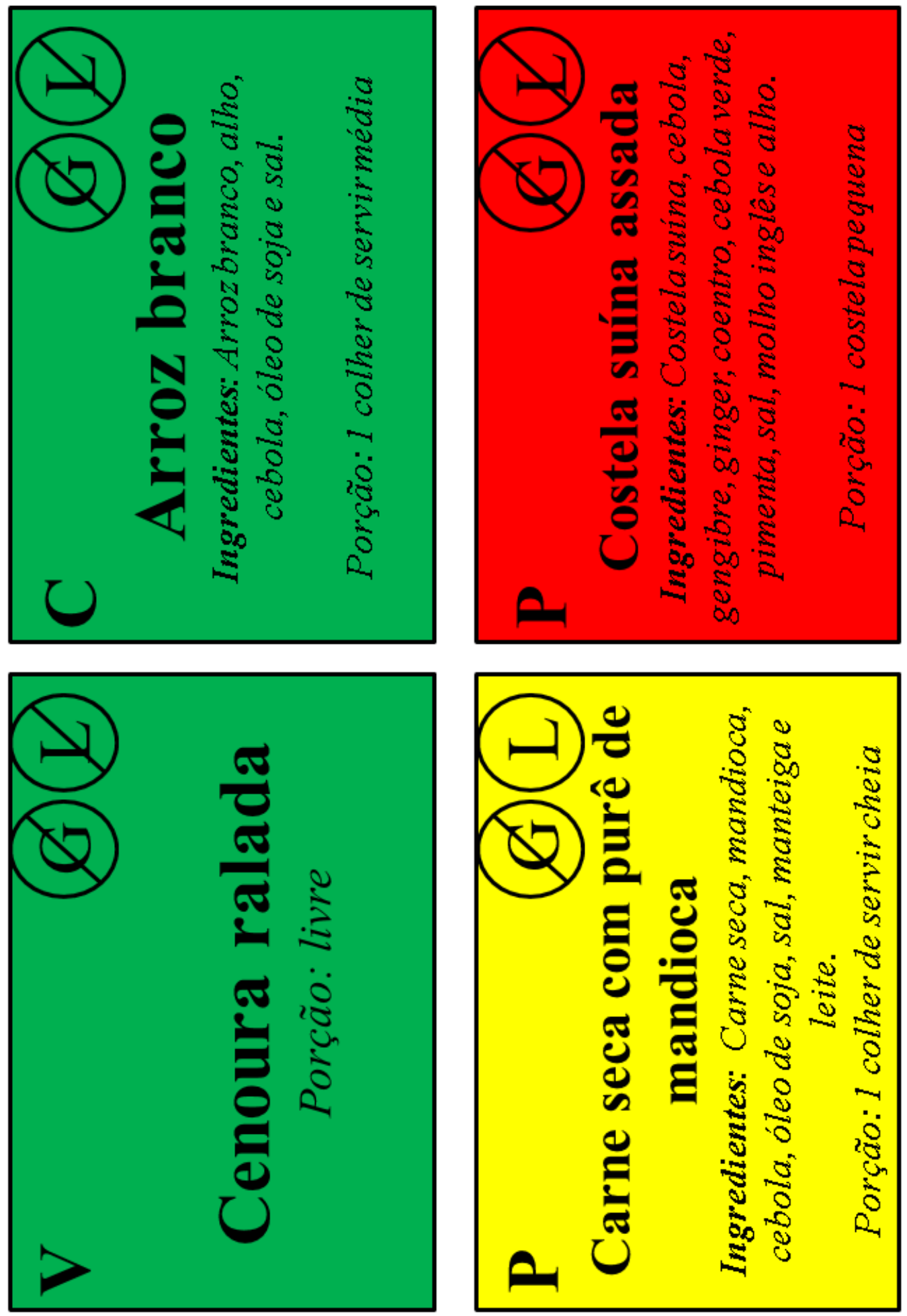


\section{De olho nas placas: refeição equilibrada é sinônimo de saúde!}

O nosso restaurante lhe dá as informações para você saber escolher e montar o melhor prato para que isso aconteça!

\section{Já reparou no nosso buffet?}

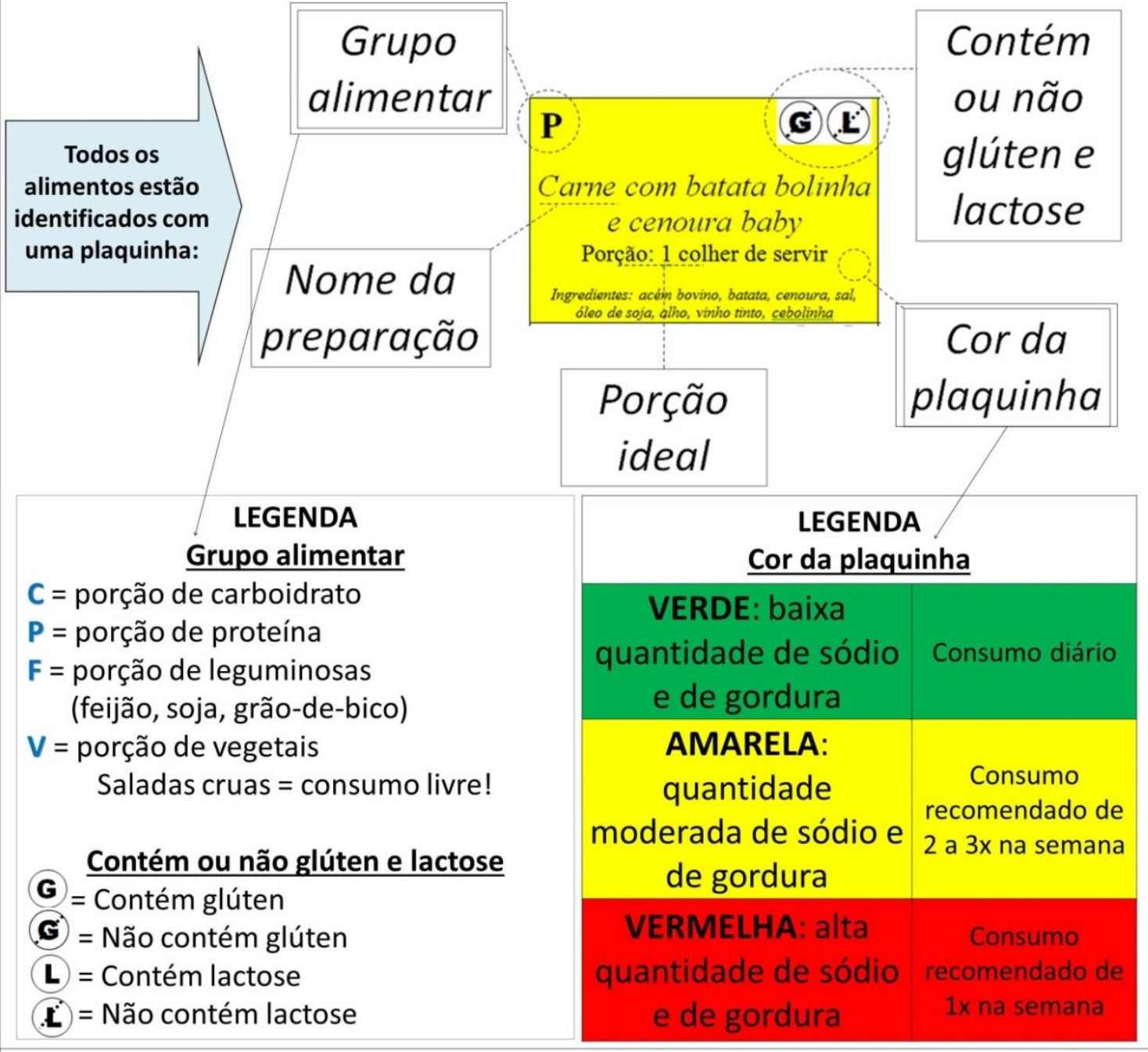

\begin{tabular}{|c|c|}
\hline \multicolumn{2}{|c|}{ Recomendação diária segundo o Ministério da Saúde } \\
\hline Homens & Mulheres \\
\hline 2 Carboidratos, 1 Proteína, 1 F - & 1 Carboidrato, 1 Proteína, 1 F - \\
leguminosa, 3 Vegetais & leguminosa, 2 Vegetais \\
+ azeite + sementes & + azeite + sementes \\
\hline
\end{tabular}


APÊNDICE 5 - Pratos de almoço elaborados de acordo com a classificação (fotografias)
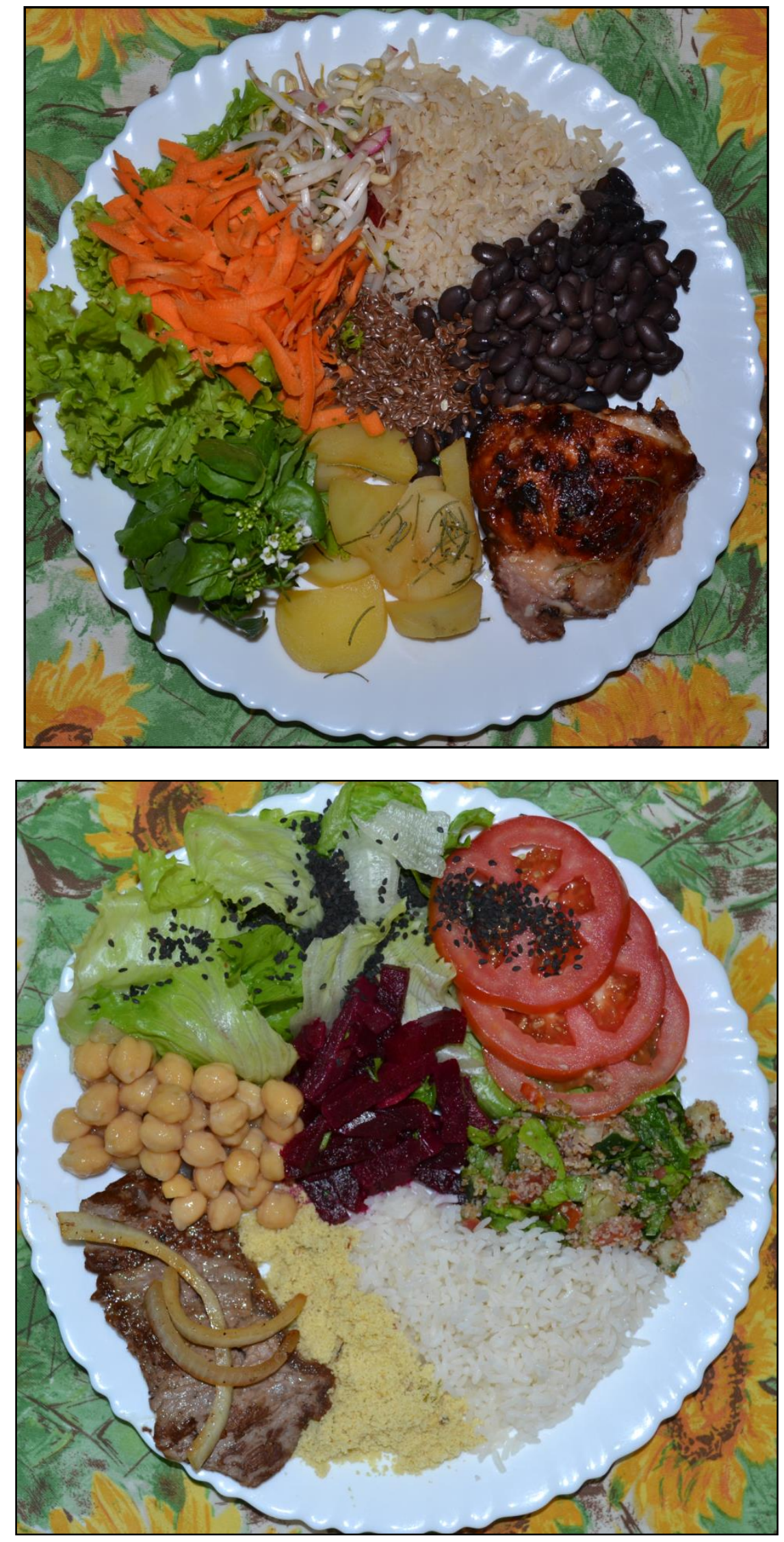

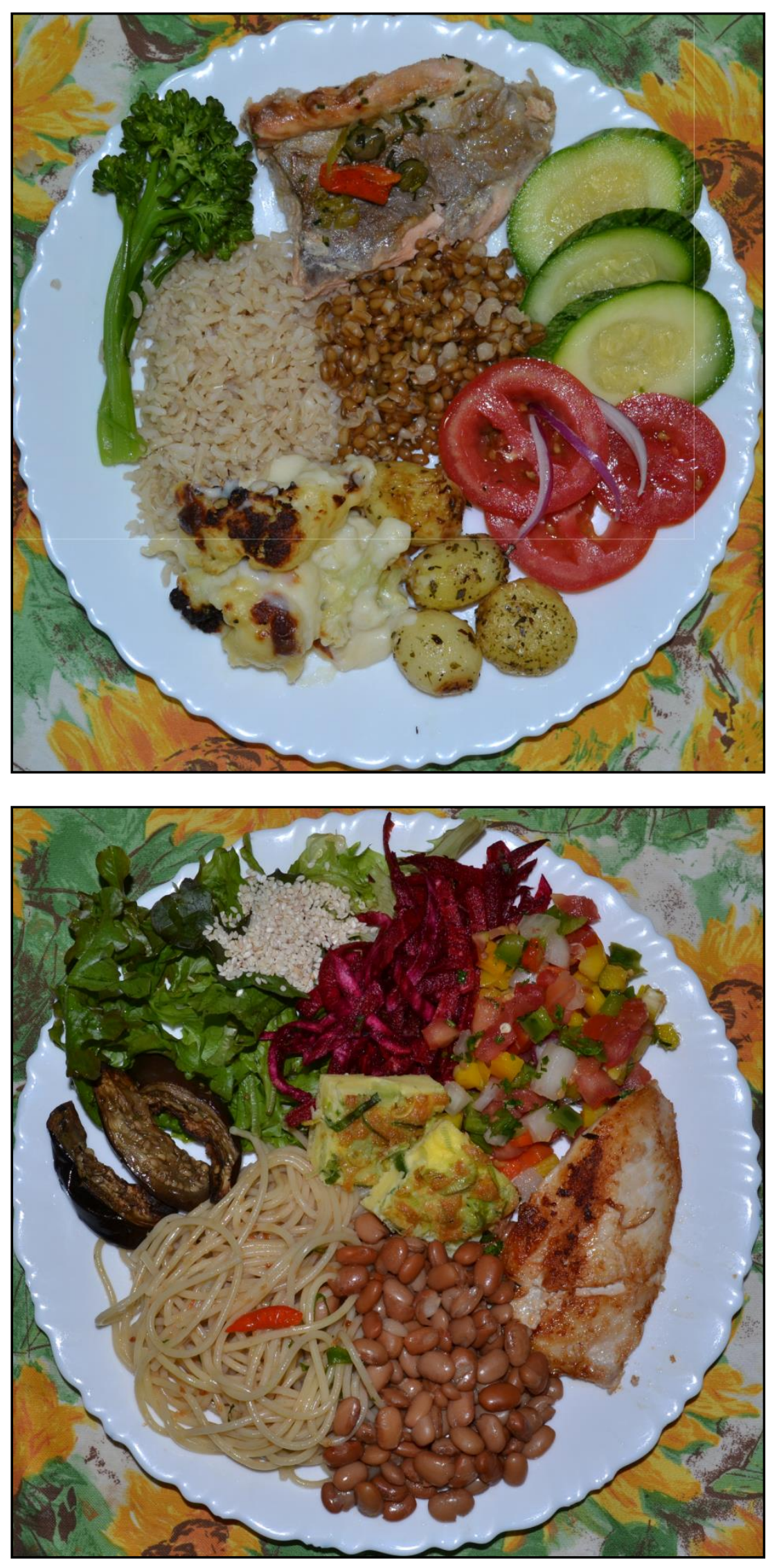
APÊNDICE 6 - Painel 2

\section{Você sabia que diminuir o consumo de sódio e de gordura reduz o risco de infartos e de \\ obesidade?}

O nosso restaurante está em parceria com o Programa de Mestrado em Nutrição Humana da Universidade de Brasília, e precisamos da sua participação.

\section{Observe o nosso buffet!}

Todos os alimentos estão identificadas com uma plaquinha, que lhe dará todas as informações necessárias para você saber escolher e montar o melhor prato!

\section{Exemplos de pratos equilibrados:}
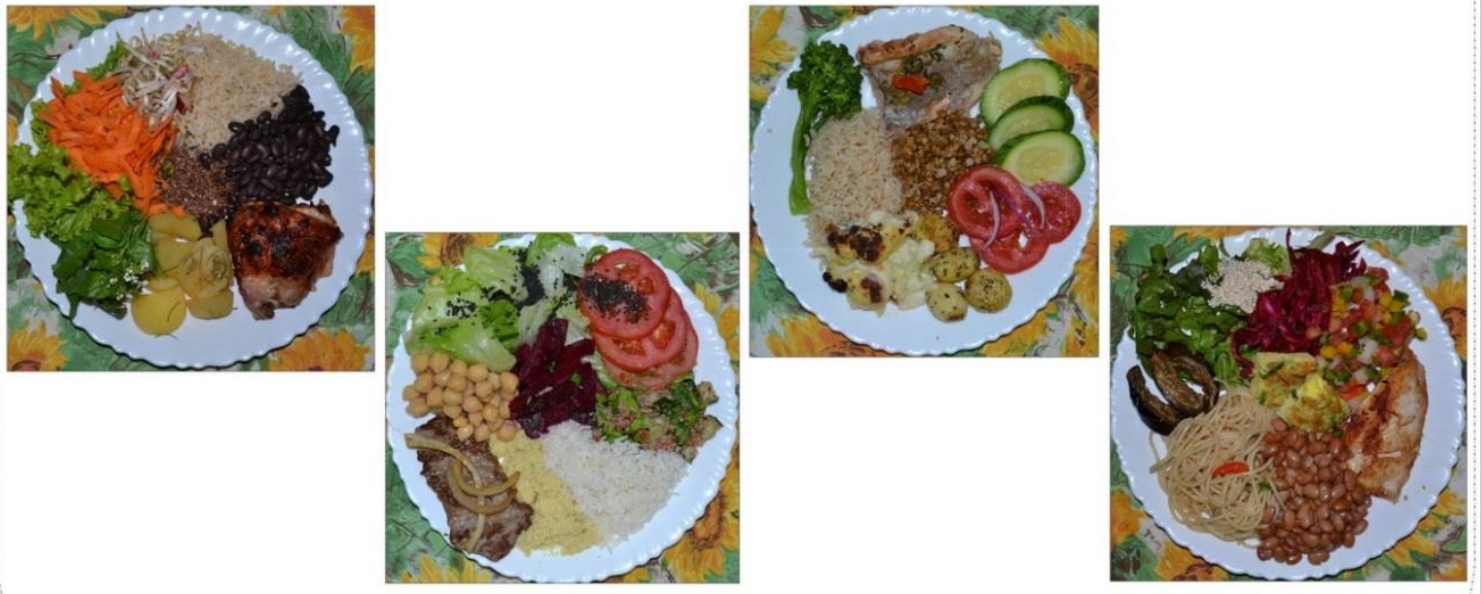

No final da semana, precisamos que você responda um questionário simples e rápido, para avaliarmos os resultados dessa pesquisa! 
ANEXO 1 - Termo de Aprovação do Projeto peço CEP/FS - Unb 
Universidade de Brasilia

Faculdade de Ciências da Saúde

Comitê de Ética em Pesquisa - CEP/FS

\section{PROCESSO DE ANÁLISE DE PROJETO DE PESQUISA}

Título do Projeto: "Avaliação de estratégia de educação nutricional em Unidade de Alimentação e Nutrição".

Pesquisadora Responsável: Larissa Mazocco

Data de Entrada: 19/05/2015

CAAE: 43544215.0 .0000 .0030

Com base na Resolução 466/12, do CNS/MS, que regulamenta a ética em pesquisa com seres humanos, o Comitê de Ética em Pesquisa com Seres Humanos da Facuidade de Ciências da Saúde da Universidade de Brasília, após análise dos aspectos éticos e do contexto técnico-científico, resolveu APROVAR o projeto intitulado "Avaliação de estratégia de educação nutricional em Unidade de Alimentação e Nutrição". Parecer n 1.081.189, em 10/06/2015.

Notifica-se o(a) pesquisador(a) responsável da obrigatoriedade da apresentação de um relatório semestral $\theta$ relatório final sobre 0 desenvolvimento do projeto, no prazo de 1 (um) ano a contar da data de aprovação.

Brasília, 28 de maio de 2015 .

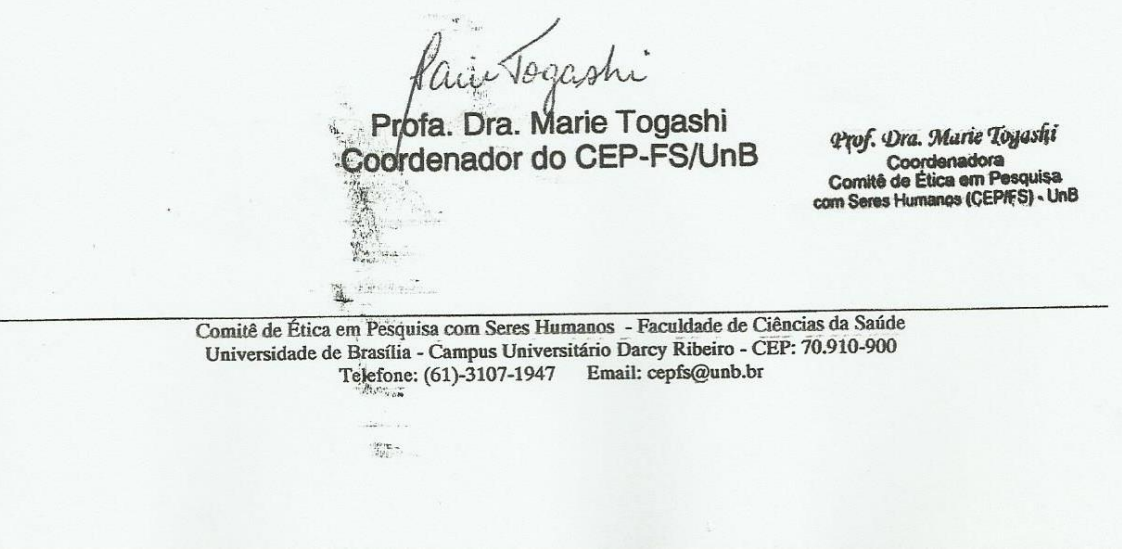


ANEXO 2 - Modelos de Fichas Técnicas de Preparação utilizados pelo software DietWin 


\section{Ficha técnica da receita}

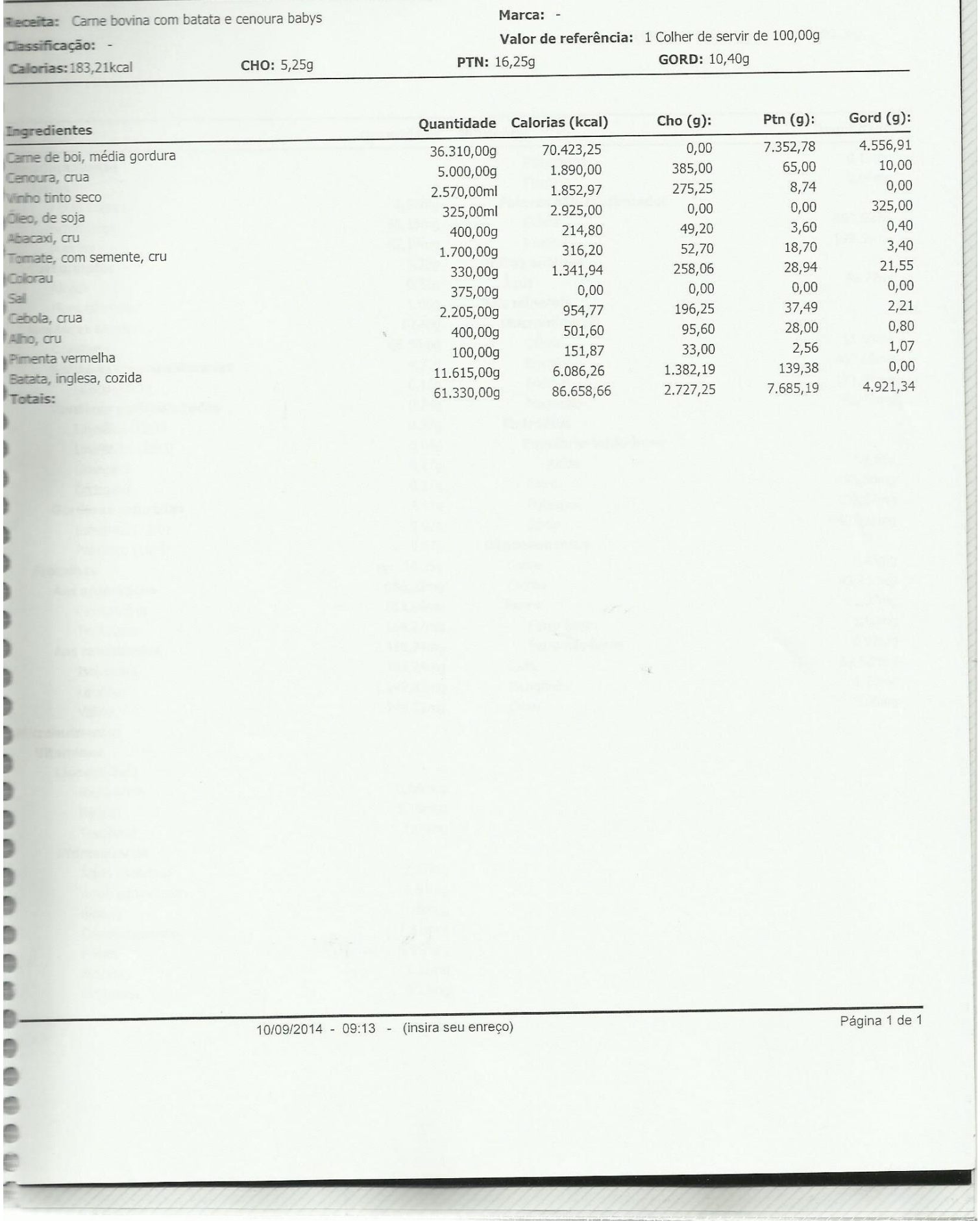




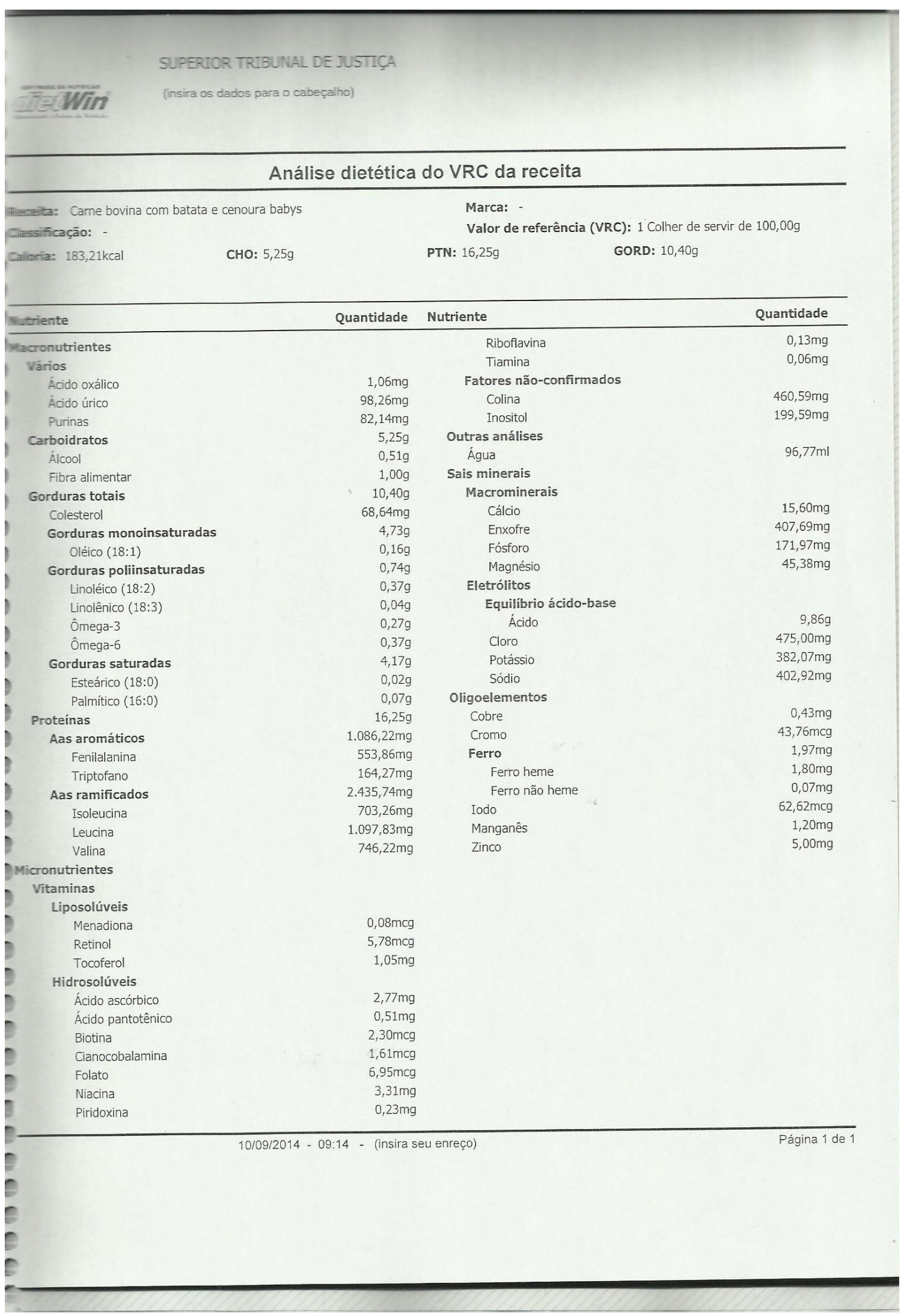

